Please cite this paper as:

Kools, M. and Stoll L. (2016), "What Makes a School a Learning Organisation?", OECD Education Working Papers, No. 137, OECD Publishing, Paris.

http://dx.doi.org/10.1787/5j|wm62b3bvh-en

OECD Education Working Papers

No. 137

\title{
What Makes a School a Learning Organisation?
}

Marco Kools and Louise Stoll 
Organisation de Coopération et de Développement Économiques

Organisation for Economic Co-operation and Development

18-Aug-2017

DIRECTORATE FOR EDUCATION AND SKILLS

English - Or. English

\section{WHAT MAKES A SCHOOL A LEARNING ORGANISATION?}

Education Working Paper No. 137

This working paper has been authorised by Andreas Schleicher, Director of the Directorate for Education and Skills, OECD.

Marco Kools, Analyst, Directorate for Education and Skills (Marco.Kools@oecd.org)

Louise Stoll, Professor of Professional Learning at University College London's Institute of Education, (Louise.Stoll@ioe.ac.uk)

JT03417968

Complete document available on OLIS in its original format

This document, as well as any data and map included herein, are without prejudice to the status of or sovereignty over any territory, to the delimitation of international frontiers and boundaries and to the name of any territory, city or area. 


\section{OECD EDUCATION WORKING PAPERS SERIES}

OECD Working Papers should not be reported as representing the official views of the OECD or of its member countries. The opinions expressed and arguments employed herein are those of the author(s).

Working Papers describe preliminary results or research in progress by the author(s) and are published to stimulate discussion on a broad range of issues on which the OECD works. Comments on Working Papers are welcome, and may be sent to the Directorate for Education and Skills, OECD, 2 rue André-Pascal, 75775 Paris Cedex 16, France.

This document and any map included herein are without prejudice to the status of or sovereignty over any territory, to the delimitation of international frontiers and boundaries and to the name of any territory, city or area.

The statistical data for Israel are supplied by and under the responsibility of the relevant Israeli authorities. The use of such data by the OECD is without prejudice to the status of the Golan Heights, East Jerusalem and Israeli settlements in the West Bank under the terms of international law.

You can copy, download or print OECD content for your own use, and you can include excerpts from OECD publications, databases and multimedia products in your own documents, presentations, blogs, websites and teaching materials, provided that suitable acknowledgement of OECD as source and copyright owner is given. All requests for public or commercial use and translation rights should be submitted to rights@oecd.org.

Comment on the series is welcome, and should be sent to edu.contact@oecd.org.

This working paper has been authorised by Andreas Schleicher, Director of the Directorate for Education and Skills, OECD.

www.oecd.org/edu/workingpapers

Copyright @ OECD 2016. 


\begin{abstract}
What are the characteristics of a school as learning organisation? This paper should be seen as an attempt to work towards a common understanding of the school as a learning organisation concept that is both solidly founded in the literature and is recognisable to all parties involved, i.e. educators, policy makers, parents and others alike. The paper provides an in-depth analysis of the learning organisation literature in general, and within a school context. It identifies and operationalises the characteristics of the school as learning organisation in an integrated model that consists of seven overarching 'action-oriented' dimensions: 1) developing and sharing a vision centred on the learning of all students; 2) creating and supporting continuous learning opportunities for all staff; 3) promoting team learning and collaboration among staff; 4) establishing a culture of inquiry, innovation and exploration; 5) establishing embedded systems for collecting and exchanging knowledge and learning; 6) learning with and from the external environment and larger learning system; and 7) modelling and growing learning leadership. The dimensions and underlying key characteristics are intended to provide practical guidance on how schools can transform themselves into a learning organisation and ultimately enhance student outcomes.
\end{abstract}

\title{
RÉSUMÉ
}

Quelles sont les caractéristiques d'une école comme structure d'apprentissage? Ce document devrait être considéré comme une tentative d'obtenir une compréhension commune du concept de l'école comme structure d'apprentissage, qui est à la fois solidement ancré dans la littérature et reconnaissable par toutes les parties prenantes, c'est-à-dire éducateurs, décideurs politiques, parents et autres parties prenantes. Le document fournit une analyse détaillée de la littérature sur la structure d'apprentissage en général, et au sein d'un contexte scolaire. Il identifie et opérationnalise les caractéristiques de l'école comme structure d'apprentissage en un model intégré qui consiste en sept dimensions globales axées sur les actions: 1) développer et partager une vision centrée sur l'apprentissage de tous les étudiants; 2) créer et encourager des opportunités de formation en continu pour tout membre du personnel; 3) promouvoir l'apprentissage en équipe et la collaboration entre les membres du personnel ; 4) établir une culture de recherche, d'innovation et d'investigation; 5) établir un système intégré de collecte et d'échange de connaissances et d'enseignements; 6) apprendre avec et depuis l'environnement externe et un système éducatif plus large; 7) façonner et développer le leadership dans l'enseignement. Les dimensions et caractéristiques fondamentales sous-jacentes ont pour but de fournir une aide pratique sur la façon dont les écoles peuvent s'auto-transformer en une structure d'apprentissage et ainsi améliorer les résultats des étudiants. 


\section{GLOSSARY}

Capacity - a quality of people or organisations that allows them routinely to learn from the world around them and apply their learning to new situations so that they continue on a path towards their goals, even if the context is changing.

Change agent - someone who triggers growth and development, helping an organisation to transform itself.

Collective learning - where group members are endeavouring to reach common learning or outcomes that will enhance all of their work. This is distinct from collaborative learning i.e. forms of learning together.

Digital literacy - helping to develop the critical knowledge, skills and behaviours for engaging with, consuming, and producing digital media.

Double-loop learning - higher-level, generative learning which involves questioning and modifying existing norms, procedures, policies and objectives as part of detecting and correcting errors.

Inquiry habit of mind - a way of thinking that is a dynamic iterative system with feedback loops that organises ideas towards clearer directions and decisions and draws on or seeks out information as people move closer to understanding the phenomenon of interest.

Knowledge creation - forming new ideas through sharing and converting different types of knowledge, involving dialogue and learning conversations, collaboration and practice.

Knowledge exchange - two-way process of sharing ideas, experience and learning to stimulate further learning and creation of new knowledge for practice.

Leadership - providing direction and exercising influence, through mobilising and working with others to achieve shared goals.

Learning leadership - directional influence that models and keeps individual, group and collective learning at the heart of the endeavour to realise its vision.

Mental models - people's beliefs, assumptions and thought processes about how things work in the real world that guide their actions.

Mentoring - the sustained support of a member of staff in developing their practice by a more experienced and expert colleague.

Modelling - a process in which behaviours are presented by one individual to another to support them in acquiring such characteristics, thereby enabling them to become familiar with the potential of the practice or intervention and to give first-hand experience of active participation.

Professional learning -what teachers, support staff and school leaders engage in to stimulate their thinking and professional knowledge and to ensure that their practice is critically informed and up-to-date. 
Professional learning community - inclusive and mutually supportive group of people with a collaborative, reflective and growth-oriented approach towards investigating and learning more about their practice in order to improve all students' learning.

Networks - an extended group of people with similar interests or concerns who interact and exchange knowledge for mutual assistance, support and to increase learning.

Organisational learning - continuous process of integrating and collectively interpreting knowledge that enhances the organisation's collective ability to make sense of and respond to internal and external change.

School as a learning organisation (SLO) - a school as a learning organisation has the capacity to change and adapt routinely to new environments and circumstances as its members, individually and together, learn their way to realising their vision.

Systems thinking - seeing and addressing the whole and interrelationships between individual parts in a complex system.

Team learning - aligning and developing a team's capacity to create results its members truly desire; thinking together.

Theory of action - an organisation's story or 'theory' of how it will make change, explaining why certain things will happen. 


\section{ACKNOWLEDGEMENTS}

The authors would like to thank Denise Esteves who supported the research of this paper and organisation of an expert meeting (on 12 February 2016 at OECD in Paris), and Tracy Burns, David Istance and Kristina Sonmark for providing ongoing feedback during the development of this paper. The authors are also grateful to Victor Bekkers, Graham Donaldson, Fije Hooglandt, Michael Fullan, Panagotis Kampylis, Dominic Richardson, Bram Steijn, Inge de Wolf and Karin Watkins for commenting on earlier drafts.

This paper was prepared by Marco Kools from the OECD Directorate for Education and Skills and Louise Stoll who is Professor of Professional Learning at University College London's Institute of Education and an international consultant. Editorial support was provided by Manon Thiebaux. 
EDU/WKP(2016)11

WHAT MAKES A SCHOOL A LEARNING ORGANISATION?

By Marco Kools and Louise Stoll 


\section{TABLE OF CONTENTS}

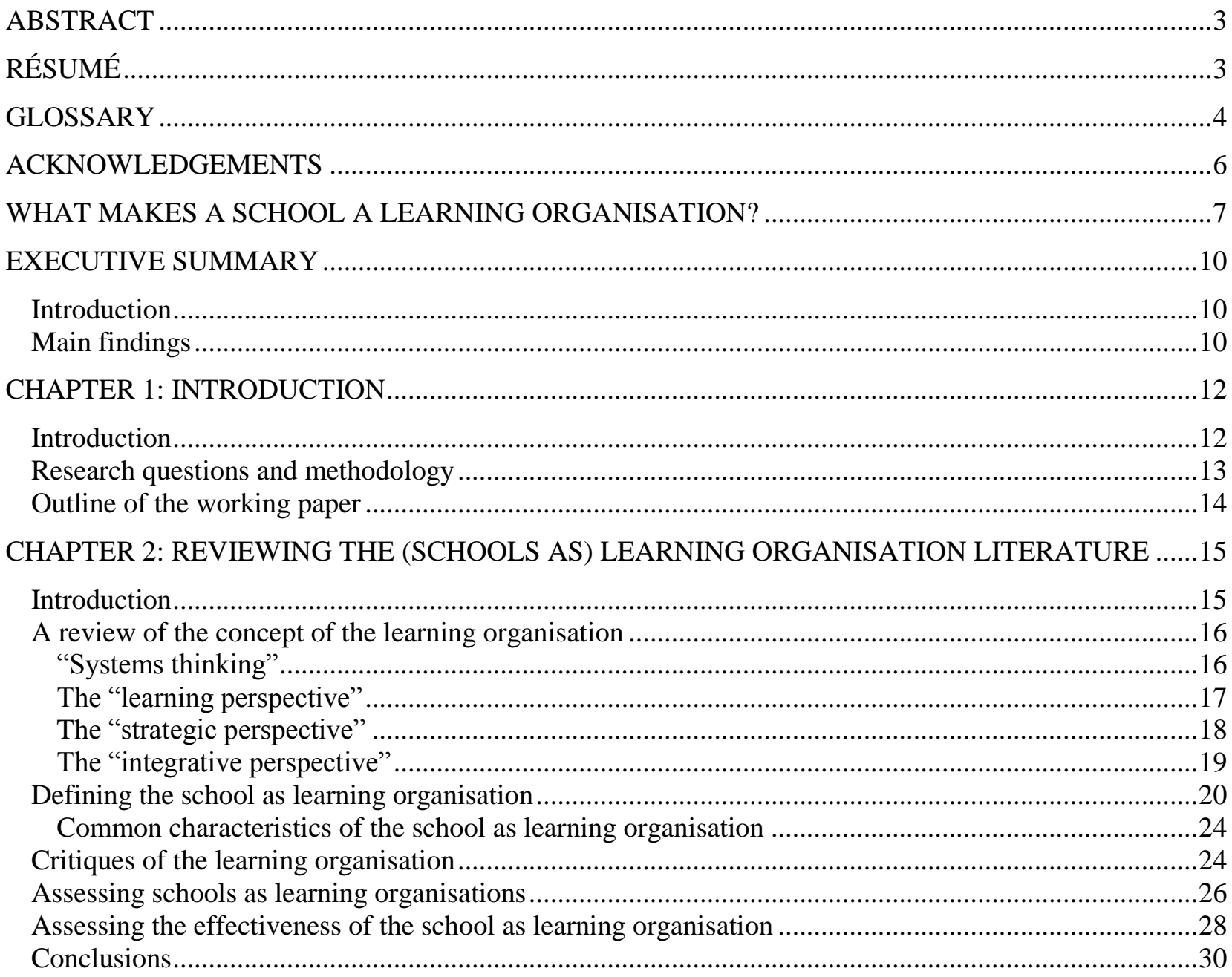

CHAPTER 3: DEFINING AN INTEGRATED MODEL OF THE SCHOOL AS LEARNING

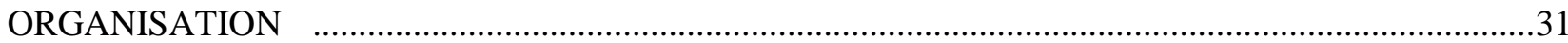

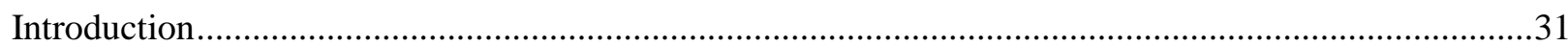

Defining the "action-oriented dimensions" and underlying "elements" of the school as learning

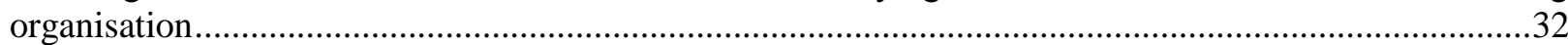

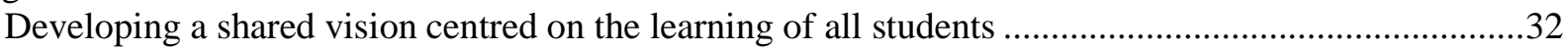

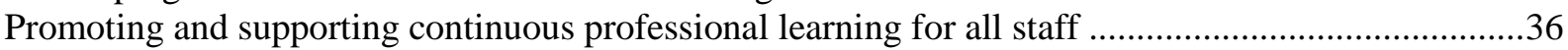

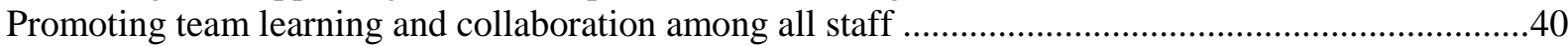

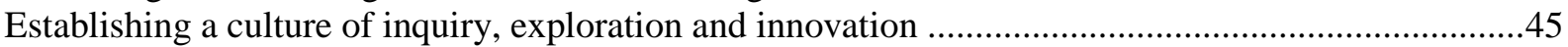

Embedding systems for collecting and exchanging knowledge and learning ......................................50

Learning with and from the external environment and larger system .................................................54

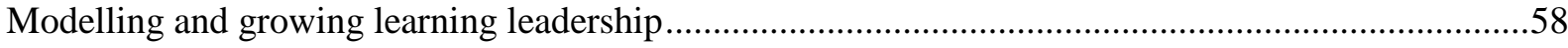

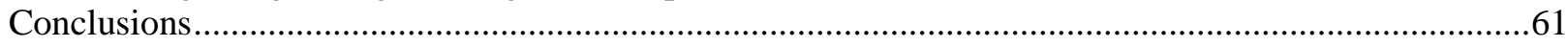

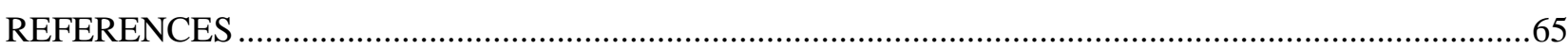

ANNEX A. SCHOOL AS LEARNING ORGANISATION DEFINITIONS ...............................................86 


\section{Tables}

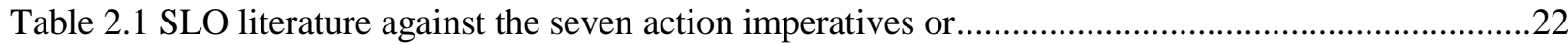

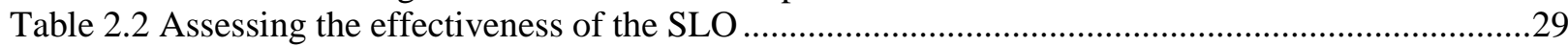

\section{Figures}

Figure 3.1 Key processes in organisational learning from failure . .49

\section{Boxes}

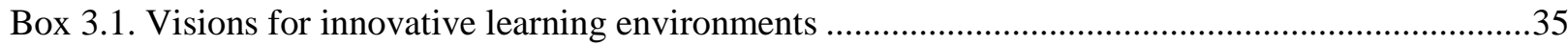

Box 3.2. Key components of the professional life cycle ........................................................................37

Box 3.3. Lesson study - a means for collaborative professional learning of teachers in Japan ................42

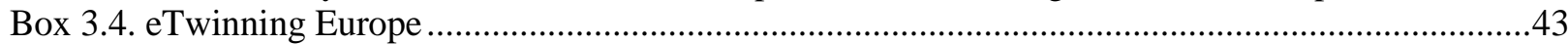

Box 3.5. "Foundation LeerKRACHT" initiative promotes peer review and collective work planning ....44

Box 3.6. Spirals of Inquiry, Networks of Inquiry and Innovation and the Aboriginal Enhancement Network, British Columbia, Canada .

Box 3.7. Using technology for improving teaching and learning - Olds High School, Alberta, Canada..52

Box 3.8. Research Learning Communities project - UCL Institute of Education, England ....................53

Box 3.9. Collaborative learning and working through networks - example from Austria ........................56

Box 3.10. Neighbourhood as school projects - Brazil ...........................................................................57 


\section{EXECUTIVE SUMMARY}

\section{Introduction}

Schools nowadays are required to learn faster than ever before as teachers are urged to become 'knowledge workers' in order to deal effectively with the growing pressures of a rapidly changing environment. In this context a growing body of scholars, educators and policy makers have argued for reconceptualising schools as 'learning organisations' which they consider the ideal type of school organisation for dealing with the changing external environment, for facilitating organisational change and innovation, and even effectiveness, i.e. improvements in the learning outcomes of students and other important outcomes. However, though the concept of the school as learning organisation, also known as the learning school, has managed to inspire the hearts and minds of a steadily growing body of scholars, educators and policy makers all over the world for around 25 years, relatively little progress has been made in advancing the concept - either in research or practice. This lack of progress partly stems from a lack of clarity around the concept. This paper should be seen as a first attempt to working towards a common understanding of the concept of the school as learning organisation that is both solidly founded in the literature and is recognisable to all parties involved, i.e. scholars, educators, policy makers, parents and others alike. It concludes by proposing an integrated model of a school as learning organisation (SLO).

\section{Main findings}

Based on an in-depth analysis of the learning organisation literature in general, and within a school context, the study proposes using the seven dimensions of Watkins' and Marsick's (school as) learning organisation model (Dimensions of the Learning Organisation Questionnaire) as a theoretical foundation for the development of our integrated SLO model. It also suggests that there is a need to refine the model, including its framework of indicators, and further strengthen its applicability to contemporary school organisations. Informed by a small network of experts the paper proposes refinements and operationalises the characteristics of the school as learning organisation in an integrated model in which the collective endeavour is focused on:

- developing and sharing a vision centred on the learning of all students

- creating and supporting continuous learning opportunities for all staff

- promoting team learning and collaboration among all staff

- establishing a culture of inquiry, innovation and exploration

- embedding systems for collecting and exchanging knowledge and learning

- learning with and from the external environment and larger learning system

- modelling and growing learning leadership.

In short, a school as learning organisation has the capacity to change and adapt routinely to new environments and circumstances as its members, individually and together, learn their way to realising their vision. 
The underlying key characteristics of the dimensions of the model, referred to as 'elements', are discussed in detail and will form the starting point for the development of indicators of an instrument to assess the school as learning organisation. The SLO model and assessment instrument are intended to provide practical guidance to policy makers, school staff and other stakeholders that wish to develop theirs schools into learning organisations. This collaboration between countries and the OECD will also enrich the OECD's work on country reviews and implementation support.

Like Watkins and Marsick (1999), the model is intended to provide practical guidance on how schools can 'support and use learning at an individual, team and organisational level' to improve and transform themselves into a learning organisation and ultimately enhance its outcomes. In that sense, it is both a process the school goes through which is the means to an end - the ultimate difference that is made for children and young people - and a positive intermediate outcome in its own right; a school that is a powerful and thriving learning organisation. The elements highlight both what a school aspires to and the processes it goes through in its journey of developing itself as a learning organisation. 
EDU/WKP(2016)11

\section{CHAPTER 1: INTRODUCTION}

\section{Introduction}

A generation ago, schools would be expected to equip students with the skills needed for the rest of their lives. In today's world they need to prepare students for life and work in a rapidly changing environment, for jobs and for using technologies some of which have not yet been created. Cognitive abilities such as literacy and problem solving are still crucial but teachers also have to support students in developing the strong social and emotional foundation skills needed to thrive in a highly dynamic labour market and rapidly changing world. Education today is much more about ways of thinking that involve creative and critical approaches to problem solving and decision making, and where students influence what they learn. Their interests, motivation and overall well-being are taken in consideration for shaping their learning (Dumont, Istance and Benavides, 2010). Traditional models of schooling whose organisational patterns deeply structure schools - the single teacher, the classroom segmented from other classrooms each with their own teacher, and traditional approaches to teaching and classroom organisation, etc. - are inadequate for delivering these 21 st century learning agendas, especially for the most disadvantaged students in society (OECD, 2013a; Schleicher, 2012, 2015).

Countries have been trying to accommodate their increasingly complex education systems to the changing times, but the education sector does not always have a good track record of innovating itself. Change is a complex, multi-faceted process (Kuijpers et al., 2010) and creating lasting change is hard: in many cases, reforms have failed to take hold in the classrooms or at best get "adopted" on the surface without altering behaviours and beliefs (Fullan, 2015). Many reform efforts have additionally failed to adequately prepare schools for the changing environment (e.g. Fullan, 2011; Giles and Hargreaves, 2006; Skalde and Pont, 2013; OECD, 2015b). Meanwhile, schools are urged to learn fast and teachers are urged to become 'knowledge workers' in order to deal effectively with the growing pressures of a rapidly changing environment (Schleicher, 2012, 2015).

To respond to often disappointing results of reform initiatives and an apparent lack in ability of many schools to initiate and sustain their own innovations, policy makers, educators and scholars have searched for alternative strategies that could foster school-wide change and affect all aspects of school culture. Schools need capacity to learn routinely from the world around them and apply their learning to new situations so that they are able to continue on a path towards their goals in an ever-changing context, and to be able to prepare children and young people both for the present and their future (Stoll and Earl, 2003; Stoll, 2009). In this context a growing body of scholars and educators have argued for reconceptualising schools as 'learning organisations' (e.g. Giles and Hargreaves, 2006; Senge, 2012; Stoll and Fink, 1996; Fullan, 1995; Gandolfi, 2006; Schlechty, 2009; Silins, Zarins and Mulford, 2002). This concept has been successfully practised in business and industry. The argument is that this is the ideal type of school organisation for dealing with the changing external environment, for facilitating organisational change and innovation, and even effectiveness, i.e. improvements in the learning outcomes of students and other important outcomes.

Support for reconceptualising schools as learning organisations is not limited to scholars and educators. During the last 25 years a considerable number of policy makers have also been drawn to the intuitive appeal and promise of the concept of school as learning organisation. Singapore provides us with one of the earliest examples. Its vision Thinking Schools Learning Nation (1997) emerged from a strategic review of education, motivated by a pre-occupation with the future. The then Deputy Prime Minister Lee noted that: 'Our schools and tertiary institutions must become learning organisations, not teaching factories. Teachers and lecturers should continually seek to improve, to pick up best practices elsewhere, 
and to challenge students to find better solutions. These changes in our education system need to be supported by a national environment that promotes a learning mind set and a society that upholds the fundamental values of equal opportunities and meritocracy'. The Netherlands offers another more contemporary example in its Teachers Agenda 2013-2017 which has the transformation of schools into learning organisations as one of its key objectives ('agenda points').

Though the concept of the school as learning organisation (SLO) has managed to inspire the hearts and minds of a steadily growing body of scholars, educators and policy makers all over the world for around 25 years, relatively little progress has been made in advancing the concept - either in research or practice.

\section{Research questions and methodology}

Despite the steadily growing support among scholars, educators and policy makers for reconceptualising schools as learning organisations, little is known about the actual spread of these schools throughout our school systems and, more importantly, whether they indeed lead to better learning and/or other outcomes. If they are found to lead to better outcomes, this could have major policy consequences internationally - the evidence would strongly argue for transforming schools into learning organisations. The question then would be how to actually do this in practice. Again, research evidence on this point is limited (Silins, Zarins and Mulford, 2002; Gandolfi, 2006).

The lack of advance of the concept of a school as learning organisation in research and practice partly stems from many different understandings of the concept. Part of the problem also lies in the shortage of systematic empirical investigations (Schleicher, 2012; Leithwood and Louis, 1998). Much of the research deals with validity testing, using different measurement instruments, rather than providing empirical evidence on the spread and performance of these schools, using representative survey data. With some notable exceptions (e.g. Silins, Zarins and Mulford, 2002) empirical investigations have often been limited in scale (e.g. Hamzah et al., 2011; Ho Park, 2008; Retna and Tee, 2006). Although these studies are often valuable contributions to the literature, they fail to give a real insight into the spread and/or performance of the school as learning organisation within and across countries. Nor do they give a thorough insight into the policies and practices, and characteristics of schools that support them in transforming into learning organisations. Where examples exist (e.g. Leithwood and Louis, 1998), they do not always use the term 'learning organisation', even if they represent many of the characteristics associated with it. The "how" is clearly an issue deserving further research attention.

In sum, the concept of a school as learning organisation lacks clarity, and little empirical evidence exists to demonstrate the effectiveness of such schools. This raises a number of key research and policy questions:

- What are the characteristics of the school as learning organisation?

- How can a school transform itself into a learning organisation?

- What does this require in terms of change and innovation capacity of leaders at other levels of the system?

- And what does this require from the governance and support structures in which these schools operate?

- Does the school as learning organisation, as often assumed, indeed lead to better learning and/or other outcomes?

This working paper should be seen as a first step towards answering these key policy questions. In particular it aims at answering the first two research questions posed above i.e. "What are the 
characteristics of the school as learning organisation?" - differently stated, how can we define the school as a learning organisation? - and "How can a school transform itself into a learning organisation?" (Chapter 2 and 3). These questions will be answered through an in-depth multi-disciplinary literature review that will include but not be limited to a careful examination of the learning organisation literature. This review will be intentionally broad and, among others, include investigation of the organisational change, learning, school improvement and effectiveness literatures. The literature review will build on the OECD's vast and growing knowledge base with specific reference to the Programme for International Student Assessment (PISA), the Teaching and Learning International Survey (TALIS), the Governing Complex Education Systems project and earlier projects like the Innovative Learning Environments project.

The literature review will aim to identify and map the various definitions and descriptors of the learning organisation concept in general, which largely stems from research on private sector organisations, and in particular in the school context. The international literature review will include an investigation of purposefully designed and other relevant measurement instruments. The review will lead to the articulation of a definition and a model of the school as a learning organisation (SLO) which is applicable to contemporary primary and (lower) secondary schools.

A small network of experts was brought together to support the development of the working paper by reviewing and giving feedback on the draft text at various stages. An expert meeting was also organised on 12 February 2016 to discuss and provide feedback to the draft working papers.

\section{Outline of the working paper}

This paper is structured as follows. The first chapter has introduced the reader to the rationale for and concept of school as learning organisation, identified the main research questions of this study and explained the methodological approach. Chapter 2 provides an in-depth analysis of the learning organisation literature in general, and within a school context, and outlines some critiques and challenges. It also reviews some of the assessment instruments that have been developed during the last decades to measure the SLO. Drawing richly from a multi-disciplinary literature review including an exploration of related concepts, Chapter 3 discusses and operationalises the characteristics of the SLO in an integrated model. These are captured in seven overarching dimensions that make up the presented SLO model. 
EDU/WKP(2016)11

\section{CHAPTER 2: REVIEWING THE (SCHOOLS AS) LEARNING ORGANISATION LITERATURE}

\section{Introduction}

For many school systems the challenge ahead is formidable. Schools are nowadays urged to learn faster than ever before in order to deal effectively with the growing pressures of a rapidly changing environment. The skills that students need to contribute effectively to society are changing constantly, but our school systems are not keeping up. Most schools look much the same today as they did a generation ago, and teachers themselves are often not developing the practices and skills required to meet the diverse needs of today's learners (Schleicher, 2012; 2015).

The call for reconceptualising schools into learning organisations is a direct response to these findings. The concept of a school as a learning organisation for many school systems will require rethinking teacher and school leader professionalism in ways that allow them to become high-quality knowledge workers and changing organisational structures and processes in order to create the type of adaptive school organisation that can thrive in a continuously changing external environment. But these are just some of the steps schools will have to take when embarking on the journey of innovation that is to transform them into learning organisations. To understand the school as a learning organisation, it is first necessary to revisit what is known about the concept of the learning organisation as used more generally. This chapter therefore consists of multi-disciplinary literature reviews on the learning organisation and the school as learning organisation in particular. The chapter starts with a discussion on different perspectives of the learning organisation that have emerged from the literature. The discussion is aimed to inform the reader on commonalities and differences among the different interpretations and definitions of the learning organisation.

The next section repeats this exercise, but this time the investigation relates to the concept of the school as a learning organisation. This is done as change evidently is a multi-level and multi-faceted phenomenon, and is indicative of the often-discussed differences between the private and the public sectors (Kuipers et al., 2013; Barrados and Mayne, 2003). The drivers for organisational change in the public sector are different from those in the private sector, emanating as they do in part from the political system. Organisational change in the public sector to some degree will be distinctive for this reason as well as for reasons to do with the specific nature of the activities undertaken in different sub-sectors: public administration and social security, education, and health and social work (OECD, 2010a).

The search for literature (i.e. books, academic articles and dissertations) on the school as learning organisation is conducted in the English language ${ }^{1}$ through: 1) focused searches of nine electronic databases - ERIC, SAGE, Google Scholar, Taylor \& Francis, Emerald, JSTOR, SpringerLink, Google, Science Direct - using the search terms 'school as learning organisation' and 'learning school'; and 2) contacts with leading experts in this area of work which have led to the identification of additional literature. The first approach has led to the selection of 25 most frequently found publications on the school as learning organisation and/or learning school. The second approach led to the identification of an additional seven publications that are used to further enrich the analysis.

This analysis is followed by a brief examination of 'critical voices' towards learning organisation theory to judge whether they hold ground and, if so, whether they could point towards areas for further development of the school as learning organisation (SLO) concept. After this there is an investigation of

\footnotetext{
${ }^{1}$ Though the authors individually master several languages, English is the one language they have in common.
} 
some of the most frequently cited SLO assessment instruments to complement the analysis of the literature and support the identification of the characteristics of the SLO.

\section{A review of the concept of the learning organisation}

The concept of the learning organisation plays a pivotal role in contemporary management theory and practice (Nakpodia, 2009; Gronhaug and Stone, 2012), and has done so for several decades. It started gaining popularity in the literature in the late 1980s, becoming more widely used following Senge's best-seller The Fifth Discipline: The Art \& Practice of The Learning Organization in 1990. Senge et al. defined a learning organisation as an: "organization where people continually expand their capacity to create the results they truly desire, where new and expansive patterns of thinking are nurtured, where collective aspiration is set free, and where people are continuously learning to see the whole together" (p. 3).

During the last 25 years organisational scholars have focused their work on conceptualising the learning organisation, identifying characteristics of such organisations that have the capacity to continuously learn, adapt and change. The learning organisation literature however is disparate and there are many different definitions. A few scholars have aimed to create order in this "scholarly chaos" by defining categories or typologies of the different approaches to defining the construct.

Among these are Yang, Watkins and Marsick (2004) who provide us with a clear and useful typology that is strongly rooted in the learning organisation literature. It consists of four types or perspectives: "systems thinking", the "learning perspective", the "strategic perspective" and the "integrated perspective".

\section{"Systems thinking”}

"Systems thinking" is considered by various scholars to be the conceptual cornerstone of the learning organisation concept. The term learning organisation stems from the 'general systems theory' which was created by Karl Ludwig von Bertalanffy (1934). General systems theory is an interdisciplinary practice that describes systems with interacting components, applicable to biology, cybernetics, and other fields. The two basic, opposing types are open and closed systems. Closed or less open systems are less influenced by and have less interaction with their environment. This limits their ability to discover changes that might influence them. In other words closed or less open organisations have less ability to learn (Portfelt, 2006).

A learning organisation is very much an open system, as many scholars have pointed out (e.g. Senior and Swailes, 2010; Argyris and Schön, 1996; Senge et al., 1990). The characteristics of open systems are their relation to and interaction with the environment as well as the ability to scan and discover changes in that environment (Birnbaum, 1988; O'Conner and McDermott, 1997). Alignment is a state of congruence between organisational sub-elements and their environment. Because the external environment changes, elements of the system must respond in order to restore the equilibrium (Spector, 2006; Birnbaum, 1988; Sporn, 1999).

The best known proponent of systems thinking, without a doubt, is Senge whose work has had a great influence on the thinking around the learning organisation. Senge et al. (1990) noted that the learning organisation is one that possesses not only adaptive capacity but is also 'generative' - it has the ability to create alternative futures. The five disciplines identified by Senge et al. that a learning organisation should possess are:

- Team learning - emphasis on the learning activities of the group rather than the development of team process; 
- Shared vision - ability to unearth shared 'pictures of the future' that foster genuine commitment and enrolment rather than compliance;

- Mental models - deeply held internal images of how the world works;

- Personal mastery - continually clarifying and deepening personal vision, focusing energies, developing patience, and seeing reality objectively; and

- Systems thinking - the ability to see the bigger picture, to look at the interrelationships of a system as opposed to simple cause-effect chains; allowing continuous processes to be studied rather than single snapshots.

The fifth discipline, i.e. systems thinking, is Senge's choice for his book title, and shows us that the essential properties of a system are not determined by the sum of its parts but by the process of interactions between those parts (Yang, Watkins and Marsick, 2004).

Various other scholars share Senge's views, giving systems thinking a central role in their own interpretations of the concept. Worrell (1995), for example described the learning organisation as:

An organizational culture in which individual development is a priority, outmoded and erroneous ways of thinking are actively identified and corrected, and the purpose and vision of the organization are clearly understood and supported by all its members. Within this framework, the application of systems thinking enables people to see how the organization really works; to form a plan; and to work together openly, in teams, to achieve that plan. (p. 352)

\section{The "learning perspective"}

The "learning perspective" is a notion of the learning organisation that is closely linked to organisational learning. Organisational learning as the study of learning processes of and within organisations was introduced in the late 1950s and 1960s, but it was only until the 1990s that the idea of organisational learning became a common concept in organisational theory (Moraga, 2006).

Already in the late 1970s Argyris and Schön (1978) had published their seminal book Organizational learning: a theory in action perspective which was the first to propose a model to facilitate organisational learning. Others have followed in this tradition. Argyris and Schön defined organisational learning as "the detection and correction of error" (p. 2) where learning can take place in three forms: single-loop, doubleloop and deutero learning. Single-loop learning occurs when errors are detected and firms carry on with their ongoing policies and goals. In double-loop learning, in addition to detection and correction of errors, the organisation is involved in questioning and modifying existing norms, procedure, policies and objectives, i.e. changing the organisational knowledge base (Dodgson, 1993). Deutero learning, adapted from earlier anthropological theory (Bateson, 1958) occurs when the organisation learns how to carry out single and double-loop learning, for example, by identifying the processes and structures that facilitate learning.

Much of the literature on organisational learning points to the importance of social interaction, context and shared cognitive schemes for learning and knowledge creation (Agyris and Schön, 1978; Lave and Wenger, 1991; Brown and Duguid, 1998). Pedler, Burgoyne and Boydell were arguably the first to give so much prominence to learning (theory) in their formulation of the learning organisation. In their influential article of 1989 The Learning Company they described the learning company - or learning organisation - as "an organization that facilitates the learning of all its members and continually transforms itself" (Pedler et al., 1989, p. 1). In a later report (in 1991) the definition was extended by adding the words "in order to meet its strategic goals". Pedler et al. (1991) depict the "learning company" as a vision of what might be 
possible. It is not brought about simply by training individuals; it can only happen as a result of learning at the whole organisation level.

Another example fitting the learning perspective is provided by Watkins and Marsick who in 1993 defined the learning organisation as "one that learns continuously and transforms itself" (p. 8), a definition they would later further refine as will be discussed below.

Yang, Watkins and Marsick (2008) note that the learning perspective provides a comprehensive focus on aspects of learning at all levels of the organisation but, at the same time (on its own), fails to provide a holistic construct of the concept. Like the systems perspective, the learning perspective captures a principle but fails to provide operational guidance to those wanting to transform their organisation into a learning organisation.

\section{The "strategic perspective"}

The "strategic perspective" responds to this lack of operational guidance. According to this approach, a learning organisation requires an understanding of the strategic internal drivers necessary for building learning capacity. Garvin (1993) for example defines a learning organisation as "an organisation skilled at creating, acquiring, and transferring knowledge, and at modifying its behaviour to reflect new knowledge and insights" (p. 80).

This perspective foregrounds the search for new ideas through exploration and exploitation (March, 1991), highlighting the importance of innovation and inquiry.

Strategy is seen as an integral part of the learning process for a learning organisation because it focuses on the organisation's development of core competencies, both in the present and in the future (Millett, 1998). In Garratt's (1987) "learning organisation model" top-managers have a central role in defining the strategy of learning processes. Many of the scholars who followed, however, have argued for a more distributed form of leadership. Goh (1998) for example synthesised the management practices and policies related to the construct. He proposes that the learning organisation has five building blocks:

- Clarity and support for mission and vision;

- Shared leadership and involvement;

- A culture that encourages experimentation;

- The ability to transfer knowledge across organisational boundaries; and

- Teamwork and co-operation.

Goh further notes that these building blocks require two main supporting foundations: an effective organisational design that is aligned with and supports the building blocks; and the appropriate employee skills and competencies needed for the tasks and roles described in these strategic building blocks.

Like Goh, other scholars fitting the strategic perspective have attempted to provide clear definitions of the learning organisation with many providing building blocks or action imperatives (e.g. Garvin, 1993; Pedlar et al., 1995; Marsick, 1993; Phillips, 2003; Goh, 1998). These strategic building blocks are aimed at providing practical guidance for operationalising the concept into daily practice (Yang, Watkins and Marsick, 2004). As also argued for by Yang, Watkins and Marsick, a weakness in this approach may be that it emphasises the macro level and thus neglects some commonly defined elements of the learning organisation, such as individual learning. 


\section{The "integrative perspective"}

Yang, Watkins and Marsick therefore propose a fourth perspective, the "integrative perspective". In their analysis they refer to the updated definition by Watkins and Marsick (1996) of the learning organisation that seems to consolidate the strengths of the prior perspectives. They describe a learning organisation as one in which: "people are aligned to a common vision, sense and interpret their changing environment, generate new knowledge which they use, in turn, to create innovative products and services to meet customers' needs" (p. 10).

Their proposed organisational model integrates two main organisational constituents: "people" and "structure". These are seen as interactive components of organisational change and development. Yang, Watkins and Marsick identified seven action imperatives that characterise companies travelling towards becoming a learning organisation at individual, team and organisational levels:

- Continuous learning, represents an organisation's effort to create continuous learning opportunities for all its members;

- Inquiry and dialogue, refers to an organisation's effort in creating a culture of questioning, feedback and experimentation;

- Team learning, reflects the 'spirit of collaboration and the collaborative skills that undergird the effective use of teams;

- Embedded system for capturing and sharing learning, indicated the efforts to establish systems to capture and share learning;

- Empowerment, signifies an organisation's process to create and share collective vision and get feedback from its members about the gap between the current status and the new vision;

- System connection, reflects global thinking and actions to connect the organisation to its internal and external environment; and

- Strategic leadership, shows the extent to which leaders think strategically about how to use learning to create change and to move the organisation in new directions or new markets (Yang, Watkins and Marsick, 2004).

A few other scholars have taken a similar approach of reviewing the literature to come up with their own integrated model of the learning organisation. Among these is Örtenblad (2002) who based on a review of the learning organisation literature - primarily on private sector organisations, as well as practitioners' understandings of the concept, developed a typology and integrated model of the learning organisation. He describes four aspects that all have to be implemented to be called a learning organisation:

- Learning at work - rather than through formal courses which should play a limited role in the learning because it is difficult to apply this type of learning in practice;

- Organisational learning - which is focused on the storage of knowledge in the organisational mind. Learning is viewed as the applications of knowledge at different levels;

- The learning climate - a learning organisation is one that facilitates the learning of all; and

- The learning structure - the learning organisation is one with an organic structure with a high degree of flexibility. 


\section{Common characteristics}

It should be clear from the above that there are many different interpretations to the learning organisation concept, even among those who have aimed to develop integrated models. These differences often find their origins in the theoretical orientations which scholars most value leading them to review the literature in a delimited area to define their definitions and/or typologies of the learning organisation.

Despite these differences some common characteristics can be identified. First, scholars seem to agree that the learning organisation is a necessity and is implicitly or explicitly argued to be suitable for any organisation - irrespective of culture and branch. Increasing numbers of organisational scholars have come to realise that an organisation's learning capability will be the only sustainable competitive advantage in the future (Örtenblad, 2002; Yang, Watkins and Marsick, 2004; OECD, 2010a).

Second, most scholars see the learning organisation as a multi-level concept and define the learning organisation as 'organic' and in terms of the interrelations between individual behaviours, team organisation and organisational practices and culture (OECD, 2010a).

Third, there is an emphasis on the importance of the beliefs, values and norms of employees for sustained learning. The importance of creating a 'learning atmosphere' (Rothwell, 2002), 'learning culture' (Gephart et al., 1996) or 'learning climate' (Örtenblad, 2002) is frequently discussed in this context. 'Learning to learn' as such is a key factor in becoming a learning organisation (OECD, 2010a).

These common characteristics are best reflected in the integrative perspective of the learning organisation. This perspective helps bring further clarity to the concept, with particular reference to the learning organisation model of Watkins and Marsick in which the seven action imperatives (dimensions) also provide necessary operational guidance. Their seven action imperatives (p. 18) might be interpreted in terms of what schools must change to become learning organisations (Watkins and Marsick, 1999). In the next section we will use these to discuss and reflect on some of the school as learning organisation definitions that have been developed throughout the years.

\section{Defining the school as learning organisation}

Though the literature on the school as learning organisation (SLO) or learning school has been steadily growing since the $1990 \mathrm{~s}$, it is less extended than the learning organisation literature which mostly deals with organisations in the private sector. And like in other sectors, the concept lacks clarity. Part of the problem is that although many scholars have placed the concept at the centre of their academic discussions, often discussing one or more of its key characteristics, several have failed to clearly articulate a definition (e.g. Diggins, 1997; Giles and Hargreaves, 2006; Gunter, 1996; Higgins et al., 2012; Kirkham, 2005; Retna and Tee, 2006; Simonaitene, 2004; Yong, 2000). This is also evident when looking at the outcome of our search for relevant publications (i.e. articles and books) which included an investigation of nine search engines and databases. From the 25 identified publications using the search terms the 'school as learning organisation' and/or 'learning organisation' five did not provide a definition (see Annex I). As such these scholars, to varying degrees, leave the reader guessing about their theoretical interpretations of the concept in a school context.

The issue is also confounded by a related body of research on "professional learning community", with a number of scholars writing about both concepts (e.g. Louis and Leithwood, 1998; Fullan, 2001; Stoll et al., 2003; Giles and Hargreaves, 2006). It could be argued that adding the perspective of community brings the heart into the concept of learning organisation. Westheimer (1999) highlights five commonly identified features of community: shared beliefs and understandings; interaction and participation; interdependence; concern for individual and minority views; and meaningful relationships. 
Central to the notion of school community is an ethic of interpersonal caring permeating the life of teachers, students and school leaders (Louis al., 1995). The community focus in "professional learning community" emphasises mutually supportive relationships and developing shared norms and values (Stoll et al., 2006), which are strongly influenced by the presence and development of trust (Bryk and Schneider, 2002). As Mitchell and Sackney (2000, p. 6) argue, "the learning community is concerned with the human experience and that this concern is not necessarily evident in a learning organization". We return to these ideas later.

A further issue arises where educational scholars "zoom in" on a particular feature of organisational learning. For example, Supovitz (2010) defines and explores "knowledge-based organizational learning", which aligns with the "knowledge worker" imperativeand endorsing the organisational learning perspective where the underlying ideas: "focus on continuous change, stimulated by multiple sources of knowledge, where knowledge is a constantly changing collective understanding not of 'facts' but of the action implications of what is known together" (Louis, 2008, p. 15-21). Some scholars have aimed to define the concept of the learning organisation. These include Senge et al. (2012) who, in applying their wider perspective to the world of education, describe the SLO as one that is:

Re-created, made vital, and sustainably renewed not by fiat or command, and not by regulation, but by taking a learning orientation. This means involving everyone in the system in expressing their aspirations, building their awareness and developing their capabilities together. In a school that learns, people who traditionally may have been suspicious of one another - parents and teachers, educators and local business people, administrators and union members, people inside and outside the school walls, students and adults - recognise their common stake in the future of the school system and the things they can learn from one another. (p. 5)

Senge et al. (2012) suggest that practising the five disciplines of "personal mastery", "mental model", "shared vision", "team learning" and "systems thinking" can empower schools to meet the challenges of educational reforms, and improve their performance.

The work of Senge et al. (2012) has inspired scholars all over the world to develop and assess schools as learning organisations using the five disciplines (e.g. Johnston and Caldwell, 2001; Park, 2008; Hamzah et al., 2011; Moloi et al., 2006). The interpretation of the specific characteristics of the five disciplines however differs among scholars, sometimes considerably. This suggests a lack of clarity and consensus as to how the five disciplines can best be operationalised. While for some this flexibility - or as Örtenblad $(2002,2004)$ would call it the "vagueness" - may be desirable, for others it diminishes its usefulness as it does not provide sufficient guidance to school leaders, teachers and others as to how to develop their school into a learning organisation. We consider ourselves among this latter group for this very reason.

A gradually growing body of scholars have aimed to provide operational guidance when developing their SLO definitions by describing the processes, strategies and structures that would enable them to learn and react effectively in uncertain and dynamic environments (DuFour, 1997; Giles and Hargreaves, 2006; Fullan, 1995; Kruse, 2003;Strain, 2000). DuFour (1997) for example views the SLO as one that devotes considerable attention to shaping the human resource management policies and procedures within the school organisation to facilitate peer learning and collaboration among colleagues.

Where earlier SLO scholars like Watkins and Marsick (1999) and Du Four (1997) have often focused on peer learning and collaboration among colleagues within the same school increasingly scholars have also pointed towards the importance for networked learning and collaboration across the school boundaries, aimed at forging synergies, sharing and creating knowledge and innovations with various 
partners (Bowen, Rose and Ware, 2006; Schlechty, 2009; OECD, 2013a). This is an important characteristic to also incorporate in our own SLO model.

In line with the learning organisation strategic perspective, DuFour (2006) emphasises the importance of strategic leadership for creating such conditions; a view that is shared by several other SLO scholars (e.g. Brandt, 2003; Coppieters, 2005). In contrast, Leithwood et al. (1998, p. 86), while endorsing school strategies as conditions fostering organisational learning, conclude from a five-year Canadian study that all eight dimensions of transformational leadership which were examined (e.g. Burns, 1978) "contribute significantly to school conditions fostering organisational learning as well to organisational learning directly". Identifying and articulating a vision is one of these elements. Other scholars like Watkins and Marsick (1999), Silins, Zarins and Mulford (2002) and Fullan (1995) also place much importance on to the need of establishing a shared vision. Table 2.1 shows that most of the identified publications highlight the importance of having a shared vision to shape the organisation and give a sense of direction to change and innovation efforts. However, it is noteworthy that in many cases - and this includes the work of Watkins and Marsick (1999) - little or no guidance is given as to what this vision is to entail and who it is to apply to. We view this as a shortcoming that we will come back to in detail in Chapter 3.

\section{Table 2.1. SLO literature against the seven action imperatives Watkins' and Marsick's learning organisation model}

\begin{tabular}{|c|c|c|c|c|c|c|c|c|}
\hline \multicolumn{2}{|c|}{$\begin{array}{c}\text { Literature on school as learning } \\
\text { organisation }\end{array}$} & \multirow[t]{2}{*}{$\begin{array}{l}\text { Empowerment } \\
\text { towards a } \\
\text { shared vision }\end{array}$} & \multirow[t]{2}{*}{$\begin{array}{l}\text { Create } \\
\text { continuous } \\
\text { learning } \\
\text { opportunities }\end{array}$} & \multirow{2}{*}{$\begin{array}{c}\begin{array}{c}\text { Promotes } \\
\text { team }\end{array} \\
\text { learning and } \\
\text { collaboration } \\
+\end{array}$} & \multirow{2}{*}{$\begin{array}{l}\text { Promotes } \\
\text { inquiry and } \\
\text { dialogue } \\
++\end{array}$} & \multirow{2}{*}{$\begin{array}{l}\text { Embedded } \\
\text { system for } \\
\text { capturing and } \\
\text { sharing } \\
\text { learning } \\
+\end{array}$} & \multirow{2}{*}{$\begin{array}{l}\text { Connected to } \\
\text { the }\end{array}$} & \multirow{2}{*}{$\begin{array}{c}\text { Strategic } \\
\text { leadership } \\
\text { for learning } \\
\text { ++ }\end{array}$} \\
\hline 1 & Higgins et al. (2012) & & & & & & & \\
\hline 2 & Schechter and Mowafaq (2013) & & & ++ & & ++ & + & \\
\hline 3 & Schechter (2008) & & & ++ & & ++ & + & \\
\hline 4 & Keefe and Howard (1997) & + & + & ++ & ++ & + & & ++ \\
\hline 5 & Fullan (1995) & ++ & ++ & ++ & ++ & & ++ & + \\
\hline 6 & Harris and Tassel (2005) & + & ++ & ++ & ++ & & ++ & + \\
\hline 7 & Park (2008) & ++ & ++ & ++ & ++ & & ++ & \\
\hline 8 & Schechter and Mowafaq (2012) & & & ++ & & ++ & + & \\
\hline 9 & $\begin{array}{l}\text { Silins, Zarins and Mulford } \\
(2002)\end{array}$ & ++ & ++ & ++ & ++ & ++ & ++ & ++ \\
\hline 10 & Paletta (2011) & ++ & ++ & ++ & ++ & ++ & + & \\
\hline 11 & Kirkham (2005) & & ++ & & + & & & ++ \\
\hline 12 & Retna and Tee (2006) & ++ & ++ & ++ & ++ & & ++ & ++ \\
\hline 13 & Wallace et al. (1997) & ++ & ++ & ++ & ++ & + & ++ & ++ \\
\hline 14 & Diggins (1997) & + & + & + & & & + & + \\
\hline 15 & Gunter (1996) & + & ++ & ++ & ++ & + & + & \\
\hline 16 & Nixon et al. (1996) & ++ & ++ & ++ & ++ & ++ & ++ & \\
\hline 17 & Alavi and McCornick (2004) & ++ & ++ & ++ & ++ & & ++ & \\
\hline 18 & Bowen, Rose and Ware (2006) & ++ & + & ++ & ++ & + & ++ & \\
\hline 19 & Kerka (1995) & + & ++ & + & ++ & & + & + \\
\hline 20 & Benjamin (2009) & ++ & ++ & ++ & ++ & ++ & ++ & ++ \\
\hline 21 & Hamzah et al. (2011) & ++ & ++ & ++ & + & & + & ++ \\
\hline 22 & Coppieters (2005) & ++ & + & + & ++ & ++ & + & \\
\hline 23 & Moloi et al. (2006) & ++ & ++ & ++ & ++ & ++ & ++ & + \\
\hline
\end{tabular}


EDU/WKP(2016)11 Table 2.1. SLO literature against the seven action imperatives Watkins' and Marsick's learning
organisation model (continued)

\begin{tabular}{|c|c|c|c|c|c|c|c|c|}
\hline \multicolumn{2}{|r|}{$\begin{array}{l}\text { Literature on school as learning } \\
\text { organisation }\end{array}$} & $\begin{array}{l}\text { Empowerment } \\
\text { towards a } \\
\text { shared vision }\end{array}$ & $\begin{array}{l}\text { Create } \\
\text { continuous } \\
\text { learning } \\
\text { opportunities }\end{array}$ & $\begin{array}{l}\text { Promotes } \\
\text { team } \\
\text { learning and } \\
\text { collaboration }\end{array}$ & $\begin{array}{l}\text { Promotes } \\
\text { inquiry and } \\
\text { dialogue }\end{array}$ & $\begin{array}{l}\text { Embedded } \\
\text { system for } \\
\text { capturing and } \\
\text { sharing } \\
\text { learning }\end{array}$ & $\begin{array}{c}\text { Connected to } \\
\text { the } \\
\text { environment }\end{array}$ & $\begin{array}{c}\text { Strategic } \\
\text { leadership } \\
\text { for learning }\end{array}$ \\
\hline 24 & Brandt (2003) & ++ & ++ & + & ++ & ++ & ++ & \\
\hline 25 & Clarke (2005) & + & + & ++ & ++ & ++ & + & ++ \\
\hline \multicolumn{9}{|c|}{ Additional publications identified by leading experts } \\
\hline 26 & Schlechty (2009) & ++ & ++ & ++ & ++ & ++ & & \\
\hline 27 & Davidoff and Lazarus (2002) & ++ & ++ & ++ & ++ & ++ & ++ & ++ \\
\hline 28 & Middlewood et al. (2005) & ++ & ++ & ++ & ++ & ++ & ++ & ++ \\
\hline 29 & $\begin{array}{ll}\text { Leithwood, Leonard and } \\
\text { Sharatt (1998) }\end{array}$ & ++ & ++ & ++ & ++ & + & ++ & ++ \\
\hline 30 & Louis and Kruse (1998) & ++ & ++ & ++ & ++ & ++ & ++ & + \\
\hline 31 & Mitchell and Sackney (1998) & ++ & ++ & ++ & ++ & ++ & & \\
\hline 32 & Senge et al. (2012) & ++ & ++ & ++ & ++ & ++ & ++ & ++ \\
\hline
\end{tabular}

Note: ++ stands for good/excellent fit; + means partial fit.

Furthermore, about half of the selected publications explicitly recognise the importance of establishing "embedded systems for capturing and sharing learning" (Watkins and Marsick, 1996) as a key feature of a SLO. The prominence scholars place on this, whether or not by extending the boarders of the learning environment, however varies. While Schechter's and Mowafaq's $(2012,2013)$ view of the SLO is focused mainly on the establishment of what they refer to "learning mechanisms", as well as on the promotion of team learning and collaboration, most scholars provide a more holistic view of the processes, strategies and structures shaping a SLO (Bowen, Rose and Ware, 2006; Nixon et al., 1996; Silins, Mulford and Zarins, 2002; Schlechty, 2009; Watkins and Marsick, 1999).

One example of a clear and holistic, and therefore useful, definition that provides operational guidance is provided by Watkins and Marsick $(1993,1996)$ who consider a learning organisation to be one in which people are aligned to a common vision, sense and interpret their changing environment, generate new knowledge which they use, in turn, to create innovative products and services to meet customers' needs. Their seven action imperatives (p. 11) might be interpreted in terms of what schools should change to become learning organisations (Watkins and Marsick, 1999).

Silins, Mulford and Zarins (2002) provide a similar holistic definition. At the start of the 21st century, they investigated the concept of secondary schools as learning organisations as part of a research project involving South Australian and Tasmanian secondary schools. The findings of this large-scale study (see Chapter 3) informed the formulation of their definition of a school as learning organisation:

Schools as learning organisations employ processes of environmental scanning; develop shared goals; establish collaborative teaching and learning environments; encourage initiatives and risk taking; regularly review all aspects related to and influencing the work of the school; recognise and reinforce good work; and, provide opportunities for continuing professional development (p. 26-27).

Through specific references to, for example, the environmental scanning to inform the internal operations (systems thinking), the focus on developing shared goals (strategic perspective) or the establishment of collaborative learning and teaching environments (learning perspective) these scholars 
incorporate the strengths of the various learning organisation perspectives and have integrated these into a holistic definition that offers guidance to those wanting to transform their school into a learning organisation.

\section{Common characteristics of the school as learning organisation}

In sum, the above offers an insight into the various definitions of the SLO developed over the last 25 years. Although the SLO literature is not as vast as the general learning organisation literature, they have in common that scholarly interpretations of the concept vary, sometimes considerably.

Despite these differences, several common characteristics of the SLO emerge from the literature. First, scholars seem to agree that the SLO is a necessity for dealing with the rapidly changing external environment. Implicitly or explicitly they argue that the concept is suitable to any school organisation, regardless of the context in which the school operates. The latter is exemplified by application of the concept in a wide range of countries, including Australia (Silins, Mulford and Zarins, 2002), England and Wales (Kirkham, 2005), Iran (Ghahramanifard, Pashaei and Mehmandoust, 2013), Israel (Schechter and Mowafaq, 2012), Korea (Park, 2008), Malaysia (Hamzah et al., 2011), South Africa (Moloi et al., 2006; Moloi, 2010) and the United States (Higgins et al., 2012; Harris and van Tassell, 2005).

Second, like the learning organisation literature in general, the SLO is defined as "organic" and closely connected to the external environment. Third, the SLO literature strongly emphasises the importance of individual, group and organisational learning with inquiry, problem solving and experimentation as key drivers of change and innovation in education. From our sample of publications almost all scholars highlight the need for promoting team learning and collaboration, and continuous individual learning (see Table 2.1), but they go further than this in implicating investigative and adaptive processes as part of this learning in order to stimulate change and innovation. The fact that many schools are still far removed from the ideal of the learning organisation - while the pressures of the external environment to make this transformation are mounting - argues (more strongly than Watkins and Marsick (1999) and many other SLO scholars have done) for the importance of exploring new ways of doing things and striving for lasting innovations in education practice. Information and communication technologies (ICT) however are rarely discussed in this context while being a powerful driver of educational change and innovation (OECD, 2013a; Kampylis, Punie and Devine, 2015).

Last, much of the literature emphasises the importance of the beliefs, values and norms of employees for continuous and collaborative learning, and the processes, strategies and structures to create the conditions for such learning, experimentation and innovation to flourish. Several scholars have brought these together in holistic, integrated models of the SLO. These models seem to have the greatest potential for advancing the SLO concept in research and practice because of the operational guidance they can provide to all those considering to transform their schools into learning organisations.

\section{Critiques of the learning organisation}

The previous section has given voice to some of the most prominent proponents or advocates of the learning organisation or SLO. The concept however is not without its critics. Despite the growing theoretical support and some real-life examples, some critics claim "this emperor has no clothes", and are sceptical whether this will ever be the case. Most critics have directed their attention to the learning organisation literature, but their critical voices will be equally important for considering the strengths and challenges of the SLO literature.

For example not all scholars agree that the learning organisation is particularly positive for its members (e.g. Cooper, 1998; Driver, 2002; Easterby-Smith et al., 1998). Some have argued that it may serve to bind workers to visions and purposes that do not serve their best interests, while garnering 
commitment for something that seems to be for the workers' own good (Easterby-Smith et al., 1998). Without seeking to exert 'coercive persuasion' (Schein, 1999), a tightly woven learning organisation may be experienced as increased pressure for conformity by its members, who may question whether they are learning to transform the organisation or rather learning to be transformed by the organisation (McHugh et al., 1998). Some scholars have further noted that the embrace of the concept of 'distributed leadership' that emerged in parallel to the learning organisation was under-theorized and often neglected issues of practice and issues of power (e.g. Caldwell, 2010).

Even proponents remind us of issues inherent in the concept. Louis and Leithwood (1998), writing about education, refer to Weick and Westley' (1996) caution that "organizing and learning are essentially antithetical processes, which means the phrase 'organizational learning' qualifies as an oxymoron. To learn is to disorganize and increase variety. To organize is to forget and reduce variety" (p. 440).

Although disequilibrium is critical to transformative processes, Louis and Leithwood argue that community in schools is also necessary to guarantee continuity and stability in relationships (Sergiovanni, 1994) and foster the necessary commitment among members.

While not denouncing the valuable arguments raised by critics, it is important to note that at the very least, as Driver (2002) comments, the learning organisation does not offer greater potential for abuse than any other type of organisation. To take a more positive and indeed humanistic view of the learning organisation, as is also the orientation of those studying professional learning communities, the strong emphasis placed on elements such as distributed leadership, the promotion of collaboration and communication, and trust and respect among all members throughout the organisation in fact should limit or ideally even prevent the abuse of power by the schools' leadership. Indeed, the abuse of power itself should disqualify an organisation from being a learning organisation.

Also, some form of control or accountability to see whether the organisation and its members are working towards achieving its vision or "specific purpose" (Butler, 1991; Robbins et al., 2006) are conditions that allow it to survive and thrive. Such mechanisms play an important role in ensuring the organisation receives the necessary feedback and information for engaging in a cyclical process of trailand-error learning that provides opportunities to reconceptualise future actions.

Finding the right balance between managerial and employee control and leadership would seem to be where the challenge lies. And this is where Driver (2002) provides us with some useful questions: How do employees perceive the distribution of power and leadership in their organisation? What influence do employees have in defining these controls ("negotiated control")? How do control mechanisms enhance employee learning? The latter question can also be extended to the learning of the organisation as a whole. These will be important questions to consider in developing our integrated model of the SLO in Chapter 3.

Other critics have noted that many of these normative learning organisation definitions, despite being practitioner-oriented, often lack in clarity and are excessively broad which reduce their utility for researchers and practitioners (e.g. Daft and Huber, 1987; Örtenblad, 2002, 2004; Popper and Lipshitz, 2000). Örtenblad (2004) discusses how this "vagueness" in concept (a term he uses in a neutral meaning) can be considered in both positive and negative ways. He points out that a vague concept can be beneficial to managers. Ambiguous language can help managers to satisfy different subgroups with different, and sometimes even contradicting, interests (Astley and Zammuto, 1992). It can also help adapt the concept more easily to different contexts (Scarbrough and Swan, 2001) and can be a condition for creativity by opening up thinking instead of closing it down (Astley and Zammuto, 1992; Bacharach, 1989).

Some will agree that this line of argumentation holds ground. However, vague ideas are difficult to implement and even more difficult to measure (Lipshittz et al., 1996). Several scholars share this view and have set out to clarify the concept, provide management aids ("disciplines" or "characteristics" of and 
"building blocks" or "action aids" for the learning organisation) and/or diagnostic instruments for assessing and developing an organisation's learning capabilities. This would seem a valuable way forward for advancing the concept - in private and public organisations. The empirical evidence generated by these assessment instruments will be essential for responding to critics' concerns about the lack of clarity and usability of the learning organisation and SLO concepts in practice. In addition, such instruments could be used to test the hypothesis that the SLO, as often assumed, leads to better learning and/or other outcomes. The paucity of empirical evidence on the impact of the SLO is a weakness in much of the literature to date (Schleicher, 2012).

\section{Assessing schools as learning organisations}

Since the early 1990s several scholars have explored the existence of SLOs through qualitative case study analysis (e.g. Giles and Hargreaves, 2006; Johnston and Caldwell, 2001; Retna, 2006; Retna and Park Tee, 2006). Increasingly however, following and building on the examples of their peers working in other sectors, SLO scholars have proposed and used assessment instruments to define to what degree contemporary schools correspond to the learning organisation ideal.

Among those in the latter category, several scholars have looked towards the work of Senge et al. $(1990,2012)$ as a source of inspiration (e.g. Ho Park, 2008; Moloi, Grobler and Gravett, 2006). Moloi, Grobler and Gravett (2006), for example, used the five learning disciplines as the theoretical framework for their study of public schools in the Vanderbijl Park-North District of the Gauteng province of South Africa. The purpose of the research was to investigate the essential features of learning organisations, the perceptions of educators towards these essential features and the guidelines that could be provided for schools to cope with the demands of continuous learning and adaptation in a turbulent environment. Structured questionnaires used consisted of 88 items. They were distributed to a random sample of 50 (20 primary and 30 secondary) schools and were completed by educators at different levels of the organisations. A major finding was that the learning disciplines were fundamental to two factors: a collaborative culture and personal beliefs about educator commitment. The study showed that schools in the Gauteng Province of South Africa can transform into learning organisations by cultivating a climate which develop the kind of collaborative culture and beliefs that stimulate educator commitment.

Another example of a quantitative assessment instrument that aims to measure the characteristics of SLOs is the School Success Profile-Learning Organization (SSP-LO) survey. The SSP-LO survey was designed by Bowen, Rose and Ware (2006) a decade ago and is increasingly cited in the literature (e.g. Berkowitz et al., 2013; Hopson and Steiker, 2008; Jafari and Kalanaki, 2012; Niroo et al., 2013). The SSPLO questionnaire consists of two aspects of "actions" and "feelings". "Actions" are based on behaviours, and mutually functional patterns of members in a SLO, which provide opportunities to educate, to explain responsibilities, and collective attempts to manage organisational objectives. The components of actions are: 1) team orientation; 2) innovation; 3) co-operation; 4) information circulation; 5) error sustainability; and 6) result-based.

"Feelings" are defined as collective modes including positive respect, positive sensations, and attitude among members of the organisation which appear through their acts and interpersonal relationships. The components of this aspect are: 1) common goals; 2) respect; 3) solidarity; 4) confidence; 5) mutual protection; and 6) optimism (Bowen, Rose and Ware, 2006). Various studies internationally confirm the theoretical framework, with the SLO containing two aspects of 'actions' and 'feelings', each of which possess six components.

Several scholars have also recently used the Dimensions of Learning Organisation Questionnaire (DLOQ) developed by Marsick and Watkins (2003) to explore its suitability for exploring the organisational features of schools as learning organisations (e.g. Benjamin, 2009; Khan, Tanveer and Saleem, 2013; Nazari and Akmaliah Lope Pihie, 2012; Akram, Watkins and Sajid, 2013; McCharen, Song 
and Martens, 2011; Ariffin, Hashim and Yahya, 2010). The comprehensiveness of the DLOQ and its proven applicability in various context, cultures and types of organisations (Watkins and Dirani, 2013; Moilanen, 2005), including school organisations, also suggests the value of using the DLOQ in schools.

Confirmatory factor analysis by Benjamin (2009), however, concludes that a one-factor model is an adequate fit. This is in contrast to Yang, Watkins and Marsick (2004) whose analysis supports a seven factor model. As for other SLO assessment instruments, more research would seem needed to further validate the DLOQ within a school context.

Another shortcoming of most of these studies and assessment instruments is their small scale application. That they mostly deal with validating the construct of the SLO also does not help in gaining a better understanding of the extent to which our contemporary school systems are made up of schools that can be considered learning organisations.

Some of the studies, however, have been more extensive. One such example is the Leadership for Organisational Learning and Student Outcomes (LOLSO) study. This involved 2000 principals and teachers in a random sample of 96 South Australian and Tasmanian secondary schools (Silins, Mulford and Zarins, 2002). The first phase of this project identified the school and leadership characteristics and processes associated with high schools operating as learning organisations. For this the Organisational Learning and Leadership Questionnaire was developed drawing on school and non-school literature on organisational learning. Seven identified constructs of the SLO formed the base for the development of the questionnaire. These were:

- Employed processes of environmental scanning;

- Developed shared goals;

- Established collaborative teaching and learning environments;

- Encouraged initiatives and risk taking;

- Regularly reviewed all aspects related to and influencing the work of the school;

- Recognised and reinforced good work; and

- Provided opportunities for continuing professional development.

Teachers and principals were asked to respond to items representing these seven dimensions on a selfreported five-point Likert type scale ranging from strongly disagree (1) to strongly agree (5). Although the seven factors structure of the Organisational Learning and Leadership Questionnaire was not supported by the study findings (instead a four-factor nested model was identified), the study's findings revealed the high-reliability of the questionnaire.

In addition, some instruments serve more as self-assessment instruments to inform the planning of school improvement efforts, rather than for external evaluation purposes. These instruments are part of a larger trend in education policy and practice over the last two decades. The OECD's international review on evaluation and assessment in education (2013) revealed an almost universal international policy focus on stimulating school self-evaluation, reinforced by supra-national bodies such as the European Union. Nowadays self-evaluation has become widely recognised internationally as integral to effective and sustained school improvement (Ehren et al., 2013; OECD, 2013b).

There are wide variations in what self-evaluation might mean in practice and in the degree of accompanying prescription and support provided by countries. Some countries have developed self-assessment instruments around the SLO concept with the aim of inspiring and supporting all those involved (teachers, school leaders, students, parents, etc.) in working towards this ideal. An example of this is the Developmental Model Learning Organisation of the Netherlands. The school as learning 
organisation is one of the seven 'agenda points' under the country's "Teachers Agenda 2013-2020". To support the implementation of the strategy this model was developed that consists of five dimensions: 1) the right course; 2) the right start; 3) the right feedback; 4) the right development; and 5) the right differentiation. The model is unique in that it provides clear descriptors of the desired behaviour for each of five Levels in relation to each of the five dimensions. Level 4 describes the desired behaviour of the respective dimension fitting the SLO, while Level 5 describes an even higher level of development. For example, Level 4 of the dimension the 'right development' states that 'a personal development plan is used for teachers and school management at least once a year and this is linked to feedback and school aspirations. Instruments for personal and/or team development needs of teachers and school are linked to personal developments plans'.

These descriptors of desired behaviours are intended to support school leaders, teachers and others involved in the self-assessment of their school and inform the following school improvement efforts. A first evaluation suggested the model served its purpose and provided Dutch school leaders and/or human resource managers with a means for self-evaluation and improvement planning (MoECS, 2014). It is not known whether this also applies to the other members of the school organisation.

An analysis of the dimensions and indicators of each of these assessment instruments shows that the School Success Profile-Learning Organization Survey (Bowen, Rose and Bowen, 2005) and the Organisational Learning and Leadership Questionnaire (Silins, Mulford and Zarins, 2002) fit the seven action imperatives of the DLOQ model well. Apart from the use of descriptors, the Development Model Learning Organisation (School has the Initiative, 2014) differs from the other instruments in that it has fewer indicators (11 at Level 5), making it also less comprehensive. In particular, the model devotes less attention to the importance of team learning and collaboration within and beyond the school compared with the other instruments.

\section{Assessing the effectiveness of the school as learning organisation}

While literature pointing towards the importance of turning schools into learning organisations has been accumulating during the last 25 years, there still is relatively little empirical evidence available to support the argument that such schools are also associated with better performance and greater innovation (Schleicher, 2012). From our sample of 32 identified publications on the SLO only five explored the impact on student outcomes (Table 2.2). Not all studies however show a positive impact of the SLO on student outcomes. Bowen, Rose and Ware (2006), for example, first tested their SSP-LO model in 2004 with employees from 11 public middle schools in North Carolina. The results of the quasi-experimental evaluation did not show a statistically significant effect between the capacity of 11 schools as learning organisations and student outcomes, and implementation fidelity for the whole-school intervention was low overall (Bowen, Rose and Ware, 2006).

In contrast, some scholars have provided evidence for "the acclaimed promise" of the SLO on student performance (e.g. Abdul-Haqq, 1998; Brasco, 2008; Teitel, 2003; Harris and van Tassell, 2005; Silins, Mulford and Zarins, 2002; Marks et al., 2002). Among them are those who define student outcomes more broadly than merely in terms of academic outcomes. The Australian LOLSO project described earlier is an example in point. The study revealed that students in Year 10 and Year 12 perceived four non-academic processes of schooling as significant: teachers' work (e.g. students liking the way teachers teach); academic self-confidence (e.g. students confident of their success); participation (e.g. students responding to questions in class and/or engaging in extra-curricular activities); and engagement (e.g. students identifying with their school). The study showed students were more likely to stay on at school and complete Year 12 if they were engaged with school, but engagement with school only indirectly influenced achievement (through staying on). Features of the home environment (such as having space to study and help with school work) also influenced student participation and self-concept. 
EDU/WKP(2016)11

Table 2.2. Assessing the effectiveness of the SLO

\begin{tabular}{|c|c|c|c|c|}
\hline \multicolumn{2}{|r|}{$\begin{array}{l}\text { Literature on school as learning } \\
\text { organisation }\end{array}$} & \multirow{2}{*}{$\begin{array}{l}\text { Student } \\
\text { learning } \\
\text { outcomes } \\
\text { No }\end{array}$} & \multirow{2}{*}{$\begin{array}{l}\text { Other } \\
\text { outcomes } \\
\text { Yes }\end{array}$} & \multirow[t]{2}{*}{ Description } \\
\hline 1 & Higgins et al. (2012) & & & \\
\hline 2 & Schechter and Mowafaq (2013) & No & Yes & Changes in shared mental models and operating procedures and routines. \\
\hline 3 & Schechter (2008) & Yes & Yes & $\begin{array}{l}\text { Changes in behavioural and cognitive outcomes such as shared mental models } \\
\text { and causal links-maps of organisational members. }\end{array}$ \\
\hline 4 & Keefe and Howard (1997) & No & No & \\
\hline 5 & Fullan (1995) & No & Yes & Teacher collaboration. \\
\hline 6 & Harris and Tassel (2005) & Yes & Yes & $\begin{array}{l}\text { Shared work and collaboration amongst teachers. Outcomes for teacher } \\
\text { candidates and school and university faculty were improved as well as } \\
\text { achievement for K-12 students and scores on state-mandated tests. }\end{array}$ \\
\hline 7 & Park (2008) & No & Yes & Engagement in professional learning and growth. \\
\hline 8 & Schechter and Mowafaq (2012) & Yes & Yes & $\begin{array}{l}\text { Raising students test scores; reducing the achievement gap and changing school } \\
\text { culture. }\end{array}$ \\
\hline 9 & $\begin{array}{l}\text { Silins, Mulford and Zarins } \\
(2002)\end{array}$ & Yes & Yes & $\begin{array}{l}\text { Improvement of engagement and participation in school } \\
\text { changes in school culture and teacher practices that result in improved student } \\
\text { performance, attendance, students' self-concept. }\end{array}$ \\
\hline 10 & Paletta (2011) & Yes & Yes & $\begin{array}{l}\text { Better results in individual learning in Italian, math and science compared with } \\
\text { the average of the other schools included in the sample. }\end{array}$ \\
\hline 11 & Kirkham (2005) & No & Yes & $\begin{array}{l}\text { Promotion gained both within the school and in other schools. Teachers' } \\
\text { confidence increased through competence and reflective learning. Findings } \\
\text { indicate that there are learning and other gains by all parties when learning is } \\
\text { contextualised and purposefully led. }\end{array}$ \\
\hline 12 & Retna and Tee (2006) & No & Yes & Improvement of communication skills. \\
\hline 13 & Wallace et al. (1997) & No & No & \\
\hline 14 & Diggins (1997) & No & Yes & $\begin{array}{l}\text { People become exceptionally skilled at creating, acquiring and transferring } \\
\text { knowledge and at modifying its behaviour to reflect new knowledge and insights } \\
\text { in a learning organisation. }\end{array}$ \\
\hline 15 & Gunter (1996) & No & No & \\
\hline 16 & Nixon et al. (1996) & No & No & \\
\hline 17 & Alavi and McCornick (2004) & No & No & \\
\hline 18 & Bowen, Rose and Ware (2006) & No & Yes & Knowledge development. \\
\hline 19 & Kerka (1995) & No & No & \\
\hline 20 & Benjamin (2009) & No & No & \\
\hline 21 & Hamzah et al. (2011) & No & Yes & Transformational leadership practices. \\
\hline 22 & Coppieters (2005) & No & No & \\
\hline 23 & Moloi et al. (2006) & No & No & \\
\hline 24 & Brandt (2003) & No & No & \\
\hline 25 & Clarke (2005) & No & Yes & $\begin{array}{l}\text { Sharing ideas and development of trust in working. Self-knowledge and } \\
\text { confidence improvement. }\end{array}$ \\
\hline 26 & Schlechty (2009) & No & Yes & Sharing authority and teacher co-operation. \\
\hline 27 & Davidoff and Lazarus (2002) & No & Yes & $\begin{array}{l}\text { Increasing participation rates of all the members of the } \\
\text { school community in school. }\end{array}$ \\
\hline 28 & Middlewood et. al. (2005) & No & Yes & Sustained and effective collaborative partnerships with all schools. \\
\hline 29 & Leithwood et al. (1998) & No & Yes & $\begin{array}{l}\text { Individual and collective understandings, skills, commitments and overt } \\
\text { practices. }\end{array}$ \\
\hline 30 & Louis and Kruse (1998) & No & Yes & $\begin{array}{l}\text { Teachers felt affirmed as professionals and better able to learn; are more } \\
\text { comfortable sharing with colleagues and improved relationships; and more } \\
\text { aware of whole school issues and needs. }\end{array}$ \\
\hline 31 & Mitchell and Sackney (1998) & No & Yes & $\begin{array}{l}\text { Non-threatening atmosphere, willingness to work with and learn from } \\
\text { colleagues and better reflection and analysis. }\end{array}$ \\
\hline 32 & Senge et al (2012) & No & No & \\
\hline
\end{tabular}

Their findings support a growing conviction among scholars, policy makers and education practitioners that what counts as effective education goes beyond academic achievement, and instead 
should include, for example, ethical values, self-esteem, students' ability to self-direct learning and personal development, their well-being or happiness (Silins, Mulford and Zarins, 2002; Mulford, 2005; Coppieters, 2005; Hills and Argyle, 2001).

\section{Conclusions}

This chapter has provided an insight into the learning organisation and SLO literature which has developed during the last 25 years. Although the SLO literature is not as vast as the general learning organisation literature, they have in common that their scholarly interpretations of the concept vary, sometimes considerably.

Despite the heterogeneity in SLO definitions, common characteristics emerge from reviewing the literature (see p. 23). However, despite commonalities, confusion still reigns about the SLO concept and some critics remain unconvinced about the acclaimed positive potential of the SLO. Further work is therefore needed to clarify the concept, extend its evidence base and assess the impact of the SLO in terms of student outcomes - both academic and broader outcomes such as self-efficacy and well-being, as measures of effectiveness.

To do this, some scholars have set out to clarify the concept by synthesising the literature and working towards an integrated model of the SLO. Some have also developed diagnostic instruments for assessing and improving a school's learning capabilities and, ultimately, its performance. This would seem to be the right way forward to advance the SLO concept in research and practice because such models and instruments can provide operational guidance to all those considering to transform their schools into learning organisations.

This paper therefore pursues a similar path, using Watkin's and Marsick's SLO model as a starting point for developing our own integrated model and assessment instrument of the SLO. Though the analysis of this paper supports the theoretical justification for the seven dimensions of the authors' model (the DLOQ) it also suggests there is scope for the further refinement of these, as well as the framework of indicators. In particular the literature and the realisation that many of today's schools are still far removed from the ideal of the learning organisation suggest for more strongly arguing for exploring new ways of doing things and striving for sustainable innovations in educational practice. In this, the role of ICT will also need to be brought more to the fore.

Schools also need further guidance around the content of a shared vision i.e. what it should focus on and who it should apply to. In addition, the evidence points to the need to further clarify teacher and school leader professionalism in ways that allow them to become high-quality knowledge workers which includes promoting engagement in networked learning and collaboration across school boundaries. Support staff should not be overlooked as a school as a learning organisation depends on the joint efforts of all of its staff to blossom and continue thriving. Implications of all of this for leadership also need reconsidering.

These and other issues will be elaborated on in Chapter 3. 
EDU/WKP(2016)11

\section{CHAPTER 3: DEFINING AN INTEGRATED MODEL OF THE SCHOOL AS LEARNING ORGANISATION}

\section{Introduction}

A steadily growing body of scholars and practitioners has tried to define, describe and measure the school as learning organisation (SLO). No one, however, has fully succeeded in bringing clarity and a common understanding of the concept. Although reaching consensus on this is a daunting task, it may be achieved through further research and sustained international dialogue among scholars, policy makers and education practitioners. This paper, and particularly this chapter, captures our intent to contribute to this effort.

This paper's analysis supports using the seven dimensions of Watkins' and Marsick's (school as) learning organisation model as a starting point for our theoretical foundation. It also suggests that there is potential to refine the model, including its framework of indicators, to further strengthen its applicability to contemporary school organisations and the leadership of innovative learning environments (OECD, 2013a).

The presented SLO model will draw heavily from the SLO literature, but also from other relevant literatures, for example organisational behaviour, knowledge management, learning sciences, school improvement and effectiveness, and professional learning literatures. This is because there is much to gain from building bridges to related literatures and concepts, like well-established literature on "professional learning communities" (e.g. Kruse, Louis and Bryk, 1995; Du Four et al., 2006; Stoll et al., 2006) or "learning environments" (e.g. Simons and Masschelein, 2008; OECD, 2013a) as these may help in working towards a common understanding of the SLO that is both solidly founded in the literature and is recognisable to all parties involved, i.e. education practitioners, policy makers, parents and others.

Watkins and Marsick (1999) refer to their dimensions as "action imperatives - activities people need to be involved in - that characterize companies becoming learning organizations". This fits with the general action orientation of the learning organisation literature. In contrast to organisational learning literature, learning organisation literature frequently focuses on using tools to help identify, promote and evaluate the quality of learning processes in the organisation (Easterby-Smith and Araujo, 1999; Tsang, 1997). The term used in this paper, "action-oriented dimensions", is intended to convey that the learning organisation is not static; it is sensitive to shifts in the local and wider environment, and adapts accordingly. It also conveys our interest in supporting schools and education systems in developing themselves as learning organisations.

In this chapter we present each of the seven dimensions and, where necessary, elaborate on and/or divert from these. The underlying key characteristics of the dimensions, referred to as "elements", are discussed in detail. The chapter concludes with a short presentation of the entire integrated SLO model and a definition of the school as learning organisation.

The elements will form the starting point for development of the indicators of the School as Learning Organisation Assessment instrument (preliminary name). The SLO model and assessment instrument are intended to provide practical guidance to policy makers, school staff and other stakeholders that wish to develop theirs schools into learning organisations. Like Watkins and Marsick (1999), they are to provide a 
lens on how the organisation "supports and uses learning at an individual, team and organizational level" in order to determine whether it is using learning to improve and transform itself and enhance its outcomes. In that sense, it is both a process the school goes through which is the means to an end - the ultimate difference that is made for children and young people - and a positive intermediate outcome in its own right; a school that is a powerful and thriving learning organisation. The elements highlight both what a school aspires to and the processes it goes through in its journey of developing itself as a learning organisation.

Based on the literature, our starting hypothesis is that the seven action-oriented dimensions, together, add up to a sustainable learning culture and that the whole - successfully realising all seven dimensions is greater than the sum of the parts. At this time, it is not clear how individual dimensions relate to each other, whether some are more important than others, whether any might be transversal, crossing the others as in the warp and weft of weaving. Analysis of indicators in the second phase of the project will enable these issues to be explored, and a refined integrated SLO model to be developed.

There appears, however, to be a set of transversal themes which flow through all of the dimensions. We call these the 4 T's: trust, time, technology and thinking together. Although they may appear with more prominence in our review of a particular dimension, they exert their influence right across the whole. For example, trust underpins the kind of relationships needed internally and externally for SLOs to thrive. Similarly, time is an essential structure for all aspects of school development. ICT enters the SLO in many different ways; it plays an essential role in shaping the learning - of students, teachers, school leaders, parents and others, and serves as a durable and valuable means for creating and transferring knowledge and facilitating collaboration within and across schools and with the external environment. And as the SLO is essentially a social enterprise, thinking together comes into play in developing a shared vision and when welcoming outside approaches as it does when staff are working as a team.

\section{Defining the "action-oriented dimensions" and underlying "elements" of the school as learning organisation}

Presentation of each of the seven action-oriented dimensions follows the same format. We outline the dimension's name and elements, then describe the literature on which this is based and provide case examples. The elements include both action processes to enhance the dimension and learning culture outcomes - what it looks like, sounds like, feels like, etc.

\section{Developing a shared vision centred on the learning of all students}

\begin{tabular}{|c|c|}
\hline SLO Dimension & Elements \\
\hline $\begin{array}{l}\text { Developing a shared } \\
\text { vision centred on the } \\
\text { learning of all students }\end{array}$ & $\begin{array}{l}\text { - A shared and inclusive vision aims to enhance the learning experiences } \\
\text { and outcomes of all students } \\
\text { - The vision focuses on a broad range of learning outcomes, encompasses } \\
\text { both the present and the future, and is inspiring and motivating } \\
\text { - Learning and teaching are oriented towards realising the vision } \\
\text { - Vision is the outcome of a process involving all staff } \\
\text { - Students, parents, the external community and other partners are invited to } \\
\text { contribute to the school's vision }\end{array}$ \\
\hline
\end{tabular}

When reviewing the learning organisation literature, whether or not in a school context, many scholars recognise the importance of having a shared vision to shape the organisation and give it a sense of direction (e.g. Caldwink and Spinks, 1992; De Vito, 1996; Duden, 1993; Hiatt-Michael, 2001; Fullan, 1999; Schlechty, 2009; Senge et al., 2012; Silins, Zarins and Mulford, 2002; Wallace et al., 1997, see 
Annex A). Caldwell and Spinks (1992) refer to school vision as "a mental picture ... an image of the way [members] would like the school to be in the future" (p.37). A vision can create energy when it inspires people to reach for ambitious goals (Leithwood and Riehl, 2003), and it can act as a motivating force for sustained action to achieve these individual and school goals.

Some of the SLO and other literature diverts or adds more details in noting what a vision should include. To be really shared and owned, individuals need to perceive the vision and goals to include a moral purpose (Fullan, 1999). This is what drives people's commitment. The moral purpose should appeal to the common good of the community and becomes the core force that binds the individuals together. We endorse the views of scholars like Schlechty (2009), Senge et al. (2012) and those focusing on educational effectiveness and improvement (e.g. Chapman et al., 2016) who note the importance of ensuring that all students are achieving at high levels. Although a focus on pragmatic questions related to classroom management or increasing attendance may be legitimate goals they cannot replace the power of a more ambitious and compelling vision that aims at enhancing the learning of all students.

\section{What is quality?}

Student outcomes measured currently by PISA, the Trends in International Mathematics and Science Study (TIMSS) and the Progress in International Reading Literacy Study (PIRLS) help us understand part of the picture, and knowledge is increasingly extensive about teaching practices that are associated with better quality in such student outcomes (e.g. Hattie, 2009). These outcomes, though, do not tell us everything we need to know about what it means for children and young people to be successful at school and prepared for life after they leave school. Other vitally important non-cognitive outcomes include students' personal and social development, such as wellbeing (OECD, 2009; UNICEF Office of Research, 2013; Rees and Main, 2015; Rees, Bradshaw and Andresen, 2015) or resilience (Benard, 1995; Masten, 2012). Wellbeing is now included in some jurisdictions' curricula (e.g. Ontario and Scotland).

In addition to being important outcomes in their own right, non-cognitive outcomes fit within a framework focused on learning in its broadest sense. Twenty years ago UNESCO's Commission on Education for the Twenty-First Century (Delors, 1996) argued that:

Traditional responses to the demand for education that are essentially quantitative and knowledge-based are no longer appropriate. It is not enough to supply each child with a store of knowledge to be drawn on from then on. Each individual must be equipped to seize learning opportunities throughout life, to broaden her or his knowledge, skills and attitudes, and to adapt to a changing, complex and interdependent world.

To this end, in an inspiringly titled report Learning: The Treasure Within, the Commission proposed "four fundamental types of learning" - learning to know, learning to do, learning to live together and learning to be. Learning to be focuses on what is required for a person to develop to their fullest potential psycho-socially, affectively as well as physically, so that they can be "an all-round complete person".

Other essential outcomes, including 21st century skills (Wagner, 2008; Trilling and Fadal, 2009) are now included in a number of countries' curricula (e.g. Singapore, Scotland, Ireland), other countries' investigations (e.g. in Norway, Ludvigsen, 2015), and recent and forthcoming PISA assessments (e.g. collaborative problem solving).

\section{Ensuring equity}

Having a vision statement which is committed to enhancing the lives of all students is vitally important as one of the biggest challenges facing society today is to integrate those on the margins of society whose learning has not been sufficiently developed to give them confidence in themselves. Not 
only is their exclusion at the margins a waste of human potential, but their alienation poses a real threat to democracy (Diggins, 1997). Unless extra effort is made to include these students we will reconstitute the status quo. Both quality and equity are fundamental. Research and daily practice show us that learning is indeed possible for all of us and is not confined to the very bright or socio-economically advantaged (Dumont, Istance and Benavides, 2010; McClelland and Burnham, 1995; OECD, 2013b).

Many examples exist of schools and even education systems around the globe that have realised their vision to succeed in uplifting the learning of even the most disadvantaged children. Von Ostade primary school in the city of The Hague, the Netherlands, provides an example in point. Located in the Schilderswijk, one of the city's most disadvantaged neighbourhoods, its students are almost exclusively of migrant and/or low socio-economic backgrounds. In response, the school sets high standards for all of its students and places extra emphasis on the learning of the Dutch language and mathematics. Its goal is for students' results to be equal to or above those of the national average. For a number of years its students have performed well on the end of primary education exam and many of them continue to perform well in secondary education. In 2014 for the third time in a row, in recognition of its work, Van Ostade School received the "Excellent School" award and is considered a learning organisation (Education Inspectorate of the Netherlands, 2015). The school ensures that vision and improvements to learning and teaching are closely linked.

PISA 2012 further shows that the countries which have shown significant improvement in student performance since 2000, like Brazil, Germany, Greece, Italy, Mexico, Tunisia and Turkey, have managed to reduce the proportion of low-achieving students. The evidence shows that even over time, excellence and equity in education are not mutually exclusive goals (OECD, 2013b).

\section{Learning for quality and equity}

It is essential to understand the nature of learning to understand how teaching can most powerfully enhance learning (Lambert and McCombs, 1998; Stoll, Fink and Earl, 2003; Dumont, Istance and Benavides, 2010). An OECD project on Innovative Learning Environments (ILE) started by examining the literature on the nature of learning, and then identifying research-informed principles of learning to guide development of learning environments for the 21 st century.

- Make learning central, encourage engagement, and be where learners come to understand themselves as learners;

- Ensure that learning is social and often collaborative;

- Be highly attuned to learners' motivations and the importance of emotions;

- Be acutely sensitive to individual differences including in prior knowledge;

- Be demanding for each learner but without excessive overload;

- Use assessments consistent with these aims, with strong emphasis on formative feedback; and

- Promote horizontal connectedness across learning activities and subjects, in and out of school.(Dumont, Istance and Benavides, 2010).

The ILE project gathered examples from more than 20 countries of schools and other cases using different learning arrangements while "promising to meet the ambitious objectives needed for the $21 \mathrm{st}$ century". Box 3.1 presents some of the ILE "school" visions, frequently seen in the school's curriculum, learning strategies and resources, and learning partnerships. 


\section{Box 3.1. Visions for innovative learning environments}

The motto at the Institute Beatenberg (Bern, Switzerland) is "fit for life". This fitness is achieved by the interplay of sustainable and ready-to-use knowledge, skills and attitudes, including social skills ( "Sozialkompetenz") and the ability to assume responsibility for one's own learning and working. Lifelong learning, an eagerness to learn, and a high level of motivation are essential for success, and learning skills are thus in high demand and must be developed at school. Skills matrices (or "competence matrices", "Kompetenzraster") used are grids with skills in a subject or field on one axis and a scale of proficiency on the other. Each cell contains a description of what a learner is supposed to be able to do at the respective level. In every subject the students can determine their skills level on the corresponding skills matrix.

At the Escola Móvel (Portugal), the aim is to give permanent access to a virtual national-curriculum learning environment for secondary-age students who would otherwise be excluded. The content is delivered through online, synchronous classes and includes both individual subjects and cross-curricular areas, personalised through an individual tutor. The virtual learning environment is complemented by four face-to face weeks a year for each learner.

Education for Sustainable Development, Flaveit School, Bergen (Norway) translates its focus on education for sustainable development into a programme on waste disposal, for which it co-operates with a waste management company. It co-operates with a green agency on water resources, as well as with a large company which shows the children the environmental issues that large companies face. The objective of the programme is to educate the students to see their place in society and work towards a sustainable future.

Source: (OECD, 2013a), Innovative Learning Environments, Centre for Educational Research and Innovation, OECD Publishing, Paris. http://dx.doi.org/10.1787/9789264203488-en.

Frequently, research on the nature of learning endorses research findings on effective teaching. For example, the ILE fifth principle argues that schools should set clear expectations for students (Muijs et al., 2014), demand hard work and challenge them without overloading. All students need to be sufficiently challenged to reach above their existing level and capacity. However having high expectations of all students should not be limited to schools but requires parents, communities and society at large to do the same if equity in learning opportunities is to prevail (Frome and Eccles, 1998; Dumont, Istance and Benavides, 2010).

The report's research highlights a range of "building blocks" associated with the principles - inquirybased approaches, cooperative learning, service learning, home-school partnerships, formative assessment, and learning with digital technology, viewed as essential for educating students "to be successful in a complex and interconnected world that faces rapid technological, cultural, economic, informational, and demographic change" (Kampylis et al., 2015, p. 6).

A vision of SLO should therefore include two things: a front and centre commitment to making a difference in the learning and lives of all students, especially disadvantaged students; and a focus on the "core of the matter" i.e. the teaching and learning (Fullan, 1995) which, in relation to the school as a learning organisation, we articulate as the learning and teaching.

\section{Creating the vision}

The content of the vision is fundamental, but the process to create the vision is also important. Having a shared vision is more an outcome of a process than it is a starting point, and it entails an inclusive process 
to create ownership (Fullan, 2006). For the school's leadership to simply present a vision to the rest of the school staff may not engage people over the long run, and even risk resistance. Watkins and Marsick (1996) therefore note that the organisation should invite people to contribute to the vision. The implications of research on students' learning experiences are that students, as autonomous, self-regulated learners, also should be meaningfully involved in school reform decisions which affect their learning (Smyth and Fasoli, 2007). Students are represented on the governing councils and boards of schools in a number of countries. As Senge et al. (2000, p. 25) note: "Students can be some of the most effective instigators for organizational learning".

Both individuals and groups need to spend time reflecting and talking in order to develop a truly shared vision for the organisation. This is important as organisational change can be difficult and takes time. People who have committed to a shared vision based on shared beliefs are more likely to persist with their efforts when they confront difficulties than are those whose only reason for participation is compliance with a directive from above (Schlechty, 2009).

To promote organisational learning, a vision also needs to be meaningful and pervasive in conversations and decision-making (Leithwood, Jantzi and Steinbach, 1998). This dialogue however should not be limited to those normally working within the physical confounds of the school building. Instead, to be truly shared and relevant, for students and society, the development of a vision should include external stakeholders, including parents, the community, other education institutions or companies (School has the Initiative, 2014). They have a common stake in each other's future and the future of their community, and successful implementation of any school vision increasingly depends on such "partnerships" as a means for growing social and professional capital (Hargreaves and Fullan, 2012), and for sustaining innovative change (Harris and van Tassel, 2005; OECD, 2013a).

In summary, success in school is very possible for all students, even those most socio-economically disadvantaged. The starting point for such great achievements and for others related to students' wellbeing and 21 st century learning is a truly shared vision that focuses all efforts on enhancing the learning of all students.

\section{Promoting and supporting continuous professional learning for all staff}

\begin{tabular}{|c|c|}
\hline SLO Dimension & Elements \\
\hline $\begin{array}{l}\text { Creating and supporting } \\
\text { continuous professional } \\
\text { learning for all staff }\end{array}$ & $\begin{array}{l}\text { - } \quad \text { All staff engage in continuous professional learning } \\
\text { - } \quad \text { New staff receive induction and mentoring support } \\
\text { - } \quad \text { Professional learning is focused on student learning and school goals } \\
\text { - } \quad \text { Staff are fully engaged in identifying the aims and priorities for their own } \\
\text { professional learning } \\
\text { - } \quad \text { Professional learning challenges thinking as part of changing practice } \\
\text { - } \quad \text { Professional learning connects work-based learning and external expertise } \\
\text { - } \quad \text { Professional learning is based on assessment and feedback } \\
\text { - } \quad \text { The and other resources are provided to support professional learning }\end{array}$ \\
\hline
\end{tabular}

A rapidly changing world requires schools and the people working in them to learn faster in order to deal effectively with the growing pressures of the external environment (Fullan, 1995; Moloi, Grobler and Gravett, 2006; Silins, Mulford and Zarins, 2002; Schleicher, 2011). Student learning becomes "inseparable from professional learning", with a culture "in which learning flows across boundaries of role and status. The professional learning environment sets the stage for the student learning environment" (MacBeath and Townsend, 2011, p. 1247). 


\section{Continuous learning of all professionals}

The kind of education needed today requires teachers to be high-level knowledge workers who constantly advance their own professional knowledge as well as that of their profession (OECD, 2013a; Schleicher, 2012, 2015). Taking this on board, and a growing body of evidence that shows that teachers' professional development can have a positive impact on student performance and teachers' practice (Yoon et al., 2007; Hill, Beisiegel and Jacob, 2013; Timperley et al., 2007) has led scholars, education practitioners and policy makers around the world to support the notion of investing in quality career-long opportunities for professional development and learning (see Box 3.2). Some jurisdictions and national organisations have also developed professional learning standards or their equivalent (e.g. Learning Forward, 2011; AITSL, 2012; GTCS, 2012), highlighting that standards for teaching need to be complemented by standards which ensure high quality learning opportunities for teachers and other practitioners.

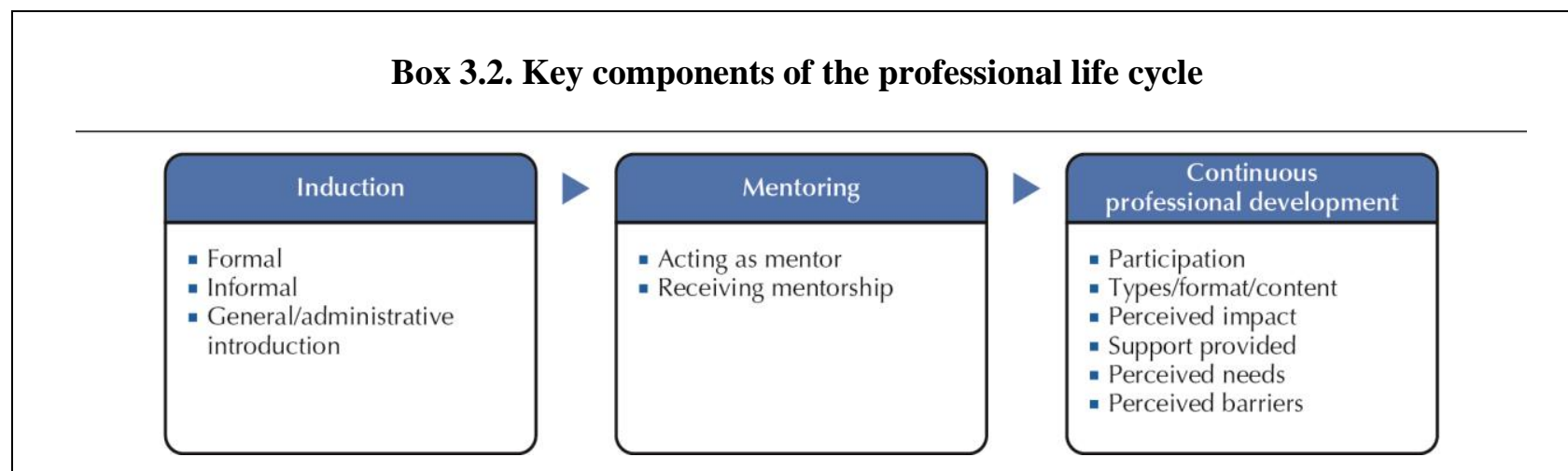

The OECD TALIS report (OECD, 2014) groups the key components of a professional life-cycle; a systemic approach to human resource development into three stages following initial phases of selection and pre-service education: induction, or the initial introduction and socialisation of educators to the work environment and the general expectations of their role in the overall system; mentoring, or the collaborative transfer of knowledge and practice between more experienced and competent practitioners to early career practitioners; and continuous professional development, or the routine enhancement, up-dating, and deepening of knowledge and skills as practitioners advance through their careers, and as knowledge and skill requirements of their work increase as a result of research-based advances in practice.

Source: OECD (2014), TALIS 2013 Results: An International Perspective on Teaching and Learning, TALIS, OECD Publishing, Paris, http://dx.doi.org/10.1787/9789264196261-en.

The learning of leaders is equally important within a school as a learning organisation, given that aspiring leaders frequently do not yet possess the skills for leading schools in the 21 st century (Huber, 2004). An OECD initiative on Improving School Leadership concluded that leadership development needs to be a lifelong learning process through different stages in the school leadership career (Pont et al., 2008). In line with the learning organisation emphasis on feedback loops, ensuring the impact of professional development of leaders is also highlighted (Huber, 2011). Leadership is, and should be a continuous process of learning (MacBeath and Dempster, 2008). The school leader as "lead learner" (Barth, 2001) engages seriously in their own learning - alone and with colleagues (Robertson, 2016, in press), is exposed to the best theories and practices on school leadership for learning and teaching to thrive (Hamzah et al., 2011) and participates with teachers in learning how to move the school forward (Fullan, 2014; Robinson, 2011).
} 


\section{From professional development to professional learning}

Notably, there has been a shift in language over the last few years, so while the term "professional development" continues to be used, there is a move towards, and increasing preference for "professional learning". This better captures the active involvement of the educator in their own learning (Stoll et al., 2012) and nature of adult self-regulated learning (Brandsford et al., 2000) that is likely to be necessary in a world which requires teachers to be knowledge workers and schools to be learning organisations. As Easton (2008, p. 756) argues that "it is clearer today than ever that educators need to learn, and that's why professional learning has replaced professional development. Developing is not enough. Educators must be knowledgeable and wise. They must know enough in order to change. They must change in order to get different results. They must become learners ...".

This language change can be seen, for example, in the renaming of what was formerly the National Staff Development Council - the major professional organisation in the United States focusing on the professional development and learning - to Learning Forward.

The SLO is one that ensures the learning needs of all its staff, i.e. teachers, school leaders and support staff, are met (Silins and Mulford, 1998; Kampylis, Punie and Devine, 2015) as individual learning is a precursor to group and organisational learning (Schechter and Mowafaq, 2013) and ultimately for schools to become learning organisations. This dimension focuses specifically on the individual learner, although targeted support is, of course, a social process. Collaborative learning of groups and teams is a major feature of the next dimension.

\section{The starting point for professional learning}

To be effective, professional learning must be seen as a long-term continuous inquiry process spanning their professional life cycle and focused on school goals and student learning (Fullan, 1995; Silins, Mulford and Zarins, 2002; OECD, 2015a). In a SLO, staff are also fully engaged in identifying aims and priorities for their own professional learning - in line with school goals and student learning needs as reflected in the school's development plan (Wallace, Engel and Mooney, 1997; Education Scotland, 2015; School has the Initiative, 2014; Fullan, 1995). In particular, there is increasing emphasis on using the problems students face in their learning as the starting point for inquiry-led professional learning (Timperley, 2011; Halbert and Kaser, 2013).

\section{Induction and mentoring}

Several SLO scholars have pointed to the importance of induction and mentoring programmes for new teachers and assigning them to experienced teachers to provide them with invaluable assistance as they face their first students and for advancing their professional development (Du Four, 1997; Schlechty, 2009; School has the Initiative, 2014; Watkins, and Marsick, 1996). Countries like Finland, Germany, Northern Ireland and Singapore have mandatory induction periods that allow starting teachers to receive systematic support. In Singapore for example teachers for the first three years of teaching have $20 \%$ less teaching hours and receive mentoring support.

Mentoring in a SLO should not be limited to those new to the profession; rather it should include professionals throughout their career. Mentoring as a practice over the career of a teacher, school leader and support staff can have a positive effect on both morale and practice (Thompson et al., 2004; OECD, $2014,2015 b$ ). The introduction of new curricula or new pedagogical practices typically require teachers to engage in extended learning and trial and error, which can benefit from close relationships with other teachers who have had prior training and experience in the new practice. Mentoring also has benefits for mentors (Holloway, 2001), supporting their own continuous professional learning. Across countries 
participating in the Teaching and Learning International Study (TALIS) 2013, on average, 14\% of teachers reported that they served as mentors, whereas in Singapore, Korea and England (United Kingdom) the numbers were considerably higher $(39 \%, 34 \%$ and $31 \%$ respectively) (OECD, 2014).

\section{Feedback for reflection that challenges thinking}

Effective professional learning and growth also depends on regular assessment and feedback and when shaped in a structured and purposeful manner it can have a strong positive influence on teachers' professional development and their daily practice (Hattie and Timperley, 2007; Kirkman, 2005; OECD, 2005; Schleicher, 2011; 2015). When teachers seek, or are at least open to, feedback from school leaders, other teachers, or students it can greatly enhance their professional learning and their performance. For this to happen, assessment and feedback need to take place in an atmosphere of trust and a culture that supports learning (Stoll et al., 2003). Assessment and providing feedback should be built into the daily practice of all staff. Appraisals help ensure the alignment of professional learning with school goals, but it is not the tool per se that counts most in helping the professional learning of staff (Darling-Hammond et al., 2014).

Feedback and other reflection-promoting approaches may be helpful in challenging educators' thinking and assumptions about their practice, which is an important feature of effective professional learning (Kelchtermans, 2004; Timperley et al, 2008). Effective professional learning and development promotes reflection and analysis around the underpinning rationale and evidence for new practices (Higgins et al., 2015), providing intentional interruption of previous assumptions (Katz and Dack, 2013). Such reflection, analysis and challenge to thinking patterns - existing mental models in terms of learning organisations - is necessary to bring about and embed change.

\section{Embedding professional learning in the workplace}

Professional development and learning need to be embedded into the workplace. Learning opportunities outside the school premises, for example formal education courses at universities or participation in workshops, can play an important role in the professional learning of individual staff. But research evidence clearly points to the importance of ensuring professional learning opportunities are sustainable (Darling-Hammond et al., 2009) and embedding them into the workplace (Örtenblad, 2002; OECD, 2010a; Joyce et al., 1999; Fullan, Rincon-Gallardo and Hargreaves, 2015). This is endorsed in the professional learning community and other related literature (Rosenholtz, 1989; Louis, Kruse et al, 1995; Stoll et al, 2006). Strong performing education systems like those of Singapore and Japan have institutionalised this good practice and have put the majority of professional development resources as close as possible to the point of use. In Singapore, for example, teachers are entitled to 100 hours of professional development each year. The majority of professional development is provided on site in the schools where teachers work, and is directed at the specific goals and problems teachers and school leaders are addressing in those schools. Each school has a fund for professional development that it can use to address specific knowledge and skills needs (OECD, 2015b).

\section{The importance of providing time and other resources}

Many countries currently ensure a formal entitlement to professional learning for their teachers and other school staff. However, the evidence shows this to be insufficient. TALIS for example, highlights that more than half $(51 \%)$ of the teachers in participating countries reported that their work schedule conflicts with professional development, about a third (32\%) reported a lack of support from their employer as a barrier to professional development, and more than two out of five (44\%) noted that professional development is too expensive (OECD, 2014). 
The SLO literature is adamant about the need to allocate sufficient time, finances and mentoring support and/or the removal of any (other) potential barriers to professional development (Du Four, 1997; Watkins and Marsick, 1996; School has the Initiative, 2014; Wohlstetter et al., 1994). There can be no organisational learning without individual learning, but individual learning must be shared and used by the organisation and its members (Kerka, 1995). This brings us to the next dimension of the SLO model fostering team learning and collaboration.

\section{Promoting team learning and collaboration among all staff}

\begin{tabular}{l|l}
\hline SLO Dimension & Elements \\
\hline $\begin{array}{l}\text { Promoting team learning } \\
\text { and collaboration among } \\
\text { all staff }\end{array}$ & - $\quad$ Staff learn how to work together as a team \\
& $\begin{array}{l}\text { - } \text { Collaborative working and collective learning - face-to-face and through ICTs } \\
\text { and/or staff practice }\end{array}$ \\
- Staff feel comfortable turning to each other for consultation and advice & Trust and mutual respect are core values \\
- & Staff reflect together on how to make their own learning more powerful \\
- & The school allocates time and other resources for collaborative working and \\
& collective learning
\end{tabular}

While the previous dimension does not suggest that the individual professional is isolated as a learner, this dimension highlights the importance of the social nature of the SLO. Senge et al. $(1990,2012)$ and various other scholars have noted that team learning is a critical dimension of the SLO as "teams, not individuals, are the fundamental learning unit in modern organizations". Team learning and collaboration are central to the SLO and support the pedagogical development of teachers and support staff. They are focused on student learning and are the means to enhancing that learning (Fullan and Quinn, 2015).

\section{Collaboration for team learning}

Schools are rife with team activity, but team activity is not team learning. As Senge et al. (2000, p.73) explain: "At its core, team learning is a discipline of practices designed, over time, to get the people of a team thinking and acting together". Team learning, therefore, is not collaborative learning per se, but the collective learning of minds coming together. Neuroscience confirms that we learn through social interaction (Dumont, Istance and Benavides, 2010) as knowledge is socially constructed, and socio-cultural theories also highlight the importance of learning through participating in communities of practice (Wenger, 1998) - reflecting what learning science informs us about effective learning of students, so a SLO encourages collaborative work and collective learning among its staff.

Teacher subject groups, staff development teams, site teams and team teaching, often involving assistant teachers or other support staff, shape the everyday live in contemporary schools. This makes teaching more than a process experienced by professionally isolated individuals in their respective classrooms and instead enables a professional growth process in which teachers learn from and with each other by sharing of knowledge and expertise (Husband and Short, 1994; Kruse and Louis, 1997; Newmann, King and Youngs, 2000). But teamwork and collaboration can be shallow. In SLOs staff have a positive attitude towards collaboration and team learning: there is a willingness to think and act together (Senge et al., 2012), so they meet regularly to address challenges and solve problems. In such an environment staff feel comfortable turning to each other for consultation and advice because there is mutual support among staff (Silins, Mulford and Zarins, 2002). This requires staff learning how to work and learn in teams (Watkins and Marsick, 1999; Silins and Mulford, 1998), sometimes supported by 
external facilitation (Senge et al., 2012), and focusing on team building which includes teaching everyone needed skills of dialogue, negotiation, consensus, and meeting management (Watkins and Marsick, 1999; Lunenburg, 2011; Senge et al., 2012).

\section{Professional learning communities and joint practice development}

According to Senge et al. $(1990,2012)$ a consequence of team learning is the establishment of professional learning communities in which members focus on the learning of students rather than on teaching, work collaboratively, and hold themselves accountable for results (Du Four et al., 2006). Collective responsibility is a key characteristic of professional learning communities (Kruse et al., 1995; King and Newmann, 2001; Stoll et al., 2006). Strong professional learning communities are collaborative cultures which deal with change more effectively (Fullan, 2003; Hargreaves, 2007) and where people care for each other as individuals, and commit to the vision the organisation is pursuing, as well as pursuing tasks of analysis and improvement together (Hargreaves, 2003; Giles and Hargreaves, 2006). Such supportive teacher work environments also tend to facilitate recruitment and retention of staff (Toole and Louis, 2002).

Peer networks are increasingly viewed as a fundamental aspect of teacher and school leader professionalism (OECD, 2015a) because of their potential for knowledge sharing, collaboration and support. Collegial relations between staff can take various forms. Little (1990) describes the form most likely to lead to deeper learning and improvement as "joint work", because it creates greater interdependence, collective commitment, shared responsibility, and review and critique. Exploring this concept further, Fielding et al. (2005) view it as "the process of learning new ways of working through mutual engagement that opens up and shares practices with others". This "deprivatisation" of practice, as it is described in literature on professional learning communities (e.g. Kruse et al., 1995) is focused on practice being open to the scrutiny and feedback of others. It is collaborative and mutual professional learning. A prime example from Japan, also taken up in other countries, is Jugyou kenkyuu, Lesson Study (see Box 3.3) (Stigler and Hiebert, 1999; Yoshida, 1999) in which teachers engage in structured processes that include joint lesson planning, observing and commenting on colleagues' classes. This has been the main form of professional learning in Japan, one of OECDs strongest performing education systems, for more than 100 years (Takahashi and McDougal, 2016). It is also used as a strategy to support implementation of new curricula.

Regular classroom observation by peers, mentoring or team teaching may also be more effective for increasing professional learning of staff, especially where colleagues support each other in problem solving (Higgins et al., 2015). 


\section{Box 3.3. Lesson study - a means for collaborative professional learning of teachers in Japan}

In Japan, all teachers participate in regular lesson studies in their schools. The Japanese tradition of lesson studies in which groups of teachers review their lessons and how to improve them, in part through analysis of student errors, provides one of the most effective mechanisms for teachers' self-reflection as well as being a tool for continuous improvement. Observers of Japanese elementary school classrooms have long noted the consistency and thoroughness with which a mathematics concept is taught and the way in which the teacher leads a discussion of mathematical ideas, both correct and incorrect, so that students gain a firm grasp on the concept. This school-by-school lesson study often culminates in large public research lessons. For example, when a new subject is added to the national curriculum, groups of teachers and researchers review research and curriculum materials and refine their ideas in pilot classrooms over a year before holding a public research lesson, which can be viewed electronically by hundreds of teachers, researchers and policy makers.

The tradition of lesson study in Japan also means that Japanese teachers are not alone. They work together in a disciplined way to improve the quality of the lessons they teach. That means that teachers whose practice lags behind that of the leaders can see what good practice is. Because their colleagues know who the poor performers are and discuss them, the poor performers have both the incentive and the means to improve their performance. Since the structure of the East Asian teaching workforce includes opportunities to become a master teacher and move up a ladder of increasing prestige and responsibility, it also pays for the good teacher to become even better.

Source: OECD (2010b), Strong Performers and Successful Reformers in Education: Lessons from PISA for the United States, OECD Publishing. www.oecd.org/pisa/46623978.pdf.

\section{Supporting collaborative learning with technology}

Technology offers great potential for enhancing collaborative learning. From the perspective of Vygotsky and others, professional knowledge, thinking and practice is socially situated and distributed in that knowledge is bound up with a professional's tools, resources and collaborators. Online professional learning needs to take account of this network of tools and resources, but also provides the opportunity both to further the life of existing communities and to create new learning communities by connecting people and enabling them to explore and share practice (Drayton and Falk, 2009), as the example of eTwinning Europe (Box 3.4) highlights. Connectivism is described as "a learning theory for a digital age" (Siemens, 2005). An underpinning argument is that in order for people to continue to learn, they need to maintain a range of connections - neural, conceptual and social/external networks (Siemens, 2008). A key principle of e-learning, therefore is that interaction with others gives them the capacity to communicate around the same topic or when using the same resource. Swanson (2013) examines how professionals use social media for professional learning in personal learning networks. Their learning "user-generated learning" occurs through active curation, reflection, and contributing to a self-selected collaborative space. All participants have to be active participants in the user-generated process, through searching, evaluating and sharing: they all have something to contribute, and synthesis and community are as valuable elements of the learning process as external research or "best practice". 


\section{Box 3.4. eTwinning Europe}

eTwinning is a fast-developing community of schools in Europe: 200000 registered teachers, head teachers, librarians, IT co-ordinators etc. (the so-called eTwinners). More than 100000 schools from 33 European countries have signed up to use its free and safe online environment, utilising the tools and the secure internet spaces offered for meeting virtually, exchanging ideas and practices, and engaging in cross-border projects and continuous professional development using Information and Communication Technologies (ICT). As part of the eTwinning Plus initiative, selected schools from six additional countries have joined the eTwinning community since March 2013.

eTwinning also provides additional services to teachers including the search for partners for Comenius school partnerships, the opportunity of taking part in communities of practice (e.g. eTwinning Groups and Teachers Rooms) and the participation in Professional Development Workshops and Learning Events (online and/or on site) at regional, national or European levels (European Commission, 2013).

It is a unique cross-border initiative that utilises social networking mechanisms for enhancing collaboration, communication and intercultural awareness among the school communities in Europe using ICT. It is a safe and supportive network for cross-border projects and teachers' peer learning and professional development.

Source: Kampylis, Law and Punie (2013 - eds), ICT-enabled innovation for learning in Europe and Asia, European Commission Joint Research Centre, http://ftp.jrc.es/EURdoc/JRC83503.pdf

\section{Meta-learning with peers}

Reflective learning is a feature of the SLO (Mitchell and Sackney, 1998; Kirkham, 2005); it is central to developing professional knowledge (Schön, 1983) and "schools that learn promote a reflective mind set" (Senge et al., 2012; Starratt, 1990). Frequently learners' experience of learning is hidden (Watkins, 2015). A SLO which promotes self-regulation for its students' learning (Dumont, Istance and Benavides, 2010) and the same kind of active involvement, autonomy and peer networking among its professionals needs to surface its learning and learn about it. Biggs (1985) characterises meta-learning as "being aware of and taking control of one's own learning". When professionals are meta-learning, they are thinking about their purpose in learning, their strategy in learning, the results and effects they have noticed, their feelings as they have been learning, and the context of their learning (Watkins and Cervero, 2000). In a fast changing context, meta-learning becomes a necessary feature of professional learning (Pui-wah, 2008). In a school that is a learning organisation, colleagues are learning about their learning together: meta-learning with peers, where they are "taking time to focus together on what all of the diverse members understand about their collective learning and knowledge creation, the conditions that support these and what these mean for the way they collaborate" (Stoll, 2010, p. 477).

An initiative by Foundation LeerKracht in the Netherlands combines many of the features of team learning and collaboration (Box 3.5). 


\section{Box 3.5. "Foundation LeerKRACHT" initiative promotes peer review and collective work planning}

Foundation leerKRACHT (the Dutch word for teacher) started in 2012 as a pro bono initiative of McKinsey \& Company. The ambition is to: 1) implement a bottom-up capacity building programme for schools, which aims to reach more than 5000 Dutch primary and secondary schools by 2020 (out of a total 8 700); and 2) reshape national education policy aimed at creating a strong body of teachers and stimulate schools to create a continuous improvement culture.

The foundation believes in the quality of the teacher and aims to return the ownership of education back to the teachers. It aims to achieve this by supporting schools to achieve a culture and "rhythm" of change of innovation in which teachers work together to improve their teaching, with the school leaders serving as role models by engaging in the improvement process. To help create this culture in schools the Foundation has developed a two-year programme. Teachers and school administrators that participate in the programme work closely together to improve education in schools at their discretion. Three improvement processes are central to the programme: 1) classroom observation and feedback conversation; 2) joint lesson planning; and 3) board sessions. This "board session" is copied from the LEAN movement in the manufacturing industry, where small teams hold daily stand-up meetings to jointly improve quality.

These improvement processes in themselves are simple. However, what makes it difficult is that they should not be carried out now and then, but each week. And not just by a group of "enthusiasts", but with everyone at school. And not because teachers "must"', but because the teachers themselves want it. To help create this culture in schools the teacher teams that work with these three improvement processes are supported by their school (through time and resources) and a school coach from within the organisation. The approach is underpinned by forum meetings with "Foundation leerKRACHT schools" in the region and by visits to company which have a continuous improvement culture.

This private initiative, starting in September 2012 now involves one in ten secondary schools in the Netherlands, one in three vocational schools and hundreds of primary schools. This rapid growth is driven by word-to-mouth advertising from teachers and school heads who have come to believe that collaborative working and learning within and across schools is essential for improving their teaching and the evidence suggests students are benefitting from this (van Tartwijk and Lockhorts, 2014).

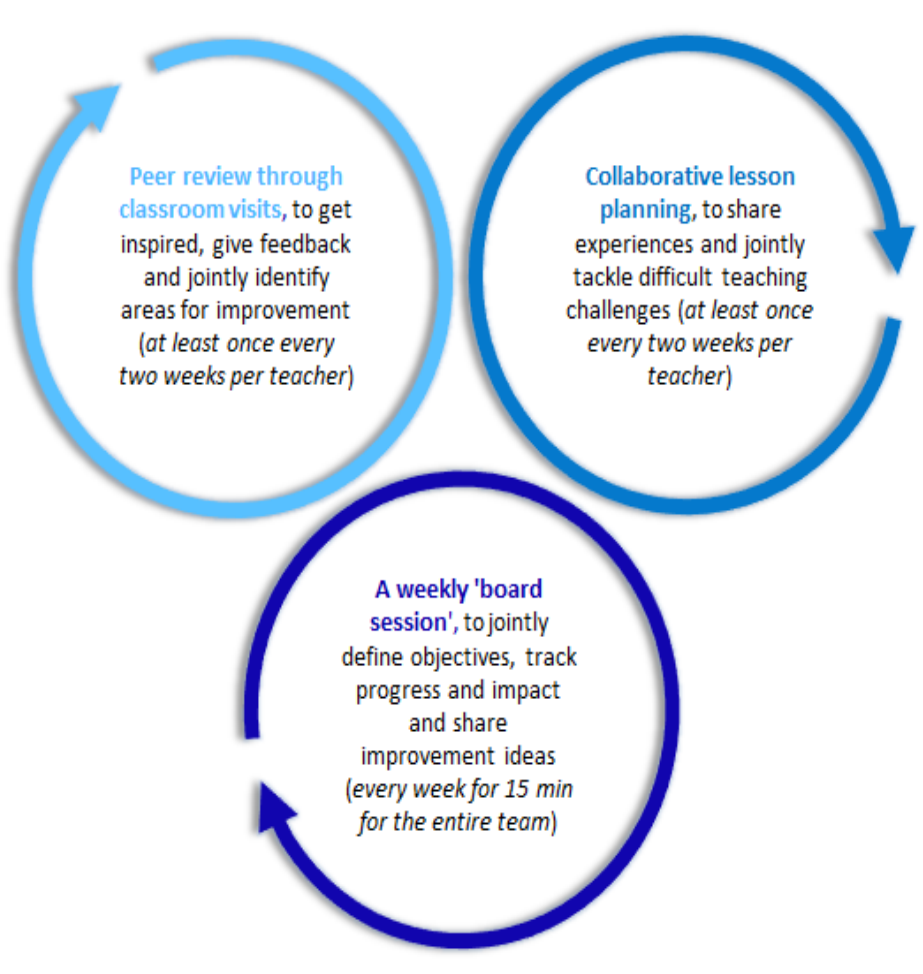

Source: Foundation LeerKRACHT (2016), www.stichting-leerkracht.nl/ik-ben-geinteresseerd/. 


\section{Relationships of mutual trust and respect}

For team learning and collaboration to thrive, relationships between staff need to be based on trust and respect. This is highlighted in literature on both learning organisations and professional learning communities (Bryk and Schneider, 2002; Tschannen-Moran, 2000; Pillai, Schriesheim and Williams, 1999; Senge et al., 1990; Silins, Mulford and Zarins, 2002; Louis, 2007). Drawing on Australian data from the LOLSO project Silins, Mulford and Zarins (2002) found that having a trusting and collaborative climate within a school positively impacted on student outcomes such as engagement and participation in school. Organisational behaviour scholars have also found that when people feel that one can safely speak up and ask for help from their colleagues this may lead to important organisational outcomes such as decreased number of errors and improved organisational systems and processes indicative of organisation level learning (Edmondson, 1999, 2003; Higgins et al., 2012).

Open and honest conversations among colleagues about what does and does not work requires high levels of relational trust and a sense of safety for teachers to expose their vulnerabilities in front of each other (Bryk and Schneider, 2002). Such trust and mutual respect also enables the kind of challenge which can push people's learning further through conversation (Earl and Timperley, 2008). Trust forms the foundation for co-operation between individuals and teams. When people trust and respect each other, other means of governance and control can be minimised to a level that is required by the type of work and risks involved (Cerna, 2014).

Building an organisational culture of trust and respect in which team learning and collaboration can thrive naturally involves all members of the organisation (or at least the vast majority). It is also reflected in the allocation of time and other resources, such as a weekly schedule of regular hours devoted to team meetings (Du Four, 1997; Somech and Drach-Zahavy, 2007), and time for colleagues to observe each other and engage in networked learning. In SLOs it is a natural expectation that staff share their insights and findings on learning and teaching with colleagues. School structures therefore encourage collaboration and dialogue among staff (Silins, Mulford and Zarins, 2002). The organisation of regular presentations to peers during staff meetings, presentations during conferences or mentoring of new teachers by other staff are examples of this.

\section{Establishing a culture of inquiry, exploration and innovation}

\section{SLO Dimension}

Establishing a culture of inquiry, exploration and innovation

\section{Elements}

- Staff want and dare to experiment and innovate in their practice

- The school supports and recognises staff for taking initiative and risks

- Staff engage in forms of inquiry to investigate and extend their practice

- Inquiry is used to establish and maintain a rhythm of learning, change and innovation

- $\quad$ Staff have open minds towards doing things differently

- Problems and mistakes are seen as opportunities for learning

- Students are actively engaged in inquiry

More than 20 years ago Goodlad (1994) noted that the intellectual habits of critical reflection and action about one's calling and daily work are the mark of a professional continuously engaged in selfimprovement which ultimately leads to the improvement in learning of students. For such behaviour to pervade throughout organisations, it is necessary to cultivate a learning habit in people and in the culture such that a spirit of inquiry, initiative and willingness to experiment with new ideas and practices predominates (Watkins and Marsick, 1996). This dimension showcases the cultural mind set of the SLO. 


\section{Inquiry for deep understanding and wise decision making}

If a learning organisation is one that is "continually expanding its capacity to create its future" (Senge et al., 1990), it will not be a linear or mechanistic process, as Earl and Katz (2002) explain. Rather, it will involve an iterative organisational learning process of "thinking in circles" (O'Connor and McDermott, 1997) where a series of decisions, actions and feedback loops guide the process. So, for example, when educators respond to data in a school that is a learning organisation, they do not operate "as technicians organizing and manipulating data in prescribed ways, like following a paint-by-number picture"; instead they bring to it an "inquiry habit of mind and view data as one source of information available to them in their quest for understanding and wise decision-making" (Earl and Katz, 2002, p. 1010). Essentially, the SLO's culture is infused with curiosity. Earl and Katz explain how inquiry and habit come together to help professionals reach better understanding.

Inquiry is, very simply, a way of finding things out - collecting data and interpreting evidence in ways that enhance and advance understanding. Habits of mind incorporate dispositional, emotional, motivational and personality variables that contribute to competence in managing the environment and making decisions (Keating, 1996). We link inquiry to habit of mind to emphasize that this is a way of thinking that is a dynamic iterative system with feedback loops that organizes ideas towards clearer directions and decisions and draws on or seeks out information as the participants move close and closer to understanding the phenomenon of interest. (pp. 1010-1011)

This process depends on the ability to tolerate ambiguity, holding back from rushing to quick judgements, as well as a willingness to take different perspectives and systematically pose increasingly focused questions in order to reach deep understanding which, ultimately leads to better decisions. Having decisional capital - "being able to make very good judgments about teaching, learning and children" gives professionals the "competence, judgment, insight, inspiration, and the capacity for improvisation as they strive for exceptional performance" (Hargreaves and Fullan, 2012, p. 5). Inquiry has benefits for teachers' professional learning. A meta-analysis exploring professional learning which leads to changes in teachers' practice and improved student outcomes, concludes that cycles of inquiry and knowledge building are central to powerful professional growth (Timperley et al., 2007). These cycles lie at the heart of the Spirals of Inquiry approach in British Columbia (see Box 3.6) which has been influenced by Timperley's work in New Zealand and other research on learning. Schools voluntarily participate in the Networks of Inquiry and Innovation (NOII) and Aboriginal Enhancement Schools Network (AESN). They work with a Spiral of Inquiry (Halbert and Kaser, 2013) process, which provides school teams with the structure for guiding their improvement and innovation work, and AESN schools link their inquiry specifically to Aboriginal ways of knowing. 


\section{Box 3.6. Spirals of Inquiry, Networks of Inquiry and Innovation and the Aboriginal Enhancement Network, British Columbia, Canada}

Spirals of Inquiry: The disciplined approach to inquiry is informing and shaping the transformative work in schools and districts across the province. Participating schools engage in a year-long period to focus on inquiry learning using the Spiral of Inquiry as the framework with six key stages: scanning, focusing, developing a hunch, new professional learning, taking action and checking that a big enough difference has been made. At each stage, three key questions are asked: What is going on for our learners? How do we know this? How does this matter?

Networks of Inquiry and Innovation (NOII) and the Aboriginal Enhancement Schools Network (AESN): These networks connect professional learning through principals, teachers and support staff and accelerate the transformative work across the province. To date, 156 individual schools in 44 districts in BC are active members of NOII and AESN. A grant from the Federal Government funded a research study on the impact of teacher involvement in AES and examined more than 50 inquiry projects around the province. The focus on inquiry learning has proved to be beneficial to the Aboriginal and non-Aboriginal students and teachers, as the model starts by analysing the interests and needs of the last. The AESN is considered to be an effective mechanism for sustainable teaching and learning change.

Source: OECD (2015), Schooling Redesigned: Towards Innovative Learning Systems, Educational Research and Innovation, OECD Publishing, Paris. http://dx.doi.org/10.1787/9789264245914-en.

Inquiry can also involve students as researchers. In a study of patterns of involvement, four different patterns emerged: students as data sources, as active respondents, as co-researchers (with teachers), and as researchers (Fielding, 2001). Fielding concluded that when students are at the level of researchers, initiating the research and dialogue with teachers, potential exists for them to be true agents of change.

\section{Innovation and exploration}

For a SLO to develop it is essential that people dare to innovate in their daily practice. Radical changes may be needed to core habits and practices in many schools for serious inroads to be made towards developing 21 st century skills and contemporary working practices and environments (OECD, 2015b). Twenty-first century educational challenges are frequently adaptive (Heifetz and Linsky, 2002); they cannot be solved by authoritative expertise or usual operating procedures. Rather, as Heifetz and Linsky (p. 13) explain:

We call these adaptive challenges because they require experiments new discoveries, and adjustments from numerous places in the organization or community. Without learning new ways - changing attitudes, values, and behaviours - people cannot make the adaptive leap necessary to thrive in the new environment. The sustainability of change depends on having the people with the problem internalize the change itself.

Evidence does not always exist about best approaches to take to address 21 st century learning outcomes. It is not always possible to know what best practice is. Sometimes, "next practices" - "emergent innovations that could open up new ways of working" (Hannon, 2007) - will be more appropriate as practitioners explore new and better solutions to intractable problems. Innovation depends on thoughtful reflection and a disciplined approach which is "hard, focused, purposeful work", according to Drucker (2002). Effective organisations are selective and deliberate in planning and integrating new approaches and experimental action plans that are consistent with their vision and goals (Aron, 2000; Fullan, 2000). 
Examples of this can be found among the schools involved in the OECD's (2013) Innovative Learning Environments project (2013) in the ways they tailor their curriculum content and learning approaches. At the John Monash Science School in Victoria, Australia, a subject highly relevant to developing 21st century competence is Creative Studies. This explores the nexus of problem solving, creativity, technology and nature. At ImPULS-Schule Schmiedfeld in Thuringia, Germany, learning is arranged with the objective of fostering personal, social and methodological competences, as well as expertise in a subject. Active and creative use of ICT and digital resources to promote digital literacy also features, as in the example of Mevo'ot HaNegev in Israel where a teacher describes how the technological infrastructure "enables the use of photographs, maps and virtual experiments; it allows the teachers' follow up of task submissions and knowing where each learner is with respect to work; and it permits knowledge creation in a way that was impossible without the technology" (OECD, 2013a, p. 48).

A mind set for innovation (Schley and Schratz, 2011) enables people to challenge their own and others' existing mental models (Senge et al., 1990). It also ensures that a critical stance is taken to innovation, ensuring that the problem is sufficiently well understood, that people are clear about their own contribution to the issue, that selected focus areas and innovations are appropriate and staff are able to engage in the necessary professional learning (Halbert and Kaser, 2013).

\section{Openness, risk taking and learning from failure}

Innovation and exploration are change processes which demand that people representing different perspectives are heard and respected without fear of judgment or reprisal (Aron, 2000; Senge, 1998). In SLOs therefore people keep an open mind about new ways of doing things. This requires helping teachers to overcome the uncertainties and isolation of teaching by supporting collegial and open dialogue, the exchange of ideas and sharing of experiences, debate over issues and techniques, and experimentation (Johnson, 1990; Senge et al., 2012). Teachers in SLOs show a tendency to co-operate rather than compete, and they work in a "safe environment", free of negative criticism. Here collegiality is nurtured through honest learning conversations and open disagreement, combined with supportive and trusting relationships.

Failure is instructive. The person who really thinks learns quite as much from his failures as from his successes. - John Dewey

Some initiatives and experiments will fail, while others will succeed. The idea that people and the organisations in which they work should learn from failure has considerable popular support. However organisations that systematically and effectively learn from failure are rare (Cannon and Edmondson, 2005). Unfortunately this also applies to many schools around the globe. This is not due to a lack of commitment to learning, but often rather because of viewing mistakes or failure of experiments in the wrong way, or being afraid to make mistakes due to fear in high accountability systems (Stoll and Temperley, 2009). Here, experimentation tends to give way to drilling students for tests and a focus on memorisation rather than understanding (Sahlberg, 2010). Problems and mistakes are not always bad; in fact they may be inevitable and, if wisely used, even desirable to making progress. For many people, the notion of risk is synonymous with danger, but those who study risk view danger as just one side of "the risk coin", the other side being opportunity. But the future can be viewed with fear. Because, the past appears more certain than it was, it makes the future seem more uncertain and even frightening, in what psychologists describe as hindsight bias (e.g. Roese and Vohs, 2012). This creates further risk aversion.

The SLO literature highlights how teachers associate a culture of willingness to take risks with their own learning (Leithwood, Leonard and Sharratt, 1998). To allay fear and risk aversion, Cannon and Edmondson (2005) note that organisations should ensure the "identification of failure", "analyse failure" and then "pursue deliberate experimentation". They propose a number of practices to ensure failures are learnt from (see Figure 3.1). For example, psychological safety can be reinforced through organisational 
policies such as blameless reporting systems, training in coaching skills, and making failures public as a means for learning. These messages resonate with the SLO literature. Several SLO scholars have for example noted the need for schools to support and protect those who take initiatives and risks, and reward them for it (e.g. Senge et al., 2012; Paletta, 2011; Silins, Mulford and Zarins, 2002).

\section{Figure 3.1. Key processes in organisational learning from failure}

\begin{tabular}{|c|c|c|c|}
\hline & Identifying failures & Analying failures & Experimentation \\
\hline $\begin{array}{l}\text { Barriers embedded } \\
\text { in technical systems }\end{array}$ & $\begin{array}{l}\text { Complex systems make many } \\
\text { small failures ambiguous. }\end{array}$ & $\begin{array}{l}\text { A lack of skills and techniques } \\
\text { to extract lessons from } \\
\text { failures. }\end{array}$ & $\begin{array}{l}\text { Lack of knowledge of } \\
\text { experimental design. }\end{array}$ \\
\hline Recommendations & $\begin{array}{l}\text { R1: Build information } \\
\text { systems to capture and } \\
\text { organise data, enabling } \\
\text { detection of anomalies, and } \\
\text { ensure availability of systems } \\
\text { analysing expertise. }\end{array}$ & $\begin{array}{l}\text { R2: Structure after action } \\
\text { reviews or other formal } \\
\text { sessions that follow specific } \\
\text { guidelines for effective } \\
\text { analysis of failures, and } \\
\text { ensure availability of data } \\
\text { analysis expertise. }\end{array}$ & $\begin{array}{l}\text { R3: Identify key individuals } \\
\text { for training in experimental } \\
\text { design; use as internal } \\
\text { consultants to advise pilot } \\
\text { projects and other } \\
\text { (operational) experiments. }\end{array}$ \\
\hline $\begin{array}{l}\text { Barriers embedded } \\
\text { in social systems }\end{array}$ & $\begin{array}{l}\text { Threaths to self-esteem inhibit } \\
\text { recognition of ones own } \\
\text { failures, and corporate } \\
\text { cultures that 's shoot the } \\
\text { messenger' limit reporting of } \\
\text { failures. }\end{array}$ & $\begin{array}{l}\text { Ineffective group process } \\
\text { limits effectiveness of failure } \\
\text { analysis discussions. } \\
\text { Individuals lack efficacy for } \\
\text { handling 'hot' issues. }\end{array}$ & $\begin{array}{l}\text { Organisations may penilize } \\
\text { failed experiments inhibiting } \\
\text { willingness to incur failure for } \\
\text { the sake of learning. }\end{array}$ \\
\hline Recommendations & $\begin{array}{l}\text { R4: Reinforce psychlogical } \\
\text { safety through organisational } \\
\text { policies such as blameless } \\
\text { reporting systems, through } \\
\text { training first line managers in } \\
\text { coaching skills, and by } \\
\text { publicizing failures as a } \\
\text { means of learning. }\end{array}$ & $\begin{array}{l}\text { R5: Ensure availability of } \\
\text { experts in group dialogue and } \\
\text { collaborative learning and } \\
\text { invest in development of } \\
\text { competencies of other } \\
\text { employees in these skills. }\end{array}$ & $\begin{array}{l}\text { R6: Pick key areas of } \\
\text { operations in which to } \\
\text { conduct an experiment, and } \\
\text { publicize results, positive and } \\
\text { negative, widely within the } \\
\text { company. Set target failure } \\
\text { rate for experiments in } \\
\text { service of innovation and } \\
\text { make sure reward systems } \\
\text { do not contradict this goal. }\end{array}$ \\
\hline
\end{tabular}

Source: Cannon M.D. and A.C. Edmondson (2005), "Failing to learning and learning to fain (effectively): How great organisations put failure to work to improve and innovate", Long Range Planning, Vol. 38, pp. 299-319, http://blog.educpros.fr/francoisfourcade/files/2014/06/Article.pdf. 


\section{Embedding systems for collecting and exchanging knowledge and learning}

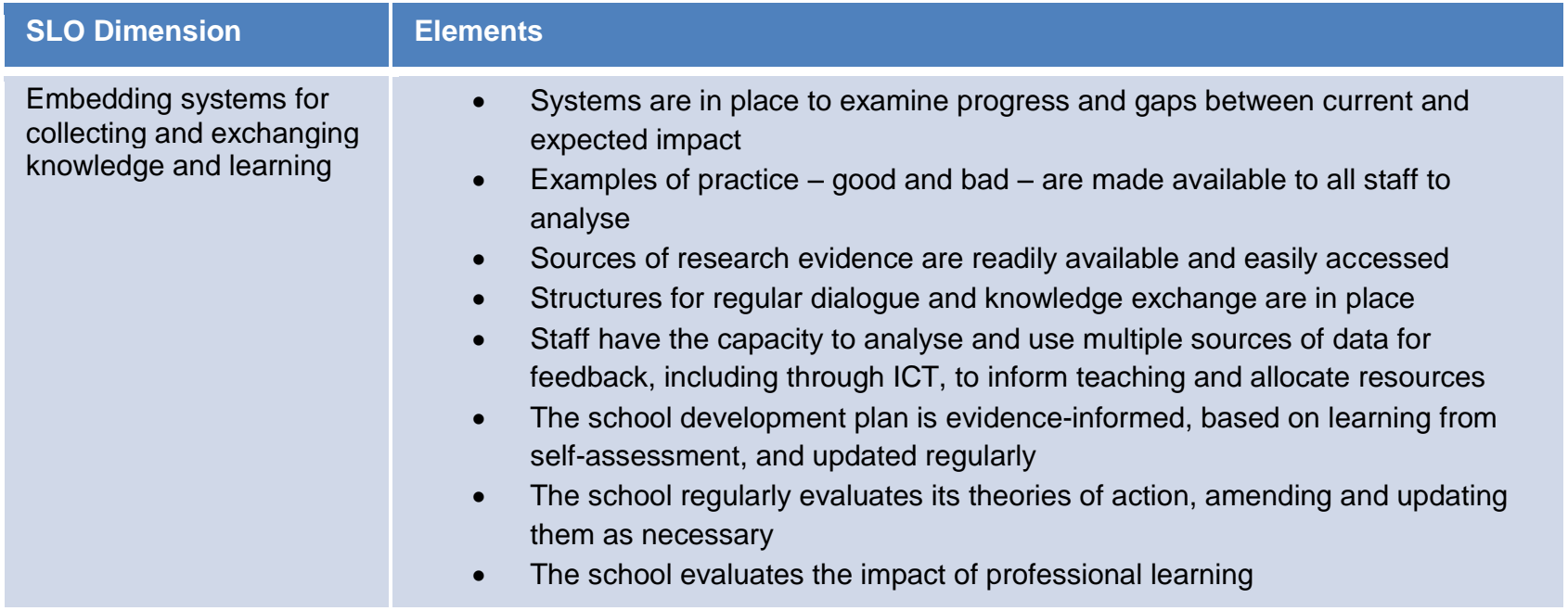

Schechter and Mowafaq $(2012,2013)$ define a SLO as one that "develops processes, strategies, and structures that would enable them to learn and react effectively in uncertain and dynamic environments. These schools institutionalize learning mechanisms in order to revise their existing knowledge. Without such mechanisms, a learning organization is unlikely to emerge". Like Schechter and Mowafaq (2012, 2013), many SLO scholars explicitly note the importance of establishing what Watkins and Marsick (1996, 1999) have referred to as "embedded systems for capturing and sharing learning" as a key feature of a SLO (see Figure 2.1). This dimension therefore focuses on the systems the SLO creates to support organisational learning.

\section{Systems to assess progress and gaps}

Knowledge exchange and collective identity are powerful forces for positive change. In line with their vision and goals SLOs therefore create systems to measure progress and gaps between current and expected impact. Effective use of data by teachers, school leaders and support staff has become a central tenet in school improvement processes, to inform wise decision making (Schildkamp, Lai and Earl, 2013) and develop professional capital (Hargreaves and Fullan, 2012), as well as raising assessment scores, reducing the achievement gap, and changing school culture (Hamilton et al., 2002; Wayman, Cho and Shaw, 2009; OECD, 2013a). When schools and school systems increase their collective capacity to engage in ongoing assessment for learning, major improvements can be achieved. Other aspects of evaluation cultures are also important, including: school-based self-assessment, meaningful use of external accountability data, and what Jim Collins (2001) found in "great" organisations, namely, a commitment to "confronting the brutal facts". A SLO makes lessons learned - whether good or bad - available to all staff. It also evaluates the impact of professional learning (Guskey, 2001; Timperley et al., 2008).

\section{Knowledge building through learning conversations and knowledge exchange}

SLOs, therefore, have the systems in place to ensure they are "information-rich" or, more appropriately, "knowledge-rich". Information (data in this case) is not knowledge. It takes social processing in the school context to bring it to life, as Nonaka and Toyama (2000, p. 7) explain:

Knowledge is dynamic, since it is created in social interactions amongst individuals and organisations. Knowledge is context specific, as it depends on a particular time and space. Without being put into context, it is just information, not knowledge. Information 
becomes knowledge when it is interpreted by individuals and given a context and anchored in the beliefs and commitments of individuals.

This has implications for the organisation of regular formal dialogue or informal conversations among staff about students' learning, sharing of information notes, etc. The SLO literature is adamant about the importance of interpersonal interaction. Knowledge is not 'transferred' like a piece of paper. Only through sharing, exchange, dialogue and collaboration, can new and meaningful knowledge and readiness for change be developed. Learning conversations - central features of knowledge exchange in professional learning communities - surface tacit knowledge and transform it into explicit knowledge (Nonaka and Takeuchi, 1995). People bring their existing mental models to conversations about learning and data. These makes sense within their own frame of reference and provide the framework for interpreting new information (Lipman, 1991). Through conversation, data - which can bring new and discrepant ideas - can help challenge existing models, helping people to move beyond them (Earl and Timperley, 2008; Stoll, 2012).

This brings in a further definition of learning: learning as knowledge creation (Paavola, Lipponen, and Hakkarainen, 2004). It is this knowledge creation that brings the collective meaning to organisational learning (Louis, 1994). By exchanging individual experiences and comparing opinions and ideas with those of colleagues, organisation members can achieve an improved level of understanding of the causal mechanisms intervening between the actions required to execute a certain task and the outcomes produced (Schechter and Mowafaq, 2013). The word "exchange" is, itself, significant, and draws on understandings about knowledge mobilisation across public services (Nutley et al., 2000). Rather than just sharing experiences and strategies, colleagues are oriented towards collective problem solving and mutual learning through ongoing interaction, collaboration and exchange of ideas, new evidence and expertise.

In sum, turning information into actionable knowledge is a social process. Therefore SLOs need to create the structures for regular dialogue and knowledge exchange among staff, involving other parties where appropriate (e.g. parents, community members, businesses), in order for a learning culture to emerge (Fullan, Cutress and Kilcher, 2005; Senge et al., 2012).

\section{Using ICTs}

Technology has the potential to revolutionise learning, as well as the school organisation, in many different ways. It has, for example, become a powerful tool for assessment and improvement planning as it makes it possible to access and analyse student achievement data on an ongoing basis, take corrective action, and share best solutions (Fullan, Cutress and Kilcher, 2005; Kampylis, Punie and Devine, 2015; see Box 3.7). Another application of technology is in the form of management information systems that allow for storing and easy access to data that can fuel new organisational routines to foster continuous improvement within schools: for example, data-informed improvement and learning through school selfassessment initiatives, or access to external research data on interventions which has been analysed in terms of its impact, value for money and the robustness of the research (e.g. the Sutton Trust/EEF toolkit in England and the Australian Teaching and Learning Toolkit).

Increasingly sophisticated technological systems are being developed to offer greater variety of data, better accessibility, increased flexibility and more thoughtful engagement. For example, Waerness et al. (2016) describe the Norwegian Evidence-Informed Quality Work (EIKA) project where a range of processes are developed by schools using digital tools to stimulate deeper learning, better decision making and more powerful interventions and innovation as they explore, contextualise and take forward findings of national and 21st century capability assessments, and teacher and leadership surveys. Developing such digital tools is based on considerations of how to grow capacity for the next century if deeper learning, 
equity and global awareness are goals, and how to promote collective responsibility and internal accountability among professionals, as the example of Olds High School in Alberta (Box 3.7) highlights.

\section{Box 3.7. Using technology for improving teaching and learning - Olds High School, Alberta, Canada}

Community Learning Campus (CLC), Olds High School, Alberta, Canada is an innovative approach to high school, post-secondary and community education, sharing resources and working jointly with a variety of community groups and agencies. It provides an active and holistic educational environment that brings together high school and postsecondary education in one place, seeking to create a seamless transition for learners wishing to enter the workforce, apprenticeship, college, or university.

The CLC is both a virtual and a physical learning space in four multi-use facilities: 1) core high school; 2) fine arts and multi-media centre; 3) health and wellness centre; and 4) the Bell eLearning Centre. Delivery is either seminarbased or class-based, both of which are constructivist and organised around project work.

A web-based information system provides learners and their parents with summative and formative feedback on a daily, weekly and interim basis and documents progress throughout a learner's four years at the school. The programmes are organised around four pillars - personal, knowledge, community, and global - and navigation relies on the CLC Learner Map, which is both a framework for individual learner pathway decisions and a graphic enabling community access.

Source: OECD (2013a), Innovative Learning Environments, Educational Research and Innovation, OECD Publishing, http://dx.doi.org/10.1787/9789264203488-en.

\section{Learning how to use evidence}

Improvement does not follow automatically from the mere availability of quality data. Rather, it depends on serious engagement. It also depends on effective data use, which longitudinal information systems can facilitate (Vincent-Lancrin and González-Sancho, 2015). For this to happen, a SLO ensures its staff have the capacity to analyse and use data for improvement and, where necessary, transformations of existing practice. This is essential as research evidence shows that in many school systems the capacity to systematically collect, analyse and exchange knowledge and learning - whether facilitated through the use of technology or not - is underdeveloped (Fullan, Cutress and Kilcher, 2005; OECD, 2013a; VincentLancrin and González-Sancho, 2015; Schildkamp et al., 2014). A recent study on education data use in schools in five EU countries (Germany, Lithuania, the Netherlands, Poland and England) for example showed that, despite the availability of a range of data sources, schools rarely use these data and reports to take action and develop strategies to improve student learning (Schildkamp et al., 2014). Organisational learning concepts may help to unpack the issues. Again, it seems that teachers and leaders are influenced by their mental models around data use (Jimerson, 2014). Existing beliefs about evidence can get in the way of productive use (Coburn and Turner, 2011).

Staff therefore need to be able to utilise multiple sources of data and information (e.g. from students, parents, teacher survey, peer review, team teaching) for feedback and to inform teaching and the allocation of resources (OECD, 2013a; School has the Initiative, 2014; Brandt, 2003; Education Scotland, 2015). These efforts are reflected in a regularly updated school development plan that is evidence-informed and based on a self-assessment, involving multiple sources of data and information. It is the result of a participatory self-assessment process involving all staff, as well as other interested parties (e.g. students, parents, community members, other schools, businesses). 
Using another form of evidence - external research findings - to improve day-to-day practice has become a "hot topic" in many countries (Brown, 2015; Hattie, 2012), although TALIS 2013 results highlight that it is far from common practice among teachers in many countries. If undertaken as part of a process of reflective and collaborative learning, teachers' engagement with research evidence can both help teachers improve their practice and promote better learning outcomes among their students (e.g. Louis, 2010). Many schools find it difficult to become "research engaged" because staff lack the necessary skills, resources or motivation. Research Learning Communities (see Box 3.8), a project supported by the UCL Institute of Education in England, is an example of how schools are learning to become more research engaged and confident about using evidence.

\section{Box 3.8. Research Learning Communities project - UCL Institute of Education, England}

Fifty-eight primary schools in England have been working with the UCL Institute of Education, University College London in a two-year pilot project, funded by the Education Endowment Foundation (EEF) focused on increasing the use of research in schools. The project has been designed to address interdependent organisational learning factors facing schools that seek to become evidence-informed: developing approaches to building teacher capacity to engage in and with research and data; exploring how school cultures can become more attuned to evidence use, making research use a cultural norm; exploring how schools can promote use of research as part of an effective learning environment; and examining the necessary structures, systems and resources to facilitate research use and the sharing of best practice.

Two leaders - a senior leader and an informal opinion leader - represent each school engaged in the Research Learning Communities (RLC) project as part of an intentional design to ensure that central actors will champion research-informed practice and promote wider reach and buy-in to the approach across the school. In the first year, teams came together in 10 groups of 5-6 schools, 4 times for one-day workshops where they examined research and evidence relating to a commonly agreed area of focus, and developed, applied and evaluated school or stage-wide development strategies based on this evidence. These were tested out in school between the sessions. The sessions were also designed to build capacity for sustainability of the approach, ensuring that schools can continue to run RLCs and use evidence effectively after the project ends. In the second year, participating schools are leading sessions, with external facilitators on hand to support and challenge.

Source: Research Learning Communities, Education Endowment Foundation and the UCL Institute of Education, University of London, https://educationendowmentfoundation.org.uk/projects/research-learning-communities/ (accessed 5 April, 2016).

\section{Evaluative thinking and theories of action}

In the SLO, innovation needs to be guided by theories of action (Argyris and Schön, 1978) which lay out the purpose of the innovation and expectations of any intervention, what people imagine will happen and the likely or intended impact. Essentially, a theory of action is an organisation's story or "theory" of how it will make change, explaining why certain things will happen. Using a diagram, the organisation maps long-term outcomes - the intended impact it will have on the world and how communities will be different because of the work it does - and the short-term outcomes which are the changes that are necessary now in order for the long-term objectives to be realised. The theory of action needs to be adapted as the organisation moves forward and learns what helps it realise its long-term objectives, and what gets in the way.

Evaluation of theories of action need to take this into account. As Earl and Timperley (2015) argue, evaluating innovation is not the same as traditional evaluation and requires evaluative thinking. The approach needs to be one of developmental evaluation (Patton, 2011), such that it is: "an extension of the summative/formative repertoire focused on using evaluation within the process of innovation in which both 
the path and the destination are evolving, as a mechanism for bringing rigorous inquiry to development by being intentional about using data in a meaningful way to inform innovation in progress".

Innovations may involve multiple players in and beyond schools, are not always predictable, and may interact with other innovations so evaluation itself needs to be: "a dynamic, flexible, process", specific to context, and actively involving all those represented "in an iterative and cyclical process" as they determine the nature of evaluation, in the context of the particular innovation and collaborate in the process as it unfolds (Earl and Timperley, 2015, p. 9).

\section{Learning with and from the external environment and larger system}

\begin{tabular}{|c|c|}
\hline SLO Dimension & Elements \\
\hline $\begin{array}{l}\text { Learning with and from } \\
\text { the external environment } \\
\text { and larger system }\end{array}$ & $\begin{array}{l}\text { - The school scans its external environment to respond quickly to challenges } \\
\text { and opportunities } \\
\text { The school is an open system, welcoming approaches from potential external } \\
\text { collaborators } \\
\text { - Partnerships are based on equality of relationships and opportunities for } \\
\text { mutual learning } \\
\text { - The school collaborates with parents/guardians and the community as } \\
\text { partners in the education process and the organisation of the school } \\
\text { Staff collaborate, learn and exchange knowledge with peers in other schools } \\
\text { through networks and/or school-to-school collaborations } \\
\text { The school partners with higher education institutions, businesses, and/or } \\
\text { public or non-governmental organisations in efforts to deepen and extend } \\
\text { learning } \\
\text { ICT is widely used to facilitate communication, knowledge exchange and } \\
\text { collaboration with the external environment }\end{array}$ \\
\hline
\end{tabular}

Schools in the 21 st century are not sustained by working in isolation but instead need to be connected to diverse partners, networks and professional learning communities. What's "out there" is "in here" in the SLO.

\section{Schools as responsive open systems}

Schools do not operate in a vacuum; they are "open systems" that are sensitive to their external environment, including social, political and economic conditions (Brandt, 2003). They function as part of a larger social system, including, in many jurisdictions, the local community in which they are embedded and, frequently, their school district (Rumberger, 2004). Schools that engage in organisational learning enable staff at all levels to learn collaboratively and continuously and put these learnings to use in response to social needs and the demands of their environment (Silins, Mulford and Zarins, 2002; Park, 2008). For this to happen, teachers have to become experts about their context. This means having the specific knowledge, understanding and skills which will enable them to relate to and take account of the views and situations of parents, communities, business partners and social agencies. Assessing the nature of this interface between schools and the larger system is essential, especially exchanges which foster or hamper efforts made by schools to function in new and creative ways.

To adapt to uncertainty arising from interactions with its environment, the SLO proactively and continuously "scans" the environment to monitor and respond as necessary to external challenges and opportunities. Environmental scanning refers to the activities of the school that contribute to broadening 
the scope of information, policy, theory and practice that is brought to bear on the school's development and decision making processes (Silins, Mulford and Zarins, 2002).

\section{Genuine partnerships}

Schools' urgent drive to avoid isolation comes from awareness that significant innovation cannot be achieved and sustained alone. As learning organisations, schools connect with their community and partners in their external environment to enrich their capacity to serve their students. They look to build and maintain the capital they need as organisations - social, intellectual, and decisional capital (Hargreaves and Fullan, 2012) - through forging partnerships and networks. SLOs are therefore organised through partnership, bringing together disparate groups to support and encourage learning including students, teachers, parents, and members of the local communities (Nixon et al., 1996; OECD, 2013a).

These relationships are two-way, as the school works with and through community and other partners: contributing to the community and strengthening community links, but also revitalising community (OECD, 2013a). As Senge et al. (2000, p. 461) argue: "a community of people is a place, rooted in the biosphere, rife with activity, mutual respect, and the recognition that everyone in that place is responsible for and accountable to one another, because the lives of all are interdependent".

The orientation is frequently one of co-production. Co-production theory derives from community policing (Östrom and Baugh, 1973) and law (Cahn, 2000), and proposes that those who use services are hidden resources who can extend service options and generate further innovation. Co-producers pool different types of knowledge and skills based on different lived experiences and professional learning (Harris and Boyle, 2009). SLOs are open to more equal relationships with external partners, sharing power and control.

\section{Parents, local community and social services as learning partners}

Parents or guardians are key partners for SLOs in the educational process and thereby strengthen it (Bowen et al., 2005; Silins, Mulford and Zarins, 2002). Parents have a unique relationship with the school: in many respects they can be considered part of the school's internal community, but they are also a key bridge to students' lives outside of school. Research evidence clearly shows that working with parents and developing strong relationships with them is fundamental to a school's effectiveness (Reynolds et al., 2016), and strong parental links are important in creating and fostering the general learning community (OECD, 2013a). But parents can be an inhibitor to change if they do not recognise the need for it or understand its potential benefits. Without the positive co-operation of family and schools, it is unlikely that all students will reach the high expectations in terms of educational outcomes set by a demanding society (Avvisati et al., 2013; Castro et al., 2015; Shute, 2011). SLOs therefore actively share information with parents and consider them as active partners in the educational process and organisation of the school.

The Jenaplan-Schule in Thuringia, Germany for example, requires and counts on the active cooperation of parents. Monthly roundtable meetings give parents the opportunity to discuss group-specific problems with the teachers. Regular discussions and consultations between parents and teachers help support the child's individual development. Parents are invited to get involved in classes, and they can also help with the design and management of classrooms, learning materials and the school building. The school also encourages parents to co-operate with other parents and the mothers and fathers publishing a newspaper, "Parents Circle", to inform a wider public about Jenaplan School's directions and activities (OECD, 2013a). 
To continue learning how to achieve quality and equity now and in the future, SLOs are also connected with a wide variety of other partners. Thinking holistically about their students means ensuring connections with a diverse range of services. SLOs dealing with a socio-economically disadvantaged or other students with special learning needs need policies, additional (financial) means and an integrated approach to service delivery, i.e. involving multiple social services, to adequately respond to the learning and other needs of students. Research beyond education exploring integrated social services highlights its benefits for facilitating information and knowledge sharing between professionals, and how increased cooperation and collaboration leads to improvements in service quality, and production of better outcomes and satisfaction amongst service users and providers (OECD, 2015b).

SLOs therefore collaborate with parents, the community and social services to ensure an integrated approach to responding to the learning and other needs of students. Through such collaborations the SLO is more able to deliver on its promise (vision) and show that success in school is indeed possible for all students.

\section{Collaborating and learning with and from other schools}

The SLO literature highlights that as schools innovate and move towards becoming learning organisations their boundaries become increasingly and deliberately blurry (open systems thinking). As a consequence, in SLOs continuous learning among staff is not limited to the physical boundaries of the school. Instead teachers and school leaders expect to engage in collaborative work and learning with peers in other schools through the establishment of networks or school-to-school collaborations (Bottrup, 2005; Harris and Tassel, 2005; Paletta, 2011; Schlechty, 2009; Senge et al., 2012; OECD, 2013a). Networks can be "vibrant motors for change" (Sliwka, 2003, p. 63). These collaborations take a range of forms, enabling schools to "upload" knowledge from their school-based professional learning communities into their networks and "download" knowledge from networks back into the individual school professional learning communities (Earl and Katz, 2006). Such networks therefore hold the potential for forming an important supplement to situated, school-based learning (Lave and Chaiklin, 1993; Lave and Wenger, 1991) and learning through formal programmes and courses. These networked learning organisations, like SLOs, pay attention to developing and maintaining trusting relationships and are flexible and adaptable to changing community member and environmental needs (Stoll, 2015). Networking between colleagues in different schools is a central feature of the Austrian New Secondary School reform (Box 3.9).

\section{Box 3.9. Collaborative learning and working through networks - example from Austria}

The Austrian New Secondary School reform started as a relatively small-scale project in 2008 with 67 pilot schools. It has since been a mandated school reform, which will be completed in phases by 2018. Central to the reform is the creation of a new leadership position at the school level, the Lerndesigner, a teacher-leader who together with the school's principal and other teacher-leaders (subject co-ordinators, school development teams, etc.) serve as change agents in their schools, driven by the principle of school-specific reform and focused on the national reform goals of equity and excellence.

The reform strategy lies in qualifying teachers to become teacher-leaders, thereby enabling them and their schools to realise effective shared leadership. Much effort is therefore placed on building social and leadership capital through networking events, which play a central role in the reform, as they provide the venue for learning, peer learning and dissemination of good practice. A specially designed two-year national accredited qualification programme for Lerndesigners and an online platform for sharing ideas and practices form an integrated part of the reform's continuous professional development and leadership development efforts. The rationale for creating and qualifying and networking change agents was clear, and focused: transformation at all levels occurs when change agents are networked and establish communities of practice. 


\section{Box 3.9. Collaborative learning and working through networks - example from Austria (continued)}

Responding to the need to connect Lerndesigners, virtual Professional Learning Communities (PLCs) have been in a prototyping phase since the school year 2013/14 and are now being implemented as common practice. With the aim of exploring the impact of Lerndesigners' digital networking, virtual PLC sessions are captured in "vignettes", short (10-20 lines) descriptions of key experiences. Rather than summarising content, vignettes focus on recreating participants' experiences by capturing the emotions and events emerging during the session. Deep understanding of their practice and new ways of thinking appear frequently in the vignettes alongside with problems like coping with technology or making the time to attend the sessions. These vignettes are used as evidence to inform the CLS on the learning impact and needed improvements of the PLC sessions.

Source: OECD (2015b), Schooling Redesigned: Towards Innovative Learning Systems, Educational Research and Innovation, OECD Publishing, Paris, http://dx.doi.org/10.1787/9789264245914-en.

\section{Other partners}

Partnerships with higher education institutions can offer schools clear advantages in drawing on these institutions' expertise and capacity, bringing an external lens and supporting them in engaging in doubleloop learning (Ainscow et al., 2016). Benefits can work both ways, as innovative ideas and practices can in turn influence the higher education/university level, and the teacher education and service missions of the university or teachers college may be very well served by such partnerships (Harris and van Tassell, 2005; OECD, 2013a). The American Professional Development Schools (Harris and van Tassell, 2005) or Sweden's recently established "training schools" are examples of such partnerships that extend the boundaries of the SLO to other parts of the education system. These are aimed at building capacity for learning and teaching at the school level, as well as in the higher education institutions (OECD, 2015b).

However as the Brazilian "Neighbourhood as School" example shows (Box 3.10), in SLOs partnerships are not necessarily confined to traditional partners. They can go beyond educational circles and to include external advisors (consultants), public organisations, non-governmental organisations, business and foundations (Wohlstetter et al., 1994; Silins, Mulford and Zarins, 2002; OECD, 2013a). Innovative learning environments, many of whom demonstrate features of SLOs, place considerable emphasis on involving a diverse range of non-formal partners (OECD, 2013a).

\section{Box 3.10. Neighbourhood as school projects - Brazil}

A new concept of education has been developed in Vila Madalena, a small district in Brazil's largest city, São Paulo. Known as "Neighbourhood as School", it is conducted by a non-governmental organisation, Cidade Escola Aprendiz, which since 1997 has been turning squares, alleys, cinemas, ateliers, cultural centres and theatres into classrooms. The Neighbourhood as School, an extension of formal school education, aims to expand learning spaces in the community, creating a pedagogic laboratory in which learning is knowing oneself and socially intervening in the community through communication, art and sports. The success of the Neighbourhood as School concept is driven by a partnership among schools, families, public authorities, entrepreneurs, associations, craftspeople, non-governmental organisations and volunteers - indispensable powers in community education. Everybody educates; everybody learns at qualification centres, so the experience helps educators and social leaders nourish the learning systems.

Source: UNICEF (2009), Child Friendly School Manual, UNICEF, New York, www.unicef.org/publications/files/Child_Friendly Schools_Manual_EN_040809.pdf. 


\section{Harnessing ICTs}

ICTs permeate in numerous ways throughout learning environments and systems, providing an additional dimension to the functioning of networks and school-to-school collaborations (OECD, 2015a; Kampylis, Punie and Devine, 2015). By many considered a driver or "pump" of innovative change in education (OECD, 2013a; OECD, 2015a; Istance and Kools, 2013), ICTs allow for easy sharing of knowledge and resources, help build communities of practice and provide network participants with a means to communicate virtually at any time, without having to meet face-to-face. The example of the Austrian New Secondary School reform (see Box 3.10) is a case in point.

Whether or not supported through powerful ICTs, networked-based learning can help build bridges between the two "traditional" learning arenas. It importantly facilitates collaboration and peer learning or as Hargreaves and Fullan may call it the building of "social capital" (Hargreaves and Fullan, 2012) and can help reduce isolation of independently functioning schools, helping to transform them to become learning organisations that are part of a larger "learning system".

\section{Modelling and growing learning leadership}

\begin{tabular}{|l|l|l}
\hline SLO Dimension & Elements \\
\hline $\begin{array}{l}\text { Modelling and growing } \\
\text { learning leadership }\end{array}$ & - School leaders model learning leadership, distribute leadership and help grow \\
other leaders, including students \\
- School leaders are proactive and creative change agents \\
- School leaders develop the culture, structures and conditions to facilitate \\
professional dialogue, collaboration and knowledge exchange \\
- School leaders ensure that the organisation's actions are consistent with its \\
vision, goals and values \\
- School leaders ensure the school is characterised by a "rhythm" of learning, \\
change and innovation \\
- School leaders promote and participate in strong collaboration with other \\
schools, parents, the community, higher education institutions and other \\
partners \\
School leaders ensure an integrated approach to responding to students' \\
learning and other needs
\end{tabular}

Today's world demands that schools keep pace with the changing external environment, while delivering on their core task - equipping students with the knowledge, skills and attitudes for life in the 21 st century. For many schools, realising this essential and demanding agenda will require transformational change. In their report for the American Educational Research Association's Task Force on educational leadership, Leithwood and Riehl (2003) articulated leaders as follows: "At the core of most definitions of leadership are two functions: providing direction and exercising influence. Leaders work with others to achieve shared goals". Leadership is the essential influence that can bring all of the separate parts of the learning organisation together to ensure that the whole adds up to more than the sum of the parts and that it is sustainable. Leadership ultimately provides direction for learning, takes responsibility for putting learning at the centre and keeping it there (OECD, 2013c; Fullan, 2014), and using it strategically (Watkins and Watkins, 1999), translating vision into strategy (OECD, 2013c) so that the organisation's actions are consistent with its vision, goals and values. We define this as "learning leadership".

As explained in the overview of Leadership for 21st Century Learning (OECD, 2013c, p. 14), "the term learning leadership is not in common use". It has many features in common with other learning- 
focused forms of leadership, for example instructional leadership, leadership for learning and learnercentred-leadership, but is distinct. In the Innovative Learning Environments project it was "specifically focused on the design, implementation and sustainability of innovative, powerful learning environments through distributed, connected activity and relationships of a range of formal and informal leaders throughout a learning system". In relation to the SLO, learning leadership keeps individual, group and collective learning at the heart of daily practice. As such, it is closely aligned to interpretations of leadership for learning (e.g. MacBeath and Townsend, 2011, p. 1246) that do not merely view learning as an outcome, but take a broader, growth-oriented view to encompass professional, leadership and organisation learning, as it "understands the vitality of their interconnections and the climate they create for exploration, inquiry and creativity. Its concern is for all of those who are part of a learning community".

\section{Modelling learning leadership}

In SLOs learning leadership is at the heart of daily practice, and school leaders are, themselves, highlevel knowledge workers. By engaging in appropriate professional learning as "lead learners" (Barth, 2001), and creating the conditions for others to do the same, school leaders model and champion such professionalism throughout the school and beyond the school boundaries (Watkins and Marsick, 1999). Leaders learn from both their students and their teachers (Hallinger and Heck, 2010), as well as the other way around: learning opportunities are mutual and embraced by leaders.

\section{Ensuring the culture, structures and conditions for organisational learning to thrive}

School leaders not only need to provide direct assistance to educational improvement efforts of their staff - spending much of their time on administrative tasks is antithetical to leaders in learning organisations - they also need to create and develop the organisational context which supports and enables such efforts (Leithwood and Louis, 1998; Leithwood, 2012). School leaders have a vital role in establishing a learning culture and for promoting and facilitating continuous organisational learning (e.g. Berkowitz et al., 2013; Senge et al., 2012, Fullan, 2006). They are the nerve centre of school improvement (Fullan, 2006) and responsible for shaping the work and administrative structures to facilitate professional dialogue, collaboration and knowledge exchange which are crucial for promoting organisational learning in schools. They also create a safe and trusting environment in which people can take on new behaviours, take initiative, experiment and realise that it is expected that they challenge the status quo. As such, they are characterised by what Collins (2001) describes as "deep personal humility" and "intense professional will". These findings resonate with those of many SLO scholars including Marsick and Watkins (1999) who note the importance of "leaders who were able to admit when they were wrong and redirect the change effort. They did this in conversation with their employees. ... And most of all they realized that becoming a learning organisation is in the details of daily life - how they interact with their people". This is not to imply that the process is easy and leadership of the SLO also involves "cushioning resistance" (Radivojevic, 2010).

Leaders' ability to create the setting in which trust can develop over time (Senge et al., 1990) is also fundamental so that colleagues will engage in mutual learning. While professional learning communities, and collaboration and collective learning among staff in general, develop leadership throughout the school, this seems in turn to be a result of effective leadership in building such communities (Stoll and Louis, 2007; OECD, 2014). School leaders can set the tone by providing time where possible, encouraging teachers to co-operate with each other to develop new teaching practices and take responsibility for improving their teaching skills, and by ensuring that teachers feel responsible for their students' learning outcomes. By encouraging teachers to learn from one another, school leaders help teachers to keep their teaching methods up-to-date and may also help to develop more collaboration among teachers in their schools (OECD, 2014) and beyond. 


\section{Creative and adaptive change agentry}

Organisational learning means significant change; as with any kind of serious learning, it interrupts and disrupts the status quo. Questioning common practices, taking risks, and avoiding letting rules limit experimentation and innovative practice are key features of learning organisations. But there are many inhibitors to organisational learning; barriers to protect the status quo. These are described as organisational learning disabilities (Senge et al., 1990) or dysfunctional learning habits (Louis, 1994), and often go undetected. Senge argues that they are created as a result of "the way we have all been taught to think and interact (not only in organizations but more broadly)" (p. 18). One example is described as competency traps (Levitt and March, 1988), well-established, reinforced, problematic organisational routines that are difficult to recognise and adjust. Another is organisational defence routines (Argyris and Schön, 1978; Nystrom and Starbuck, 1984), such as accusing an inquirer of being to judgmental or too evaluative when he or she questions the validity and appropriateness of an intervention (Argyris, 1990).

School leaders need to foster their own capacity to challenge these habits and current ways of thinking and operating. They need to be adventurous (MacBeath, 2013) and develop as change agents; a key role for any school leader of a SLO or any other school that wants to reform its educational practices. They have to be adaptive (Heifetz and Linsky, 2002), creative and, where appropriate, courageous (OECD, 2013b). An example in point is the "Lerndesigner", or teacher-leader of Austria's New Secondary School reform (Box 3.10) who, together with the school leader, forms a "dynamic developmental duo" and jointly serves as change agents in their school. The Lerndesigners take on various roles including supporting development of learning and teaching and advising and coaching of staff (OECD, 2015b).

\section{Extending and growing leadership}

This example also shows the daily practice in many schools that leadership to be effective must be spread throughout the organisation. The demands of leadership in the 21 st century are far too extensive for any one person. Because principals' work has become so complex, some of these responsibilities need to be more broadly shared with others, both inside and outside the school (Schleicher, 2012). Leadership is fundamentally social in nature and interaction is the essence of leadership practice. Leading and managing teaching depends on the interactions of many people to co-produce improved practice (Spillane, 2013). Distributed leadership develops, grows and is sustained through collaboration, team work, and participation in professional learning communities and networks. And importantly research evidence shows that teachers tend to report a greater sense of self-efficacy and more job satisfaction when they are given the opportunity to participate in decision making at school (OECD, 2014).

SLOs therefore have a culture of shared responsibility for school issues, and staff are encouraged to actively participate in decision making. This collective responsibility again mirrors that of professional learning communities. Through school leaders mentoring and coaching those they lead (Watkins and Marsick, 1996) they also prepare them to take on more senior level responsibilities and ensure sustainable leadership through succession. By connecting with other schools (see below), schools can also draw on each other's resources and expertise to grow leaders across their schools, for example shadowing leaders in other schools, paired coaching and mentoring across schools, sharing experiences and expertise, collaborating to lead development of peers in several schools (Matthews et al., 2011).

Developing students' leadership also fits within the SLO. Increasing students' ability to participate in authentic ways in school development decisions and to engage more actively in designing initiatives that address their own interests is a powerful way to improve relevance and outcomes for students (Whitehead, 2009). The Influence and Participation of Children and Young people in their Learning project, supported by the University of Cambridge demonstrated how involvement of students and their teachers together in regional enquiry teams could promote shared leadership (Frost and MacBeath, 2010). This was developed 
more actively in the University's Learning to Lead initiative, working with student project teams and aimed at enabling students to become activists as they exercised leadership around tackling problems and challenges in practical and transformative ways. Involvement in student leadership led to students feeling a stronger sense of commitment to their own learning, strengthening and focusing of their "emerging sense of moral purpose" and enhanced agency, as well as wider benefits to the school and its community, including raising teacher expectations (Frost, 2011).

\section{Connecting strategically and systemically}

In SLOs school leaders are what Fullan (2014) calls "system players" who promote the establishment of strong collaborations with other schools, parents, the community and higher education institutions (see, also, Dimmock, Kwek and Toh, 2013). OECD's comparative review of school leadership suggests that school leaders have an important role in collaborating with other schools or communities around them, or as Fullan (2006) and Hargreaves and Fink (2004) call it "lateral leadership across schools". Schools and their leaders strengthen collaboration, form networks, share resources, and/or work together. These engagements enlarge the scope of leadership beyond the school to the welfare of young people in the city, town or region (Schleicher, 2012). A key challenge is encouraging and engendering others to participate with a network, and mobilising them to work collaboratively, which involves brokering (Hadfield and Chapman, 2009).

Support of policy makers and administrators (superintendents, inspectors, etc.) however is crucial. They give direction to action, encourage professional learning and development, promote innovations and school-to-school collaboration, and help disseminate good practices. Lacking governmental/policy support for collaboration and collective learning in an age of accountability will serve only to perpetuate practitioners' isolation (Schechter, 2008). But if such learning leadership is to be transformative, multilevel chemistry between those in and outside schools is needed (OECD, 2013c).

Research evidence also shows that leaders of the most successful schools in challenging circumstances are typically highly engaged with and trusted by the schools' parents and wider community (Harris et al., 2006). Efforts to improve the performance and wellbeing of socio-economically disadvantaged students increasingly require school leaders to become more involved with other partners beyond the school such as local businesses, sports clubs, faith-based groups and community organisations (OECD, 2010a).

\section{Conclusions}

Building on the theoretical foundation of Watkins' and Marsick's (school as) learning organisation model, and drawing from a multi-disciplinary literature review, this chapter has aimed to provide clarity and a common understanding of the concept school as learning organisation by proposing an integrated model (see below).

\section{Integrated model of the school as learning organisation}

\begin{tabular}{l|l}
\hline SLO dimensions & Elements \\
\hline $\begin{array}{l}\text { Developing a shared } \\
\text { vision centred on the } \\
\text { learning of all students }\end{array}$ & - $\begin{array}{l}\text { A shared and inclusive vision aims to enhance the learning experiences and } \\
\text { outcomes of all students }\end{array}$ \\
& - $\begin{array}{l}\text { The vision focuses on a broad range of learning outcomes, encompasses both } \\
\text { the present and the future, and is inspiring and motivating }\end{array}$ \\
- & Learning and teaching are oriented towards realising the vision \\
- Vision is the outcome of a process involving all staff
\end{tabular}




Creating and
supporting continuous
professional learning
for all staff

Promoting team
learning and
collaboration among all
staff

Establishing a culture of inquiry, exploration and innovation
- $\quad$ Students, parents, the external community and other partners are invited to contribute to the school's vision

- All staff engage in continuous professional learning

- New staff receive induction and mentoring support

- Professional learning is focused on student learning and school goals

- Staff are fully engaged in identifying the aims and priorities for their own professional learning

- Professional learning challenges thinking as part of changing practice

- Professional learning connects work-based learning and external expertise

- Professional learning is based on assessment and feedback

- Time and other resources are provided to support professional learning

- The school's culture promotes and supports professional learning

- $\quad$ Staff learn how to work together as a team

- Collaborative working and collective learning - face-to-face and through ICTs are focused and enhance learning experiences and outcomes of students and/or staff practice

- Staff feel comfortable turning to each other for consultation and advice

- Trust and mutual respect are core values

- Staff reflect together on how to make their own learning more powerful

- The school allocates time and other resources for collaborative working and collective learning

- $\quad$ Staff want and dare to experiment and innovate in their practice

- The school supports and recognises staff for taking initiative and risks

- Staff engage in forms of inquiry to investigate and extend their practice

- Inquiry is used to establish and maintain a rhythm of learning, change and innovation

- $\quad$ Staff have open minds towards doing things differently

- Problems and mistakes are seen as opportunities for learning

- Students are actively engaged in inquiry

- $\quad$ Systems are in place to examine progress and gaps between current and expected impact

collecting and exchanging knowledge and learning

Learning with and from the external environment and larger system
- Examples of practice - good and bad - are made available to all staff to analyse

- Sources of research evidence are readily available and easily accessed

- Structures for regular dialogue and knowledge exchange are in place

- Staff have the capacity to analyse and use multiple sources of data for feedback, including through ICT, to inform teaching and allocate resources

- The school development plan is evidence-informed, based on learning from selfassessment, and updated regularly them as necessary

- The school evaluates the impact of professional learning

- The school scans its external environment to respond quickly to challenges and opportunities

- The school is an open system, welcoming approaches from potential external collaborators

- Partnerships are based on equality of relationships and opportunities for mutual learning

- The school collaborates with parents/guardians and the community as partners in
- The school regularly evaluates its theories of action, amending and updating 


\begin{tabular}{|c|c|}
\hline & $\begin{array}{l}\text { the education process and the organisation of the school } \\
\text { Staff collaborate, learn and exchange knowledge with peers in other schools } \\
\text { through networks and/or school-to-school collaborations } \\
\text { - The school partners with higher education institutions, businesses, and/or public } \\
\text { or non-governmental organisations in efforts to deepen and extend learning } \\
\text { ICT is widely used to facilitate communication, knowledge exchange and } \\
\text { collaboration with the external environment }\end{array}$ \\
\hline $\begin{array}{l}\text { Modelling and growing } \\
\text { learning leadership }\end{array}$ & $\begin{array}{l}\text { - School leaders model learning leadership, distribute leadership and help grow } \\
\text { other leaders, including students } \\
\text { - School leaders are proactive and creative change agents } \\
\text { - School leaders develop the culture, structures and conditions to facilitate } \\
\text { professional dialogue, collaboration and knowledge exchange } \\
\text { - School leaders ensure that the organisation's actions are consistent with its } \\
\text { vision, goals and values } \\
\text { - School leaders ensure the school is characterised by a 'rhythm' of learning, } \\
\text { change and innovation } \\
\text { - School leaders promote and participate in strong collaboration with other schools, } \\
\text { parents, the community, higher education institutions and other partners } \\
\text { School leaders ensure an integrated approach to responding to students' learning } \\
\text { and other needs }\end{array}$ \\
\hline
\end{tabular}

The integrated model defines a school as a learning organisation as one in which the collective endeavour is focused on:

- developing and sharing a vision centred on the learning of all students

- creating and supporting continuous learning opportunities for all staff

- promoting team learning and collaboration among all staff

- establishing a culture of inquiry, innovation and exploration

- embedding systems for collecting and exchanging knowledge and learning

- learning with and from the external environment and larger learning system

- modelling and growing learning leadership.

As a consequence of this collective endeavour, a school as a learning organisation has the capacity to change and adapt routinely to new environments and circumstances as its members, individually and together, learn their way to realising their vision.

But a school does not transform into a SLO on its own. Rather it needs the right conditions and support to make this transformation. As we have indicated, time, money and other resources, including engagement in networked learning and collaboration across school boundaries, are essential for making this happen. In some countries schools have considerable discretion over such resources while in others school boards, local or higher levels of government play a more prominent role. Also, schools are not equal in terms of their resources and capacity to use these effectively. This argues for facilitating government policies and support structures that are sensitive to local and school differences if SLOs are to blossom and thrive. What is required in terms of governance and support structures, including the change and innovation capacity of leaders at other levels of the system, is not yet well understood. These are important questions deserving research attention. 
Also how schools can transform themselves into learning organisations merits further research. This paper should be seen as our first attempt to respond to this research question. It has set out to clarify the concept of a school as a learning organisation. The presented model and the set of indicators of the to be developed schools as learning organisations assessment (preliminary name) are intended to provide practical guidance on how schools can transform themselves into a learning organisation. Our starting hypothesis is that the seven action-oriented dimensions of the SLO model together add up to a sustainable learning organisation - successfully realising all seven dimensions is greater than the sum of the parts. Analysis of indicators in the second phase of the project will enable these issues to be further explored and refinement of the integrated SLO model. 


\section{REFERENCES}

Abdul-Haqq, I. (1998), Professional development schools: Weighing the evidence, Corwin, Thousand Oaks.

Ainscow, M. et al. (2016), "Using collaborative inquiry to foster equity within school systems: Opportunities and barriers", School Effectiveness and School Improvement, Vol. 27/1, pp. 7-23.

Australian Institute for Teaching and School Leadership (AITSL) (2012), Australian Charter for the Professional Learning of Teachers and School Leaders: a shared responsibility and commitment, AITSL, Melbourne.

Akram, M., K.E. Watkins and S.A. Sajid (2013), "Comparing the Learning Culture of High and Low Performing High Schools in Pakistan", Literacy Information and Computer Education Journal, Vol. 4/2, pp. 1022-1028.

Alavi, S. and J. McCormick (2004), "A cross-cultural analysis of the effectiveness of the learning organization model in school contexts", International Journal of Educational Management, Vol. 18/7, pp. 408-416.

Argyris, C. (1990), Overcoming Organizational Defenses. Facilitating Organizational Learning, Allyn and Bacon, Boston.

Argyris, C. and D. Schön (1978), Organisational Learning: A Theory of Action Perspective, Mass, Addison Wesley, Reading.

Ariffin, T.F.T., R.A. Hashim and K.K. Yahya (2010), "Modelling the Relationships between Personality Factors, Perceptions of the School as a Learning Organisation and Workplace Learning of School Teachers", MJLI, Vol. 7, pp. 15-35.

Aron, I. (2000), Becoming a Congregation of Learners: Learning as a Key to Revitalizing Congregational Life, Jewish Lights Publishing, Woodstock, VT.

Astley, W.G. and R.F. Zammuto (1992), "Organization science, managers and language games", Organisational Science, Vol. 3/4, pp. 443-460.

Avvisati, F. et al. (2013), "Review of the Italian Strategy for Digital Schools", OECD Education Working Papers, No. 90, OECD Publishing, Paris, http://dx.doi.org/10.1787/5k487ntdbr44-en.

Bacharach, S. (1989), "Organizational Theories: Some Criteria for Evaluation", The Academy of Management Review, Vol. 14/4, pp. 496-515.

Barrados, M. and J. Mayne (2003), “Can Public Sector Organisations Learn?”, OECD Journal On Budgeting, Vol. 3/3, pp. 87-136.

Barth, R.S. (2001), Learning by heart, Jossey-Bass, San Francisco.

Baser, H. and P. Morgan (2008), "Capacity, Change and Performance: Study Report", Discussion Paper, No. 59B, European Centre for Development Policy Management, Maastricht. 
Bass, B. (1985), Leadership and Performance Beyond Expectations, The Free Press, New York.

Bateson, G. (1958), Naven: A survey of the problems suggested by a composite picture of the culture of a New Guinea tribe drawn from three points of view, Stanford University Press, Standford.

Beaver, J.K. and E.H. Weinbaum (2012), "Measuring School Capacity, Maximizing School Improvement", CPRE Policy Briefs, Consortium for Policy Research in Education, Philadelphia.

Benard, B. (1995), Fostering Resilience in Children, ERIC Clearinghouse on Elementary and Early Childhood Education, Urbana.

Benjamin, D. (2009), "The School as Learning Organization: Validation of the DLOQ with School Staff", PhD Thesis, Alfred University, Alfred, http://gradworks.umi.com/34/33/3433910.html.

Berkowitz, R. et al. (2013), "A Cross-Cultural Validity Study of the School Success Profile Learning Organization Measure in Israel", Children \& Schools, Vol. 35/3, pp. 137-146.

Biggs, J. (1985), "The role of metalearning in study process", British Journal of Educational Psychology, Vol 55/3, pp. 185-212.

Birnbaum, R. (1988), How Colleges Work. The Cybernetics of Academic Organisation and Leadership, Jossey-Bass Publishers, San Francisco.

Blanchenay, P., T. Burns and F. Köster (2014), "Shifting Responsibilities - 20 years of Education Devolution in Sweden: A Governing Complex Education Systems Case Study", OECD Education Working Papers, No. 104, OECD Publishing, Paris, http://dx.doi.org/10.1787/5jz2jg1rqrd7-en.

Bowen, G.L., R.A. Rose and W.B. Ware (2006), "The Reliability and Validity of the School Success Profile Learning Organization Measure", Evaluation and Program Planning, Vol. 29, pp. 97-104.

Bowen, G.L., R.A. Rose and N.K. Bowen (2005), The reliability and validity of the School Success Profile, Xlibris Press, Philadelphia.

Boyle, D. and M. Harris (2009), The challenge of co-production: How equal partnerships between professionals and the public are crucial to improving public services, Nesta, London.

Bransford, J.D., A.L. Brown and R.R. Cocking (2000), How people learn: brain, mind, experience, and school, National Academy Press, Washington.

Brandt, J. (2003), "Is this school a learning organization? 10 ways to tell", Journal of Staff Development, Vol. 24/1, pp. 10-16.

Brasco, S. (2008), The relationship between learning organization principles and student achievement in Catholic schools, Florida Atlantic University, Boca Raton.

Brown, C. (2015), Leading the use of research \& evidence in schools, Institute of Education Press, London.

Brown, J.S. and P. Duguid (1998), “Organizing Knowledge”, California Management Review, Vol. 40/3, pp. 90-111. 
Bryk, A.S. and B. Schneider (2002), Trust in schools: A core resource for school improvement, Russell Sage, New York.

Burns, J. (1978), Leadership, Harper and Row, New York.

Butler, R. (1991), Designing organizations. A decision making perspective, Routledge, London.

Cahn, E. (2000), No more throw away people: the co-production imperative, Essential Books, Washington.

Caldwell, R. (2010), Leadership and Learning: A Critical Reexamination of Senge's Learning Organization, Springer, London.

Caldwell, B. and J. Spinks (1992), Leading the Self-Managing School, Falmer Press, Taylor and Francis Inc., Bristol.

Cannon, M.D. and A.C. Edmondson (2005), "Failing to learning and learning to fain (effectively): How great organisations put failure to work to improve and innovate", Long Range Planning, Vol. 38, pp. 299-319.

Castro, M. et al. (2015), "Parental involvement on student academic achievement: a meta-analysis", Educational Research Review, Vol. 14, pp. 33-46.

Cerna, L. (2014), "Trust: what it is and why it matters for governance and education", OECD Education Working Papers, No. 108, OECD Publishing, Paris, http://dx.doi.org/10.1787/5jxswcg0t6wl-en.

Chapman, C. et al. (2016), The Routledge International Handbook of Educational Effectiveness and Improvement: Research, Policy and Practice, Routledge, Abingdon, Oxford.

Clarke, P. (2000), Learning Schools, Learning Systems, Bloomsbury, London.

Clay, E.J. and B.B. Schaffer (1984), Room for manoeuvre: an exploration of public policy in agricultural and rural development, Heinemann Educational Books, London.

Coburn, C.E., M.I. Honig and M.K. Stein (2009), "What is the evidence on districts' use of evidence?", in J.D. Bransford et al., The Role of Research in Educational Improvement, Harvard Education Press, Cambridge, pp. 67-86.

Coburn, C.E. and E.O. Turner (2011), "Research on data use: A framework and analysis", Measurement: Interdisciplinary Research and Perspectives, Vol. 9/4, pp 173-206.

Collins, J. (2001), Good to Great, Collins, New York.

Cooper, C.L. (1998), Theories of Organizational Stress, Oxford University Press, Oxford.

Coppieters, P. (2005), "Turning schools into learning organizations", European Journal of Teacher Education, Vol. 28/2, pp. 129-139.

Daft, R.L. and G.P. Huber (1987), "How organisations learn: a communication framework", Research in Sociology of Organisations, Vol. 5, pp. 1-36. 
Daglio, M., D. Gerson and H. Kitchen (2015), "Building Organisational Capacity for Public Sector Innovation", OECD Conference 'Innovating the Public Sector: from Ideas to Impact', Paris, 12-13 November 2014.

Darling-Hammond, L., M.B. Zielezinski and S. Goldman (2014), Using Technology to Support At-Risk Students' Learning, Alliance for Excellent Education, Washington.

Darling-Hammond, L. et al. (2009), Professional Learning in the Learning Profession: A Status Report on Teacher Development in the U.S. and Abroad, National Staff Development Council, Dallas.

David, J.L. (1981), "Local uses of Title I evaluations", Educational Evaluation and Policy Analysis, Vol. 3/1, pp. 27-39.

Davidoff, S. and S. Lazarus (2002), The Learning School: an Organisation Development Approach, Juta and Company Ltd, Johannesburg.

Delors, J. (1996), Learning: The Treasure Within, Report to UNESCO of the International Commission on Education for the Twenty-first Century, UNESCO Publishing, Paris.

De Vito, J. (1996), "The learning organization", in R. Craig (Eds.), The ASTD training and development handbook, Fourth Edition, McGraw-Hill, New York.

Diggins, P. (1997), "Reflections on Leadership Characteristics Necessary to Develop and Sustain Learning School Communities", School Leadership \& Management: Formerly School Organisation, Vol. 17/3, pp. 413-426.

Dimmock, C., D. Kwek and Y. Toh (2013), "Leadership for 21st century learning in Singapore's highperforming schools", in OECD (2013), Leadership for 21 st Century Learning, Educational Research and Innovation, OECD Publishing, http://dx.doi.org/10.1787/9789264205406-en.

Dodgson, M. (1993), Organizational Learning: A Review of Some Literatures, Science Policy Research Unit, University of Sussex, Brighton.

Drayton, B. and J. Falk (2009), Creating and sustaining online professional learning communities, Teachers College Press, New York.

Driver, M. (2002), "The Learning Organisation: Foucauldian gloom or utopian sunshine?", Human Relations, Vol. 55/1, pp. 33-53.

Du Four, R. (1997), "The school as a learning organization: Recommendations for school improvement", NASSP Bulletin, Vol. 42/58, pp. 81-88.

Du Four, R. et al. (2006), Learning by Doing: A Handbook for Professional, Learning Communities at Work, Solution Tree Press, Bloomington.

Duden, N. (1993), “A Move from Effective to Quality”, School Administrator, Vol. 50/6, pp. 18-21.

Dumont, H., D. Istance and F. Benavides (Eds.) (2010), The Nature of Learning: Using Research to Inspire Practice, Educational Research and Innovation, OECD Publishing, Paris, http://dx.doi.org/10.1787/9789264086487-en. 
Earl, S., F. Carden and T. Smutylo (2001), Outcome Mapping: Building Learning and Reflection into Development Programs, IDRC, Ottawa.

Earl, L. and S. Katz (2006), "How Networked Learning Communities Work", Seminar Series Paper, No. 155, Centre for Strategic Education, Melbourne.

Earl, L. and S. Katz (2002), "Leading schools in a data-rich world", in K. Leithwood and P. Hallinger (Eds.), Second International Handbook of Educational Leadership and Administration, pp. 10031022.

Earl, L. and H. Timperley (2015), "Evaluative thinking for successful educational innovation", OECD Education Working Papers, No. 122, OECD Publishing, Paris, http://dx.doi.org/10.1787/5jrxtk1jtdwf-en.

Earl, L. and H. Timperley (2008), “Understanding how evidence and learning conversations work”, in L. Earl and H. Timperley (Eds.), Professional Learning Conversations: Challenges in Using Evidence for Improvement, Springer, Dordrecht.

Easterby-Smith, M. and L. Araujo (1999), "Current debates and opportunities", in M. Easterby-Smith, L. Araujo and J. Burgoyne (Eds.), Organizational Learning and the Learning Organization, Sage, London.

Easterby-Smith, M., R. Snell and S. Gerhardi (1998), "Organizational learning: Diverging communities of practice?”, Management Learning, Vol. 29/3, pp. 259-272.

Easton, L.B. (2008), "From professional development to professional learning", Phi Delta Kappan, Vol. 89/10, pp. 755-759.

Edmondson, A. (1999), "Psychological safety and learning behavior in work teams", Administrative Science Quarterly, Vol. 44, pp. 350-383.

Edmondson, A.C. (2003), "Speaking up in the operating room: How team leaders promote learning in interdisciplinary action teams", Journal of Management Studies, Vol. 40/6, pp. 1419-1453.

Education Endowment Foundation and the UCL Institute of Education, University of London Research Learning Communities, https://educationendowmentfoundation.org.uk/projects/researchlearning-communities/ and www.lcll.org.uk/research-learning-communities.html (accessed 5 April, 2016).

Education Scotland (2015), "Professional learning", Education Scotland, www.educationscotland.gov.uk/professionallearning/prd/proflearning.asp.

Ehren, M.C.M. et al. (2013), "School inspections and school improvement: Testing assumptions on causal mechanisms", Oxford Review of Education (submitted and under review).

Education Inspectorate of the Netherlands (2015), "Den Haag, Van Ostade School", www.onderwijsinspectie.nl/binaries/content/assets/excellente-scholen/2014-po/ostadeschool-denhaag-juryrapport-2014.pdf.

Fielding, M. (2001), "Students as Radical Agents of Change", Journal of Educational Change, Vol. 2, pp. $123-141$. 
Frome, P.M. and J.S. Eccles (1998), "Parents' Influence on Children's Achievement-Related Perceptions", Journal of Personality and Social Psychology, Vol. 74/2, pp. 435-452.

Frost, D. and J. MacBeath (2010), Learning to lead: An evaluation, University of Cambridge Faculty of Education, Cambridge.

Fullan, M. (2015), The New Meaning of Educational Change, Fifth Edition, Routledge, London.

Fullan, M. and J. Quinn (2015), Coherence: The Right Drivers in Action for Schools, Districts and Systems, Corwin Press and the Ontario Principals' Council, Toronto.

Fullan, M. (2014), Three Keys to Maximizing Impact, Jossey-Bass and Ontario Principal's Council, Toronto.

Fullan, M. (2011), Change Leader: Learning to Do What Matters Most, Jossey-Bass, San Francisco.

Fullan, M. (2006), Quality Leadership, Quality Learning, Co. Cork, Glounthaune.

Fullan, M. (2003), The Moral Imperative of School Leadership, Corwin Press and Ontario Principals' Council, Thousand Oaks.

Fullan, M. (2001), The New Meaning of Educational Change, Third Edition, Teachers College Press, New York.

Fullan, M. (2000), “The return of large-scale reform”, Journal of Educational Change, Vol. 1/1, pp. 5-28.

Fullan, M. (1999), Changing Forces: The Sequel, Falmer Press, London.

Fullan, M. (1995), "The school as a learning organization: Distant dreams", Theory Into Practice, Vol. 34/4, pp. 230-235.

Fullan, M. (1993), Change Forces: Probing the Depths of Educational Reform, Falmer Press, London, Levittown.

Fullan, M., C. Cuttress and A. Kilcher (2005), "Eight Forces for Leaders of Change", Journal of Staff Development, Vol. 26/4, pp. 54-64.

Fullan, M., S. Rincón-Gallardo and A. Hargreaves (2015), "Professional Capital as Accountability", Education Policy Analysis Archives, Vol. 23/15, pp. 1-18.

Gandolfi, F. (2006), "Can a School Organization be Transformed into a Learning Organization?", Contemporary Management Research, Vol. 2/1, pp. 57-72.

Garratt, B. (1987), "Learning is the Core of Organisational Survival: Action Learning is the Key Integrating Process", Journal of Management Development, Vol. 6/2, pp. 38-44.

Garvin, D.A. (1993), "Building a learning organization”, Harvard Business Review, Vol. 71/4, pp, 78-91.

General Teaching Council Scotland (2012), The Standard for Career-long Professional Learning: supporting the development of teacher professional learning, GTCS, Edinburgh. 
Gephart, M.A. et al. (1996), "Learning organizations come alive", Training \& Development, Vol. 50/12, pp. 34-36.

Ghahramanifard, K., J. Pashaei and H. Mehmandoust (2013), "The study of learning high schools based on "Peter M. Senge" learning", IOSR Journal Of Humanities And Social Science, Vol. 13/5, pp. 81-84.

Giles, C. and A. Hargreaves (2006), "The Sustainability of Innovative Schools as Learning Organizations and Professional Learning Communities During Standardized Reform", Educational Administration Quarterly, Vol. 42/1, pp. 124-156.

Goh, S.C. (1998), "Towards a learning organisation: The strategic building blocks", SAM Advanced Management Journal, Vol. 63/2, pp. 15-22.

Goodlad, J.I. (1994), Educational renewal: Better teachers, better schools, Jossey-Bass, San Francisco.

Gronhaug, K. and R. Stone (2012), "The learning organisation: A historical perspective, the learning process, and its influence on competitiveness", The Learning Organisation, Vol. 22/3, pp. 261-275.

Gunter, H. (1996), “Appraisal and the School as a Learning Organisation”, School Organisation, Vol. 16/1, pp. 89-100.

Guskey, T.R. (2001), “The backward approach”, Journal of Staff Development, Vol. 22/3, p. 60.

Hadfield, M. and C. Chapman (2009), "School Based Networking for Educational Change", Second International Handbook of Educational Change, Springer, London.

Halbert, J. and L. Kaser (2013), Spirals of Inquiry for Equity and Quality, BCPVPA Press, Vancouver.

Hallinger, P. and R.H. Heck (2010), "Collaborative leadership and school improvement: Understanding the impact on school capacity and student learning", School Leadership \& Management, Vol. 30/2, pp. 95-110.

Hallsworth, M., S. Parker and J. Rutter (2011), Policy making in the real world, Institute for Government, London.

Hamilton, L. and K. Pepper (2002), "Making a Change: The Effects of the Leadership Role on School Climate, Learning Environments Research, Vol. 5/2, pp. 155-166.

Hamzah, M.I.M. et al. (2011), "School as Learning Organisation: The Role of Principal's Transformational Leadership in Promoting Teacher Engagement", World Applied Sciences Journal, Vol. 14, pp. 58-63.

Handy, C. (1991), The Age of Unreason, Arrow Books, London.

Hannon, V. (2007), 'Next practice' in education, Innovation Unit, London.

Hargreaves, A. (2007), "Sustainable Leadership and Development in Education: creating the future, conserving the past", European Journal of Education, Vol. 42/2, pp. 223-233.

Hargreaves, A. and D. Fink (2004), "The Seven Principles of Sustainable Leadership", Educational Leadership, Vol. 61/7, pp. 8-13. 
Hargreaves, A. (2003), Teaching in the Knowledge Society: Education in the Age of Insecurity, Teachers' College Press, New York and Open University Press, Buckingham.

Hargreaves, A. and M. Fullan (2012), Professional Capital: Transforming Teaching in Every School, Teachers College Press, New York.

Hargreaves, A. and D. Shirley (2009), The Fourth Way: The Inspiring Future for Educational Change, Boston College, Boston.

Harris, A. et al. (2006), "Improving Schools in Challenging Contexts: Exploring the Possible", School Effectiveness and School Improvement, Vol. 17/4, pp. 409-425.

Harris, M. and F. van Tassell (2005), "The professional development school as learning organization", European Journal of Teacher Education, Vol. 28/2, pp. 179-194.

Hattie, J. (2012), Visible Learning for Teachers: Maximizing Impact on Learning, Routledge, London.

Hattie, J. (2009), Visible Learning: A Synthesis of Over 800 Meta-analysis Relating to Achievement, Routledge, London.

Hattie, J. and H. Timperley (2007), “The power of feedback”, Review of Educational Research, Vol. 77, pp. 81-112.

Heifetz, R.A. and M. Linsky (2002), Leadership on the Line: Staying Alive through the Dangers of Leading, Harvard Business School Press, Boston.

Hiatt-Michael, D.B. (2001), "Schools as learning communities: A vision for organic school reform", School Community Journal, Vol. 11, pp. 113-127.

Higgins, M. et al. (2012), "Examining Organizational Learning in Schools: The Role of Psychological Safety, Experimentation, and Leadership that Reinforces Learning", Journal of Educational Change, Vol. 13/1, pp. 67-94.

Higgins, S. et al. (2015), Developing great teaching: lessons from the international reviews into effective professional development, Teacher Development Trust, London.

Hill, H.C., M. Beisiegel and R. Jacob (2013), "Professional Development Research Consensus, Crossroads, and Challenges", Educational Researcher, Vol. 42/9, pp. 476-487.

Hills, P. and M. Argyle (2001), "Emotional stability as a major dimension of happiness", Personality and Individual Differences, Vol. 31, pp. 1357-1364.

Holloway, J. (2001), “The benefits of mentoring”, Educational Leadership, Vol. 58/8, pp. 85-86.

Ho Park, Y. (2008), "Validation of Senge's Learning Organization Model with Teachers of Vocational High Schools at the Seoul Megalopolis", Asia Pacific Education Review, Vol. 9/3, pp. 270-284.

Ho Park, Y. (2006), "Measurement and Validation of Senge's Leaning Organisation Model in Korean Vocational High Schools", Doctoral dissertation, Graduate Faculty of The University of Georgia, Athens. 
Hopfenbeck, T. et al. (2013), "Balancing Trust and Accountability? The Assessment for Learning Programme in Norway: A Governing Complex Education Systems Case Study", OECD Education Working Papers, No. 97, OECD Publishing, Paris, http://dx.doi.org/10.1787/5k3txnpqlsnn-en.

Hopson, L.M. and L.K.H. Steiker (2008), "Methodology for Evaluating and Adaptation of Evidence-Based Drug Abuse Prevention in Alternative Schools", Children \& Schools, Vol. 30/1, pp. 116-127.

Huber, G.P. (2011), “Organizations: Theory, Design, Future”, in S. Zedeck (Eds.), American Psychological Association Handbook of Industrial and Organizational Psychology, American Psychological Association, Washington.

Husband, R.E. and P.A. Short (1994), Middle school interdisciplinary teams: An avenue to greater teacher empowerment, Pennsylvania State University, College Park.

Istance, D. and M. Kools (2013), "OECD Work on Technology and Education: Innovative learning environments as an integrative framework", European Journal of Education, Vol. 48/1, pp. 43-57.

Jafari, P. and M. Kalanaki (2012), "Relationships between the dimensions of learning organizations and readiness-to-change", Procedia - Social and Behavioural Sciences, Vol. 46, pp. 5811-5815.

James, C. et al. (2006), How Very Effective Primary Schools Work, Paul Chapman, London.

Jimerson, J.B. (2014), "Thinking about data: Exploring the development of mental models for "data use" among teachers and school leaders", Studies in Educational Evaluation, Vol. 42, pp. 5-14.

Johnson, S.M. (1990), Teachers at Work: Achieving Success in Our Schools, Basic Books, New York.

Johnston, C. and B. Caldwell (2001), "Leadership and organisational learning in the quest for world class schools”, International Journal of Educational Management, Vol. 15/2, pp. 94-103.

Joyce, B. et al. (1999), The New Structure of School Improvement, Open University Press, Buckingham

Kampylis, P., Y. Punie and J. Devine (2015), Promoting effective digital age learning. A European Framework for Digitally-Competent Educational Organisations, JRC-IPTS, Seville, http://publications.jrc.ec.europa.eu/repository/bitstream/JRC98209/jrc98209_r_digcomporg_final.pd f.

Kampylis, P., N. Law and Y. Punie (Eds.) (2013), ICT-enabled innovation for learning in Europe and Asia: Exploring conditions for sustainability, scalability and impact at system level, Publications Office of the European Union, Luxembourg, http://ipts.jrc.ec.europa.eu/publications/pub.cfm?id=6362.

Katz, S. and L. Dack (2013), Intentional interruption: Breaking down learning barriers to transform professional practice, Corwin, Thousand Oaks.

Keating, D. (1996), "Habits of mind for a learning society: educating for human development", in D. Olsen and N. Torrance (Eds.), The Handbook of Education and Human Development, Blackwell, Cambridge.

Keefe, J. and E. Howard (1997), “The School as a Learning Organization”, NASSP Bulletin, Vol. 81/589, pp. 35-44. 
Kelchtermans, G. (2004), "CPD for professional renewal: moving beyond knowledge for practice", in C. Day and J. Sachs (Eds.), International Handbook on the Continuing Professional Development of Teachers, Open University Press, Maidenhead.

Kerka, S. (1995), The Learning Organization. Myths and Realities, Office of Educational Research and Improvement, Washington.

Khan, Z.W., M. Tanveer and I. Saleem (2013), “Analyzing Learning Environment: A Comparative Study of Public and Private Sector Schools of Pakistan", International Journal of Management \& Organizational Studies, Vol. 2/1, pp. 49-54.

King, M.B. and F.M. Newmann (2001), "Building school capacity through professional development: conceptual and empirical considerations", International Journal of Educational Management, Vol. 15/2, pp. 86-93.

Kirkham, G. (2005), "Leading and achieving a learning school through developing middle leaders", European Journal of Teacher Education, Vol. 28/2, pp. 151-163.

Kruse, S.D. (2003), "Remembering as organizational memory", Journal of Educational Administration, Vol. 41/4, pp. 332-347.

Kruse, S., K.L. Louis and A. Bryk (1995), "Let's build teacher's professional community", WCER Highlights, www.wcer.wisc.edu/publications/WCER Highlights/Vol.7 No.1 Spring 1995/Teachers prof com munity.html (accessed 1, May 2011).

Kruse, S.D., K.S. Louis and A.S. Bryk (1995), "An emerging framework for analyzing school-based professional community", in K.S. Louis and S.D. Kruse \& Associates, Professionalism and Community: Perspectives on Reforming Urban Schools, Corwin, Long Oaks.

Kuijpers, B.S. et al. (2013), "Managing change in public organizations: A review of the literature between 2000 and 2010", Public Administration, Vol. 92/1, pp. 1-20.

Lambert, N.M. and B.L. McCombs (1998), How Students Learn: Reforming Schools Through LearnerCentred Education, American Psychological Association, Washington.

Lave, J. and S. Chaiklin (1993), Understanding Practice: Perspectives on Activity and Context, Cambridge University Press, Cambridge.

Lave, J. and E. Wenger (1991), Situated Learning: Legitimate Peripheral Participation, Cambridge University Press, Cambridge.

Learning Forward (2011), Standards for Professional Learning, Learning Forward, Oxford.

Leithwood, K. (2012), The Ontario Leadership Framework 2012 with a Discussion of the Research Foundations, The Institute for Educational Leadership, Ontario, http://iel.immix.ca/storage/6/1345688978/Final_Research_Report_-_EN.pdf.

Leithwood, K., D. Jantzi and R. Steinbach (1998), "Leadership and other conditions which foster organizational learning in schools", in K. Leithwood and K.S. Louise (Eds.), Organizational Learning in Schools, Swets \& Zeitlinger, Lisse. 
Leithwood, K. and K.S. Louis (1998), Organizational Learning in Schools, Swets \& Zeitlinger, Lisse.

Leithwood, K., L. Leonard and L. Sharratt (1998), "Conditions for Organizational Learning in Schools", Educational Administration Quarterly, Vol. 34/2, pp. 243-276.

Leithwood, K.A. and C. Reihl (2003), What We Know About Successful Leadership, National College for Educational Leadership, http://dcbsimpson.com/randd-leithwood-successful-leadership.pdf.

Levitt, B. and J.G. March (1988), “Organizational learning”, Annual Review of Sociology, Vol. 14, pp. 319-340.

Lipman, M. (1991), Thinking in Education, Cambridge University Press, Cambridge.

Lipshitz, R., M. Popper and S. Oz (1996), "Building learning organization: the design and implementation of organizational learning mechanisms", Journal of Applied Behavioral Science, Vol. 32/3, pp. 292-305.

Little, J.W. (1990), "The mentor phenomenon and the social organization of teaching", Review of Research in Education, Vol. 16, pp. 297-351.

Louis, K.S. (2007), “Trust and improvement in schools", Journal of Educational Change, Vol. 8/1, pp. $1-24$.

Louis, K.S. (1994), "Beyond 'managed change': rethinking how schools improve", School Effectiveness and School Improvement, Vol. 5/1, pp. 2-24.

Louis, K.S. (2008), "Creating and sustaining professional communities", in A.M. Blankstein (Eds.), Sustaining Professional Learning Communities, Corwin Press, Thousand Oaks.

Louis, K.S., S. Kruse and A.S. Bryk (1995), "Professionalism and community: what is it and why is it important in urban schools?" in K.S. Louis, S. Kruse and Associates (1995), Professionalism and Community: Perspectives on Reforming Urban Schools, Corwin, Long Oaks.

Louis, K.S and K. Leithwood (1998), "From organizational learning to professional learning communities", in K. Leithwood and K.S. Louis (Eds.), Organizational Learning in Schools, Swets \& Zeitlinger, Lisse.

Ludvingsen, S. (2015), "The School of the Future - Renewal of subjects and competences", Official Norwegian Report NOU 2015:8, www.regjeringen.no/contentassets/da148fec8c4a4ab88daa8b677a700292/en$\mathrm{gb} / \mathrm{pdfs} /$ nou201520150008000engpdfs.pdf.

Lunenburg, F.C. (2011), "Self-Efficacy in the Workplace: Implications for Motivation and Performance, International", Journal of Management, Business and Administration, Vol. 14, pp. 1-22.

MacBeath, J. (2013), "Leading learning in a world of change", in OECD (2013), Leadership for 21st Century Learning, Educational Research and Innovation, OECD Publishing, http://dx.doi.org/10.1787/9789264205406-en.

MacBeath J. and T. Townsend (2011), International Handbook of Leadership for Learning, Springer, Dordrecht. 
MacBeath, J. and N. Dempster (2008), Connecting Leadership and Learning: Principles for Practice, Routledge, London.

March, J.G. (1991), "Exploration and exploitation in organizational learning", Organization Science, Vol. 2/1, pp. 71-87.

Marks, H., K.S. Louis and S. Printy (2002), "The capacity for organizational learning: implications for pedagogy and student achievement", in K. Leithwood (Eds.), Organizational Learning and School Improvement, JAI Press, Greenwhich.

Marsick, V.J. and K.E. Watkins (2003), "Making Learn Count! Diagnosing the Learning Culture in Organizations", Advances in Developing Human Resources, Vol. 5/2, Sage, Thousand Oaks.

Marzano, R.J., T. Waters and B.A. McNulty (2005), School leadership that works: From research to results, Association for Supervision and Curriculum Development (ASCD), Alexandria.

Masten, A.S. and A. Tellegen (2012), "Resilience in developmental psychopathology: Contributions of the Project Competence Longitudinal Study", Development and Psychopathology, Vol. 24, pp. 345-361.

Matthews, P. et al. (2011), Prepared to lead: how schools, federations and chains grow education leaders, National College for School Leadership, Nottingham.

McCharen, B., J. Song and J. Martens (2011), "School innovation: The mutual Impacts of Organizational learning and Creativity", Educational Management Administration \& Leadership, Vol. 39, pp. 676-694.

McClelland, D.C. and D.H. Burnham (1995), "Power is the great motivator", Harvard Business Review, January/February 1995.

McHugh, D., D. Groves and A. Alker (1998), "Managing learning: What do we learn from a learning organization?", The Learning Organization, Vol. 5/5, pp. 1-14.

McMillan, E. and Y. Carlise (2007), "Strategy as Order Emerging from Chaos: A Public Sector Experience”, Long Range Planning, Vol. 40, pp. 574-593.

Middlewood, D. et al. (2005), Creating a Learning School, Sage Publications, London.

Millet, B. (1998), "The Dominance of Systems Theory", International Journal of Organisational Behaviour, Vol. 1/1, pp. 1-12.

Mitchell, C. and L. Sackney (2000), Profound Improvement: Building Capacity for a Learning Community, Swets \& Zeitlinger, Lisse.

Ministry of Education, Culture and Science of the Netherlands (MoECS) (2014), Progress report Teacher's Agenda 2013-2020 [Voortgangsrapportage Lerarenagenda 2013-2020], MoECS, www.rijksoverheid.nl/binaries/rijksoverheid/documenten/kamerstukken/2014/10/08/kamerbriefvoortgangsrapportage-lerarenagenda/kamerbrief-voortgangsrapportage-lerarenagenda.pdf.

Moilanen, R. (2005), "Diagnosing and measuring learning organisations", Learning Organisations, Vol. 12/1, pp. 71-89. 
Moloi, K.C. (2010), "How can schools build learning organisations in difficult education contexts?", South African Journal of Education, Vol. 30/1, pp. 621-633.

Moloi, K.C., B. Grobler and S. Gravett (2006), "Educators' perceptions of the school as a learning organization in the Vanderbijlpark-North District, South Africa", South African Journal of Education, Vol. 22/2, pp. 88-94.

Moraga, E. (2006), "Cultural Learning Organisations: A management and organisational model", www.culturallearningorganizations.net/.

Muijs, D. et al. (2014), "State of the art - teacher effectiveness and professional learning", School Effectiveness and School Improvement, Vol. 25/2, pp. 231-256.

Mulford, B. (2002), "Balance and learning: Crucial elements in leadership for democratic schools", Commonwealth Council for Educational Administration and Management Conference, Umea, Sweden, September 2002.

Mulford, B. (2005), Leadership for school and student learning - what do we know?, NCSL, Nottingham.

Nakpodia, E.D. (2009), "The concept of the university as learning organization: Its functions, techniques and possible ways of making it effective", Journal of Public Administration and Policy Research, Vol. 1/5, pp. 79-83.

Nazari, K. and Z. Akmaliah Lope Pihie (2012), "Assessing Learning Organization Dimensions and Demographic Factors in Technical and Vocational Colleges in Iran", International Journal of Business and Social Science, Vol. 3/3, pp. 210-219.

Newmann, F., M. King and P. Youngs (2000), "Professional development that addresses school capacity: Lessons from urban schools", American Journal of Education, Vol. 108/4, pp. 259-299.

Niroo, M., M. Haghani and G. Haji HosseinNejhad (2013), "Learning School and Readiness for Change", International Journal of Management Perspective, Vol. 1/3, pp. 15-22.

Nixon, J. et al. (1996), Encouraging Learning: Towards a Theory of the Learning School, Open University Press, Bristol.

Nonaka, I. and R. Toyama (2000), "SECI, Ba and Leadership: a Unified Model of Dynamic Knowledge Creation", Long Range Planning, Vol. 33, pp. 5-34.

Nonaka, I. and H. Takeuchi (1995), The Knowledge-Creating Company, Oxford University Press, New York.

Nutley, S.M, H.T.O. Davies and P.C. Smith, (2000), What works? Evidence-based policy and practice in public services, Policy Press, Bristol.

Nystrom, P.C. and W.H. Starbuck (1984), “To avoid organizational crises, unlearn”, Organizational Dynamics, Vol. 12/4, pp. 53-65.

O'Connor, J. and I. McDermott (1997), The art of system thinking. Essential skills for creativity and problem-solving, Thorsons, London. 
O'Day, J., M.E. Goertz and R.E. Floden (1995), "Building Capacity for Education Reform”, CPRE Policy Briefs, Consortium for Policy Research in Education, www.cpre.org/sites/default/files/policybrief/859_rb18.pdf.

OECD/CERI Governing Complex Education Systems project (GCES) (2012), "Getting it Right: Capacity Building for Local Stakeholders in Education", Effective Governance on the Local Level Conference, 16-17 April, 2012.

OECD (2015a), Schooling Redesigned: Towards Innovative Learning Systems, Educational Research and Innovation, OECD Publishing, Paris, http://dx.doi.org/10.1787/9789264245914en.

OECD (2015b), Integrating Social Services for Vulnerable Groups: Bridging Sectors for Better Service Delivery, OECD Publishing, Paris, http://dx.doi.org/10.1787/9789264233775-en.

OECD (2014), Talis 2013 Results: An International Perspective on Teaching and Learning, TALIS, OECD Publishing, Paris, http://dx.doi.org/10.1787/9789264196261-en.

OECD (2013a), Innovative Learning Environments, Educational Research and Innovation, OECD Publishing, Paris, http://dx.doi.org/10.1787/9789264203488-en.

OECD (2013b), PISA 2012 Results: Excellence Through Equity: Giving Every Student the Chance to Succeed (Volume II), PISA, OECD Publishing, Paris, http://dx.doi.org/10.1787/9789264201132-en.

OECD (2013c), Leadership for 21st Century Learning, Educational Research and Innovation, OECD Publishing, Paris, http://dx.doi.org/10.1787/9789264205406-en.

OECD (2010a), Innovative Workplaces: Making Better Use of Skills within Organisations, OECD Publishing, Paris, http://dx.doi.org/10.1787/9789264095687-en.

OECD (2010b), Strong Performers and Successful Reformers in Education: Lessons from PISA for the United States, OECD Publishing, Paris, http://dx.doi.org/10.1787/9789264096660-en.

OECD (2009), Doing Better for Children, OECD Publishing, Paris.

OECD (2005), Teachers Matter: Attracting, developing and retaining effective teachers, OECD Publishing, Paris, http://dx.doi.org/10.1787/9789264018044-en.

Östrom, E. and W.H. Baugh (1973), Community organization and the provision of police services, SAGE, Beverly Hills.

Örtenblad, A. (2004), "The learning organization: towards an integrated model", The Learning Organization, Vol. 11/2, pp. 129-144.

Örtenblad, A. (2002), "A Typology of the idea of Learning Organization", Management Learning, Vol. 33/2, pp. 213-230.

Paavola, S., L. Lipponen and K. Hakkarainen (2004), "Models of innovative knowledge communities and three metaphors of learning", Review of Educational Research, Vol. 74/4, pp. 557-576.

Paletta, A. (2011), "Managing Student Learning: Schools as Multipliers of Intangible Resources", Educational Management Administration Leadership, Vol. 39/6, pp. 733-750. 
Park, J. (2008), "Validation of Senge's Learning Organization Model with Teachers of Vocational High Schools at the Seoul Megalopolis", Asia Pacific Education Review, Vol. 9/3, pp. 270-284.

Patton, M.Q. (2011), Developmental Evaluation: Applying Complexity to Enhance Innovation and Use, Guilford Press, New York.

Pedler, M., T. Boydell and J.G. Burgoyne (1989), "Towards the learning company", Management Education and Development, Vol. 20/1, pp. 1-8.

Pedler, M. (1995), “A guide to the learning organisation”, Industrial and Commercial Training, Vol. 27/4, pp. 21-25.

Pedler, M. et al. (1991), The Learning Company. A Strategy for Sustainable Development, Mc Graw-Hill, London.

Phillips, B.T. (2003), "A four-level learning organisation benchmark implementation model", The Learning Organization, Vol. 10/2, pp. 98-105.

Pilai, R., C.A. Schriesheim and E.S. Williams (1999), "Fairness Perceptions and Trust as Mediators for Transformational and Transactional Leadership: A Two-Sample Study", Journal of Management, Vol. 25/6, pp. 897-933.

Popper, M. and R. Lipshitz (2000), "Installing mechanisms and instilling values: the role of leadership in organisational learning", The Learning Organisation, Vol. 7/3, pp. 135-144.

Portfeld, I.S. (2006), The University; A Learning Organization? An Illuminative Review Based on System Theory, Karlstad University Studies, Karlstad.

Pui-wah, D.C. (2008), "Meta-learning ability a - crucial component for the professional development of teachers in a changing context", Teacher Development, Vol. 12/1, pp. 85-95.

Radivojevic, N. (2010), “The principal's role in the Finnish Schools", Metodicki obzori, Vol. 9/5, pp. $91-96$.

Rees, G., S. Andresen and J. Bradshaw (Eds.) (2016), Children's Views on Their Lives and Wellbeing in 16 Countries: A report on the Children's Worlds survey of children aged 8 years old, Children's Worlds Project (ICSWeb), York, www.isciweb.org/_Uploads/dbsAttachedFiles/8yearsoldreport.pdf.

Rees, G. and G. Main (Eds.) (2015), Children's Views on Their Lives and Wellbeing in 15 Countries: An initial report on the Children's World's survey, 2013-14, Children's Worlds Project (ICSWeb), York, www.isciweb.org/_Uploads/dbsAttachedFiles/10and12FullReport.pdf.

Retna, K.S. (2006) "The Learning Organisation: A Comparative Study of Singapore Organisations", International Journal of Learning, Vol 13/1.

Retna K.S. and N. Tee (2006), "The Challenges of Adopting the learning Organization Philosophy in a Singaporean School”, International Journal of Educational Management, Vol. 20/2, pp. 140-152.

Robbins, S. et al. (2006), Management, Pearson Education Australia, Melbourne.

Robertson, J. (2016, in press), Coaching Leadership: Building educational leadership capacity through coaching partnerships, Second Edition, NZCER, Wellington. 
Robinson, V. (2011), Student-Centered Leadership, John Wiley \& Sons, San Francisco.

Roese N.J. and K.D. Vohs (2012), "Hindsight Bias", Perspectives on Psychological Science, Vol. 7/5, pp. 411-426.

Rosenholtz, S.J. (1989), Teachers' Workplace: the Social Organization of Schools, Longman, New York.

Rothwell, W.J. (2002), "Putting success into your succession planning", Journal of Business Strategy, Vol. 23/3, pp. 32-37.

Rumberger, R.W. (2004), "Why students drop out of school, in G. Orfield (Eds.), Dropouts in America: Confronting the Graduation Rate Crisis, Harvard Education Press, Cambridge.

Sahlberg, P. (2010), Finnish lessons: What can the world learn from educational change in Finland?, Teachers College Press, New York.

Scarbrough, H. and J. Swan (2001), "Explaining the diffusion of knowledge management: The role of fashion", British Journal of Management, Vol. 12/1, pp. 3-12.

Schechter, C. (2008), "Organizational Learning Mechanisms: The Meaning, Measure, and Implications for School Improvement”, Educational Administration Quarterly, Vol. 44/2, pp.155-186.

Schechter, C. and Q. Mowafaq (2012), “Toward an Organizational Model of Change in Elementary Schools: The Contribution of Organizational Learning Mechanisms", Educational Administration Quarterly, Vol. 48/1, pp. 116-153.

Schechter, C. and Q. Mowafaq (2013), "From Illusion to Reality: Schools as Learning Organizations", International Journal of Educational Management, Vol. 27/5, pp. 505-516.

Schein, E.M. (1999), The corporate culture survival guide, Josey-Bass, San Francisco.

Schildkamp, K., M.K. Lai and L. Earl (Eds.) (2012), Data-based decision making in education: Challenges and opportunities, Springer, Dordrecht.

Schildkamp, K., L. Karbautzki and J. Vanhoof (2014), "Exploring data use practices around Europe: Identifying enablers and barriers", Studies in educational evaluation, Vol. 42, pp. 15-24.

Schlechty, P.C. (2009), Leading for Learning: How to Transform Schools into Learning Organizations, Jossey-Bass, San Francisco.

Schleicher, A. (2015), Schools for 21st-Century Learners: Strong Leaders, Confident Teachers, Innovative Approaches, International Summit on the Teaching Profession, OECD Publishing, Paris, http://dx.doi.org/10.1787/9789264231191-en.

Schleicher, A. (Eds.) (2012), Preparing Teachers and Developing School Leaders for the 21st Century: Lessons from around the World, OECD Publishing, Paris, http://dx.doi.org/10.1787/9789264174559-en.

Schleicher, A. (2011), Building a High-Quality Teaching Profession: Lessons from Around the World, OECD Publishing, Paris, http://dx.doi.org/10.1787/9789264113046-en. 
Schley, W. and M. Schratz (2011), "Developing leaders, building networks, changing schools through system leadership", in T. Townsend and J. MacBeath (Eds.), International Handbook of Leadership for Learning, Springer, Dordrecht.

School has the Initiative (2014), Ontwikkelmodel Lerende Organisatie [Developmental Model Learning Organisation], http://schoolaanzet.nl/fileadmin/contentelementen/school aan zet/Bijlagen bij nieu wsberichten/Ontwikkelmodel_Lerende_Organisatie.pdf (accessed 18 June 2015).

Senge, P. et al. (2012), Schools That Learn, Crown Business, New York.

Senge, P. et al. (2000), Schools that Learn: A Fifth Discipline Fieldbook for Educators, Parents, and Everyone Who Cares about Education, Doubleday, New York.

Senge, P. et al. (1990), The Fifth Discipline: The Art and Practice of the Learning Organisation, Currency Doubleday, New York.

Senior, B. and S. Swailes (2010), Managing Organisational Change, SOAS, University of London, London.

Senturia, T., L. Flees and M. Maceda (2008), Leading change management requires sticking to the plot, Bain and Company, London.

Sergiovanni, T. J. (1994), Building Community in Schools, Jossey-Bass, San Francisco.

Shute, V.J. et al. (2011), "A Review of the Relationship between Parental Involvement and Secondary School Students' Academic Achievement”, Education Research International, Vol. 2011, pp. 1-10.

Siemens, G. (2005), "Connectivism: A Learning Theory for the Digital Age", International Journal of Instructional Technology and Distance Learning, Vol 2/1, pp. 3-10.

Silins, H. and Mulford, B. (1998), "School leadership for organisational learning and student outcomes: The LOLSO Project", ACEA National Conference, Gold Coast, Queensland.

Silins, H., B. Mulford and S. Zarins (2002), "Organizational Learning and School Change”, Educational Administration Quarterly, Vol. 38/5, pp. 613-642.

Silins, H., S. Zarins and B. Mulford (2002), "What characteristics and processes define a school as a learning organisation? Is it a useful concept to apply to schools?", International Education Journal, Vol. 3/1, pp. 24-32.

Simister, N. and R. Smith (2010), "Monitoring and Evaluating Capacity Building: Is it really that difficult?", INTRAC Praxis Paper, No. 23, INTRAC, www.intrac.org/data/files/resources/677/Praxis-Paper-23-Monitoring-and-Evaluating-CapacityBuilding-is-it-really-that-difficult.pdf.

Simonaitene, B. (2004), "The teachers collaboration as element of school as learning organization activity”, European Conference on Educational Research, University of Crete, 22-25 September 2004.

Simons, M. and J. Masschelein (2008), "From Schools to Learning Environments: The Dark Side of Being Exceptional", Journal of Philosophy of Education, Vol. 42/3-4, pp. 687-704. 
Skalde, A. and B. Pont (2013), "A literature review on the implementation of school improvement programmes: Common success factors and the role of context", OECD document for official use, Paris, EDU/EDPC/RD(2013)5.

Sliwka, A. (2003), "Networking for Educational Innovation: A Comparative Analysis", Networks of Innovation: Towards New Models for Managing Schools and Systems, OECD Publishing, Paris.

Smyth, J. and L. Fasoli (2007), "Climbing over the rocks in the road to student engagement and learning in a challenging high school in Australia", Educational Research, Vol. 49/3, pp. 273-295.

Snyder, S. (2013), "The Simple, the Complicated, and the Complex: Educational Reform Through the Lens of Complexity Theory", OECD Education Working Papers, No. 96, OECD Publishing, Paris, http://dx.doi.org/10.1787/5k3txnpt1lnr-en.

Somech, A. and A. Drach-Zahavy (2007), "Strategies for coping with work-family conflict: The distinctive relationships of gender-role ideology", Journal of Occupational Health Psychology, Vol. 12, pp. 1-19.

Spector, B. (2006), Implementing Organisational Change: Theory and Practice, New Jersey, PrenticeHall.

Spillane, J. (2013), "The practice of leading and managing teaching in educational organisations", in OECD (2013), Leadership for 21st Century Learning, Educational Research and Innovation, OECD Publishing, Paris, http://dx.doi.org/10.1787/9789264205406-en.

Spillane, J. (2005), "Standards Deviation: How Schools Misunderstand Education Policy", CPRE Policy Briefs, Consortium for Policy Research in Education, Philadelphia, www.cpre.org/sites/default/files/policybrief/883_rb43.pdf.

Sporn, B. (1999), "Adaptive University Structure. An Analysis of Adaptation to Socioeconomic Environments of US and European Universities", Higher Education Policy Series, Vol. 54, Kingsley Publishers, London.

Starratt, R.J. (1990), The drama of schooling/the schooling of drama, Falmer Press, London.

Stigler, J. and J. Hiebert (1999), The Teaching Gap: Best Ideas from the World's Teacher for Improving Education in Classroom, Free Press, New York.

Stoll, L. (2015), Three greats for a self-improving school system - pedagogy, professional development and leadership: Teaching schools R\&D network national themes project 2012-14, National College for Teaching \& Leadership, Nottingham.

Stoll, L. (2012), "Stimulating learning conversations", Professional Development Today, Vol. 14/4, pp. 6-12.

Stoll, L., Harris, A. and G. Handscomb (2012), Great professional development which leads to great pedagogy: nine claims from research, National College for School Leadership, Nottingham.

Stoll, L. (2009), "Capacity building for school improvement or creating capacity for learning? A changing landscape", Journal of Educational Change, Vol. 10/2, pp. 115-127. 
Stoll, L. and D. Fink (1996), Changing our schools. Linking school effectiveness and school improvement, Open University Press, Buckingham.

Stoll, L., A. Harris and G. Handscomb (2012), Great professional development which leads to great pedagogy: nine claims from research, National College for School Leadership, Nottingham.

Stoll, L. (2010), "Connecting learning communities: capacity building for systemic change", in A. Hargreaves et al. (Eds.), Second International Handbook of Educational Change, Springer, The Netherlands.

Stoll, L. and J. Temperley (2009), "Creative leadership: a challenge of our times", School Leadership and Management, Vol. 29/1, pp. 63-76.

Stoll, L. and K.S. Louis (2007), Professional Learning Communities: Divergence, Depth and Dilemma, McGraw-Hill Education, London.

Stoll, L. et al. (2006), "Professional learning communities: a review of the literature", Journal of Educational Change, Vol. 7/4, pp. 221-258.

Stoll, L. and L. Earl (2003), "Making it last: building capacity for sustainability", in B. Davies and J. WestBurnham (Eds.), The Handbook of Educational Leadership and Management, Pearson Education, London.

Stoll, L., D. Fink and L. Earl (2003), It's About Learning (and It's About Time), Routledge Falmer, London.

Supovitz, J. (2010), "Knowledge-based organizational learning for instructional improvement", in A. Hargreaves et al. (Eds.), Second International Handbook of Educational Change, Springer, Dordrecht.

Strain, M. (2000), "Schools in a learning society: New purposes and modalities of learning in late modern society", Educational Management and Administration, Vol. 28/3, pp. 281-298.

Swanson, K. (2013), Professional learning in the digital age: The educator's guide to user-generated learning, Eye on Education, Larchmont.

Takahashi, A. and T. McDougal (2016), "Collaborative Lesson Research: Maximizing the Impact of Lesson Study", The International Journal on Mathematics Education, Vol. 48/4, pp. 513-526.

Teitel, L. (2003), The professional development schools handbook, Corwin Press, Thousand Oaks.

Thompson, M. et al. (2004), Study of the Impact of the California Formative Assessment and Support System for Teachers: Report 1, Beginning Teachers' Engagement with BTSA/CFASST, ETS, Princeton.

Timperley, H. (2011), Realising the Power of Professional Learning, Open University Press, Maidenhead.

Timperley, H. et al. (2008), Teacher Professional Learning and Development: Best Evidence Synthesis Iteration, New Zealand Ministry of Education and University of Auckland, Wellington. 
Toole, J.C. and K.S. Louis (2002), "The role of professional learning communities in international education", in K. Leithwood and P. Hallinger (Eds.), Second International Handbook of Educational Leadership and Administration, Kluwer, Dordrecht.

Trilling, B. and C. Fadel (2009), $21^{\text {st }}$ Century Skills: Learning for Life in Our Times, John Wiley \& Sons, San Francisco.

Tsang, E. (1997), "Organizational learning and the learning organization: a dichotomy between descriptive and prescriptive research", Human Relations, Vol. 50/1, pp. 57-70.

Tschannen-Moran, M. (2000), "Collaboration and the need for trust", Journal of Educational Administration, Vol. 39/4, pp. 308-331.

UNICEF Office of Research (2013), "Child Well-being in Rich Countries: A comparative overview", Innocenti Report Card 11, UNICEF Office of Research, Florence.

UNICEF (2009), Child Friendly School Manual, UNICEF, New York, www.unicef.org/publications/files/Child_Friendly_Schools_Manual_EN_040809.pdf.

Van Tartwijk, J. and D. Lockhorst (2014), Public Summary of Research Report Evaluation Change Approach LeerKRACHT 2013-2014 [Publiekssamenvatting Onderzoeksrapport evaluatieonderzoek veranderaanpak leerKRACHT 2013-2014], University of Utrecht and Oberon, www.oberon.eu/data/upload/Portfolio/files/publiekssamenvattingevaluatie-leerkracht-20142015.pdf.

Vincent-Lancrin, S. and C. González-Sancho (2015), "Innovation Strategy for Education and Training: Progress Report No. 10", OECD Centre for Educational Research and Innovation Governing Board, Paris, EDU/CERI/CD(2015)9.

Von Bertalanffy, L. (1938), "A quantitative theory of organic growth (inquiries on growth laws II)", Human Biology, Vol. 10, pp. 181-213.

Wagner, T. (2008), The Global Achievement Gap: Why Even Our Best Schools Don't Teach the New Survival Skills Our Children Need - and What We Can Do About It, Basic Books, New York.

Wallace, R., D. Engel and J. Mooney (1997), The Learning School: A Guide to Vision-Based Leadership, Corwin Press, Thousand Oaks.

Watkins, K.E. and K.M. Dirani (2013), "A meta-analysis of the Dimensions of a Learning Organization Questionnaire: Looking across cultures, ranks, and Industries", Advances in Developing Human Resources, Vol. 15/2, pp. 148-162.

Watkins, K.E. and R. Cervero (2000), "Organizations as contexts for learning: A case study in certified public accountancy”, Journal of Workplace Learning, Vol. 12/5, pp. 187-194.

Watkins, K.E. and V.J. Marsick (1999), Dimensions of the Learning Organization Questionnaire: Introduction, www.partnersforlearning.com/instructions.html.

Watkins, K.E. and V.J. Marsick (1996), In action: Creating the learning organization, American Society for Training and Development, Alexandria. 
Watkins, K.E. and V.J. Marsick (1993), Sculpting the learning organization Lessons in the art and science of systematic change, Jossey-Bass, San Francisco.

Wayman, J.C., V. Cho and S. Shaw (2009), First-year results from an efficacy study of the acuity data system, The University of Texas, Austin.

Woods, D., C. Husbands and C. Brown (2013), Transforming Education for All: The Tower Hamlets Story, Tower Hamlets and Institute of Education, University of London, London.

Waerness, J.I. et al. (2016), "Towards deeper levels of learning with digital tools in collaborative evidenceinformed processes", Annual Conference of the International Congress for School Effectiveness and Improvement, Glasgow, January 2016.

Weick, K. and F. Westley (1996), "Organizational learning: affirming an oxymoron", in S. Clegg, C. Hardy and W. Nord (Eds.), Handbook of Organizational Studies, Sage Publications, Thousand Oaks.

Weinbaum, E.H. and J. Supovitz (2010), "Planning Ahead: Make Program Implementation More Predictable", Phi Delta Kappan, Vol. 91/7, pp. 68-71.

Wenger, E. (1998), Communities of Practice: Learning, Meaning and Identity, Cambridge University Press, New York.

Westheimer, J. (1999), “Communities and consequences: an inquiry into ideology and practice in teachers' professional work", Educational Administration Quarterly, Vol. 35/1, pp. 71-105.

Whitehead, G. (2009), “Adolescent leadership development: Building a case for an authenticity framework", Educational Management Administration \& Leadership, Vol 37/6, pp. 847-872.

Wohlstetter, P., R. Smyer and S.A. Mohrman (1994), "New Boundaries for School-Based Management: The High Involvement Model", Educational Evaluation and Policy Analysis, Vol. 16/3, pp. 268-286.

Worrell, D. (1995), "The learning organization: Management theory for the information age or new age fad?", Journal of Academic Librarianship, Vol. 21/5, pp. 351-357.

Yang, B., K.E. Watkins and V.J. Marsick (2004), "The construct of the learning organization: Dimensions, measurement, and validation", Human Resource Development Quarterly, Vol. 15/1, pp. 31-55.

Yong, T.C. (2000), "High-performance human resource strategies in learning schools", The Learning Organization, Vol. 7/1, pp. 32-39.

Yoon, K.S. et al. (2007), Reviewing the evidence on how teacher professional development affects student achievement, U.S. Department of Education, Institute of Education Sciences, National Center for Education Evaluation and Regional Assistance, Regional Educational Laboratory Southwest, Washington.

Yoshida, M. (1999), "Lesson Study: A Case Study of the Japanese Approach to Improving Instruction through School-Based Teacher Development", $\mathrm{PhD}$ dissertation, The University of Chicago, Chicago. 


\section{ANNEX A. SCHOOL AS LEARNING ORGANISATION DEFINITIONS}

\begin{tabular}{|c|c|c|c|}
\hline & Author(s) \& book or article & Page(s) & Definition \\
\hline 1 & $\begin{array}{l}\text { Higgins, M.C. et al. (2012), "Examining } \\
\text { Organizational Learning in Schools: The Role of } \\
\text { Psychological Safety, Experimentation, and } \\
\text { Leadership that Reinforces Learning", Journal of } \\
\text { Educational Change, Vol. 13/1, pp. 67-94, } \\
\text { http://link.springer.com/article/10.1007\%2Fs10833- } \\
\text { 011-9167-9 }\end{array}$ & & No. \\
\hline 2 & $\begin{array}{l}\text { Schechter, C. and Q. Mowafaq (2013), "From } \\
\text { Illusion to Reality: Schools as Learning } \\
\text { Organizations", International Journal of Educational } \\
\text { Management, Vol. 27/5, pp. 505-516, } \\
\text { http://www.emeraldinsight.com/doi/pdfplus/10.1108/ } \\
\text { 09513541311329869. }\end{array}$ & $508-509$ & $\begin{array}{l}\text { As learning organizations, schools develop processes, } \\
\text { strategies, and structures that would enable them to learn and } \\
\text { react effectively in uncertain and dynamic environments. } \\
\text { These schools institutionalize learning mechanisms in order to } \\
\text { revise their existing knowledge. Without such mechanisms, a } \\
\text { learning organization is unlikely to emerge. }\end{array}$ \\
\hline 3 & $\begin{array}{l}\text { Schechter, C. (2008), "Organizational Learning } \\
\text { Mechanisms: The Meaning, Measure, and } \\
\text { Implications for School Improvement", Educational } \\
\text { Administration Quarterly, Vol. 44/2, pp.155-186, } \\
\text { http://eaq.sagepub.com/content/44/2/155.full.pdf+ht } \\
\text { ml?. }\end{array}$ & $155-156$ & $\begin{array}{l}\text { As learning organizations, schools develop processes, } \\
\text { strategies, and structures that would enable them to react } \\
\text { effectively and manage change in uncertain and dynamic } \\
\text { environments. Organisational learning can be perceived along } \\
\text { two tracks: first, learning as an independent variable; } \\
\text { activities, structures, and strategies performed by the } \\
\text { organization to promote learning; put simply, the learning } \\
\text { processes that are implemented to generate learning and } \\
\text { second, learning as a dependent variable, detecting the } \\
\text { outcomes of the learning process (a) through changes in } \\
\text { shared mental models of organizational members regarding } \\
\text { goals, desired actions, historical events, tacit assumptions, } \\
\text { causal maps, and strategies and (b) through behavioral } \\
\text { outcomes, such as changes in organizational standard } \\
\text { operating procedures, routines, and performance. }\end{array}$ \\
\hline 4 & $\begin{array}{l}\text { Keefe, J. and E. Howard (1997), "The } \\
\text { Learning } \quad \text { Organization", NASSP }\end{array}$ & $42-43$ & $\begin{array}{l}\text { The learning organization has formal and informal processes } \\
\text { and structures for the acquisition, sharing, and utilization of } \\
\text { knowledge and skills. Typically, successful learning } \\
\text { organizations exhibit three characteristics that enable them to } \\
\text { initiate and sustain improvement: } \\
\text { 1. Well-developed core competencies that serve as launch } \\
\text { points for new products and services. In schools these } \\
\text { competencies would involve such components as teacher } \\
\text { selection and induction, staff development, instructional } \\
\text { strategy, student services, etc. } \\
\text { 2. Attitudes that support continuous improvement. The } \\
\text { cultural norms and expectations of the school must support a } \\
\text { climate of student support and continuous improvement of the } \\
\text { school's curriculum, instructional programs, communication } \\
\text { structures, etc. The school climate must be positive, actively } \\
\text { sustained, and risk-free. } \\
3 \text {. The capability to redesign and renew. Improvement is not } \\
\text { an event but a process that must be continuously renewed and } \\
\text { revitalized. Schools must have a design process in place that } \\
\text { makes this possible. } \\
\text { The catalyst for the school learning organization and } \\
\text { subsequent school improvement is the school } \\
\text { management/design team. }\end{array}$ \\
\hline 5 & $\begin{array}{l}\text { Fullan, M. (1995), "The school as a learning } \\
\text { organization: Distant dreams", Theory Into Practice, } \\
\text { Vol. 34/4, pp. 230-235. }\end{array}$ & & No. \\
\hline
\end{tabular}




\begin{tabular}{|c|c|c|c|}
\hline & Author(s) \& book or article & Page(s) & Definition \\
\hline 6 & $\begin{array}{l}\text { Harris, M. and F. van Tassell (2005), "The } \\
\text { professional development school as learning } \\
\text { organization", European Journal of Teacher } \\
\text { Education, Vol. 28/2, pp. 179-194, } \\
\text { http://www.tandfonline.com/doi/pdf/10.1080/026197 } \\
\text { 60500093255. }\end{array}$ & 181 & $\begin{array}{l}\text { A Professional Development School (PDS) is a relationship } \\
\text { between schools and universities to better prepare teacher } \\
\text { candidates who are of high quality and safe to practice in a } \\
\text { climate of increasing teacher shortage. PDS is a learning } \\
\text { organization where schools share the common goals of } \\
\text { maximizing the performance and achievement of students, } \\
\text { preparing quality teachers and other school personnel, } \\
\text { enhancing the professional development of novice and veteran } \\
\text { teachers and inquiry into best practice. PDS (i) promote } \\
\text { significant teaching and learning; (ii) create learning } \\
\text { communities for large numbers of students; (iii) serve } \\
\text { everybody's children, not just an elite group such as the } \\
\text { children of university faculty; (iv) promote professional } \\
\text { development of educators; (v) foster inquiry about teaching } \\
\text { and learning; (vi) forge new types of partnerships between K- } \\
12 \text { and higher education. }\end{array}$ \\
\hline 7 & $\begin{array}{l}\text { Park, J. (2008), "Validation of Senge's Learning } \\
\text { Organization Model with Teachers of Vocational } \\
\text { High Schools at the Seoul Megalopolis", Asia Pacific } \\
\text { Education Review, Vol. 9/3, pp. 270-284, } \\
\text { http://files.eric.ed.gov/fulltext/EJ835200.pdf. }\end{array}$ & 271,274 & $\begin{array}{l}\text { A learning organisation is one in which people continually } \\
\text { expand their capacity to create results they truly desire, where } \\
\text { new and expansive patterns of thinking are nurtured, where } \\
\text { collective aspiration is set free and where people are } \\
\text { continually learning how to learn together. Park defined } \\
\text { Senge's five learning disciplines as: } \\
\text { Personal mastery: At the school, teachers expand personal } \\
\text { growth and capacity by having a strong desire to improve } \\
\text { professionally, engaging in continual learning, and focusing } \\
\text { on the future vision in order to make choices about their } \\
\text { development. } \\
\text { Mental models: At the school, teachers continually reflect on } \\
\text { assumptions about schooling; openly dialogue, share views } \\
\text { and develop knowledge about each other's assumptions; and } \\
\text { engage in their own work with flexibility. } \\
\text { Shared vision: Vision and goals of school are planned and } \\
\text { created through a process of shared commitment, participatory } \\
\text { activities, and consensus of all school members including } \\
\text { students and parents; and a teacher's personal vision is aligned } \\
\text { with the school vision and goals. } \\
\text { Team learning: At the school, various group or team activities } \\
\text { are encouraged to address schooling issues or teacher's } \\
\text { professional work; teachers become committed to, skilled at, } \\
\text { and involved in collaborative work. } \\
\text { Systems thinking: Teachers understand and manage their own } \\
\text { work in an interrelationship within the school environment } \\
\text { that includes processes of change; they consider the impact of } \\
\text { their own work on the entire school organization and the } \\
\text { stakeholders' interests. }\end{array}$ \\
\hline 8 & $\begin{array}{l}\text { Schechter, C. and Q. Mowafaq (2012), "Toward an } \\
\text { Organizational Model of Change in Elementary } \\
\text { Schools: The Contribution of Organizational } \\
\text { Learning Mechanisms", Educational Administration } \\
\text { Quarterly, Vol. 48/1, pp. 116-153, } \\
\text { http://eaq.sagepub.com/content/48/1/116.full.pdf+ht } \\
\text { ml. }\end{array}$ & 118 & $\begin{array}{l}\text { As learning organizations, schools develop processes, } \\
\text { strategies, and structures that enable them to learn and react } \\
\text { effectively in uncertain and dynamic environments. }\end{array}$ \\
\hline
\end{tabular}




\begin{tabular}{|c|c|c|c|}
\hline & Author(s) \& book or article & Page(s) & Definition \\
\hline 9 & $\begin{array}{l}\text { Silins, H., B. Mulford and S. Zarins (2002), } \\
\text { "Organizational Learning and School Change", } \\
\text { Educational Administration Quarterly, Vol. 38/5, pp. } \\
\text { 613-642, } \\
\underline{\text { http://eaq.sagepub.com/content/38/5/613.full.pdf+ht }} \\
\underline{\text { ml. }}\end{array}$ & 616,617 & $\begin{array}{l}\text { Schools that function as learning organizations in a context of } \\
\text { rapid global change are those that have systems and structures } \\
\text { in place that enable staff at all levels to collaboratively and } \\
\text { continuously learn and put new earnings to use. More } \\
\text { specifically the authors defined learning organizations as } \\
\text { schools that employed processes of environmental scanning; } \\
\text { developed shared goals; established collaborative teaching and } \\
\text { learning environments; encouraged initiatives and risk taking; } \\
\text { regularly reviewed all aspects related to and influencing the } \\
\text { work of the school; recognized and reinforced good work; and } \\
\text { provided opportunities for continuing professional } \\
\text { development. }\end{array}$ \\
\hline 10 & $\begin{array}{l}\text { Paletta, A. (2011), "Managing Student Learning: } \\
\text { Schools as Multipliers of Intangible Resources", } \\
\text { Educational Management Administration Leadership, } \\
\text { Vol. } \quad 39 / 6, \quad \text { pp. } \\
\text { http://ema.sagepub.com/content/39/6/733.full.pdf+ht } \\
\underline{\text { ml. }}\end{array}$ & 735 & $\begin{array}{l}\text { The school as a learning organization is an ideal approach to } \\
\text { promoting an active and proactive adaptability in dynamic } \\
\text { environments with different social expectations, including } \\
\text { students with different backgrounds, geographic location } \\
\text { (rural, suburban, urban) and socio-economic and cultural } \\
\text { conditions of the community, government structures and } \\
\text { administrative procedures in education at the local level. } \\
\text { The following characteristics that turn schools into learning } \\
\text { organizations: Continued professional development; Tendency } \\
\text { to take risks; Honest cooperation; Shared vision; Monitoring } \\
\text { and assessment. }\end{array}$ \\
\hline 11 & $\begin{array}{l}\text { Kirkham, G. (2005), "Leading and achieving a SLO } \\
\text { through developing middle leaders", European } \\
\text { Journal of Teacher Education, Vol. 28/2, pp. 151- } \\
\text { 163, } \\
\text { http://www.tandfonline.com/doi/pdf/10.1080/026197 } \\
\underline{60500093180 .}\end{array}$ & & No. \\
\hline 12 & $\begin{array}{l}\text { Retna, K. and N. Tee (2006), "The challenges of } \\
\text { adopting the learning organisation philosophy in a } \\
\text { Singapore school", International Journal of } \\
\text { Educational Management, Vol. 20/2, pp. } 140-152 \text {, } \\
\text { http://www.emeraldinsight.com/doi/pdfplus/10.1108/ } \\
\underline{09513540610646127 .}\end{array}$ & 144 & $\begin{array}{l}\text { In such a SLO, students, teachers, leaders and administrators } \\
\text { are all learners. The ethos of the school is an aspiration for } \\
\text { everyone to be efficient and effective at learning and learning } \\
\text { how to learn together. Members of the school really want to } \\
\text { learn and find joy and satisfaction in learning. Such a school } \\
\text { always seeks ways to change for the better. It does so through } \\
\text { the active learning of its members. }\end{array}$ \\
\hline 13 & $\begin{array}{l}\text { Wallace, R., D. Engel and J. Mooney (1997), The } \\
\text { SLO: A Guide to Vision-Based Leadership, Corwin } \\
\text { Press, Thousand Oaks. }\end{array}$ & 179,14 & $\begin{array}{l}\text { The SLO is one in where all stakeholders engage in the } \\
\text { continual reflection on practice to identify ways in which the } \\
\text { operations of the school can be improved. The main focus is } \\
\text { on improving student learning and providing the support } \\
\text { conditions to facilitate that goal. A major part of the effort } \\
\text { must be to establish the conditions where the professionals } \\
\text { and other stakeholders can create the sense of community as a } \\
\text { learning organisation. Not only teachers and administrators } \\
\text { but parents and the community members must reflect on how } \\
\text { they can contribute to the more effective operations of the } \\
\text { school as learning community. One of the key values of the } \\
\text { SLO is that the organisation has the capacity to continually } \\
\text { renew itself as it strives to fulfil its vision. }\end{array}$ \\
\hline 14 & $\begin{array}{l}\text { Diggins, P. (1997), "Reflections on Leadership } \\
\text { Characteristics Necessary to Develop and Sustain } \\
\text { SLO Communities", School Leadership \& } \\
\text { Management: Formerly School Organisation, } \\
\text { Vol. } \quad 17 / 3, \quad \text { pp. } \\
\text { http://www.tandfonline.com/doi/pdf/10.1080/136324, } \\
\text { 39769953. }\end{array}$ & & No. \\
\hline 15 & $\begin{array}{l}\text { Gunter, H. (1996), "Appraisal and the School as a } \\
\text { Learning Organisation", School Organisation, } \\
\text { Vol. 16/1, pp. 89-100. }\end{array}$ & & No. \\
\hline
\end{tabular}




\begin{tabular}{|c|c|c|c|}
\hline & Author(s) \& book or article & Page(s) & Definition \\
\hline 16 & $\begin{array}{l}\text { Nixon, J., et al. (1996), Encouraging Learning: } \\
\text { Towards a Theory of the Schools as Learning } \\
\text { Organisaion, Open University Press, Bristol. }\end{array}$ & $92-116$ & $\begin{array}{l}\text { The values which drive the institutional structures of the SLO } \\
\text { are centrally concerned with participation and involvement, } \\
\text { with the continual search for quality and with public } \\
\text { accountability. The SLO values: vision and purpose; the } \\
\text { search for quality (self-evaluation); accountability to the } \\
\text { public; parent participation; and community involvement. } \\
\text { It is characterised by collegial collaborative and partnership } \\
\text { practices which express these values. These practices seek to } \\
\text { integrate the organizational structures of schooling through } \\
\text { systems of dialogue and deliberation which involve the whole } \\
\text { staff and require participation and commitment; institutions } \\
\text { working together in such a way as to provide a coherent and } \\
\text { continuous public education service; and schools, parents and } \\
\text { the public working together in partnership. } \\
\text { The SLO confirms and extends the meaning of membership: } \\
\text { organising through dialogue, it creates opportunities for } \\
\text { individuals and groups to meet and talk about the ends and } \\
\text { means of education. The organisation of the SLO is itself } \\
\text { implicated in the processes and procedures of learning; } \\
\text { organising through partnership, it brings together disparate } \\
\text { groups to support and encourage learning including students, } \\
\text { teachers, parents, and members of the local communities; and } \\
\text { organising for life, it focuses on learning as a lifelong process } \\
\text { and on the need for close links between institutions, including } \\
\text { neighbouring schools and colleges. }\end{array}$ \\
\hline 17 & $\begin{array}{l}\text { Alavi, S. and J. McCormick (2004), "A cross-cultural } \\
\text { analysis of the effectiveness of the Learning } \\
\text { Organization model in school contexts", } \\
\text { International Journal of Educational Management, } \\
\text { Vol. 18/7, pp. 408 - 416, } \\
\text { http://www.emeraldinsight.com/doi/pdfplus/10.1108/ } \\
\underline{09513540410563112 .}\end{array}$ & 409 & $\begin{array}{l}\text { The learning organizations learn to continually adapt } \\
\text { themselves to environmental changes, detect and } \\
\text { fundamentally correct their errors, and improve their } \\
\text { effectiveness through collective actions. The learning } \\
\text { organisation model proposes that continuously enhancing } \\
\text { employees' personal mastery experiences, collective thinking } \\
\text { and actions, systematically analyzing situations, and building } \\
\text { shared visions are necessary to enhance the effectiveness of } \\
\text { organizational changes and actions. }\end{array}$ \\
\hline 18 & $\begin{array}{l}\text { Bowen, G.L., R.A. Rose and W.B. Ware (2006), } \\
\text { "The Reliability and Validity of the School Success } \\
\text { Profile Learning Organization Measure", Evaluation } \\
\text { and Program Planning, Vol. 29, pp. 97-104, } \\
\text { http://www.sciencedirect.com/science/article/pii/S01 } \\
\text { 49718905000959\#. }\end{array}$ & 98,99 & $\begin{array}{l}\text { Learning organizations are associated with a core set of } \\
\text { conditions and processes that support the ability of an } \\
\text { organization to value, acquire, and use information and tacit } \\
\text { knowledge acquired from employees and stakeholders to } \\
\text { successfully plan, implement, and evaluate strategies to } \\
\text { achieve performance goals. It involves not only employees but } \\
\text { also those served by the organization and consists of two } \\
\text { aspects of 'actions' and 'feelings'. 'Actions' include: team } \\
\text { orientation; innovation; cooperation; information circulation; } \\
\text { error sustainability; and result-based. 'Feelings' are made up } \\
\text { of: common goal; respect; solidarity; confidence; mutual } \\
\text { protection; optimism } \\
\text { Networking and collaboration are key strategies in } \\
\text { organizational learning. Schools that effectively develop a } \\
\text { culture of organizational learning will continuously focus on } \\
\text { solving new problems through team learning, identifying } \\
\text { problems and proposing and implementing solutions from the } \\
\text { inside. Schools that develop a culture of organizational } \\
\text { learning must constantly identify and solve new problems and } \\
\text { invent solutions, thereby institutionalizing the generating of } \\
\text { new knowledge. Learning organizations plan their } \\
\text { intervention efforts with a focus on measurable, achievable } \\
\text { results in a few high-priority areas. }\end{array}$ \\
\hline
\end{tabular}




\begin{tabular}{|c|c|c|c|}
\hline & Author(s) \& book or article & Page(s) & Definition \\
\hline 19 & $\begin{array}{l}\text { Kerka, S. (1995), "The Learning Organization. Myths } \\
\text { and Realities", Office of Educational Research and } \\
\begin{array}{l}\text { Improvement, Washington, } \\
\text { http://files.eric.ed.gov/fulltext/ED388802.pdf. }\end{array}\end{array}$ & 3 & $\begin{array}{l}\text { Learning organisations provide continuous learning } \\
\text { opportunities, use learning to reach its goals, link individual } \\
\text { performance with organisational performance, foster inquiry } \\
\text { and dialogue, embrace the creative tension as a source of } \\
\text { energy and renewal and be continuously aware of and interact } \\
\text { with its environment. }\end{array}$ \\
\hline 20 & $\begin{array}{l}\text { Benjamin, D. (2009), "The School as Learning } \\
\text { Organization: Validation of the DLOQ with School } \\
\text { Staff", PhD Thesis, Alfred University, } \\
\text { http://gradworks.umi.com/34/33/3433910.html. }\end{array}$ & 28 & $\begin{array}{l}\text { The seven dimensions identified as learning actions for the } \\
\text { construct of learning organizations are: 1) continuous } \\
\text { learning, continuous learning opportunities; 2) inquiry and } \\
\text { dialogue, a culture of questions, feedback, experimentation; } 3 \text { ) } \\
\text { team learning, collaboration and collaborative skills which } \\
\text { support effective use of teams; 4) empowerment, the process } \\
\text { to create and share a collective vision and get feedback from } \\
\text { members regarding the difference between present and shared } \\
\text { vision; 5) embedded system of collective efforts to establish } \\
\text { and capture shared learning; 6); system connection which } \\
\text { reflects global thinking and connects the organization to its } \\
\text { external environment 7) strategic leadership to promote } \\
\text { learning. }\end{array}$ \\
\hline 21 & $\begin{array}{l}\text { Hamzah, M.I.M. et al. (2011), "School as Learning } \\
\text { Organisation: The Role of Principal's } \\
\text { Transformational Leadership in Promoting Teacher } \\
\text { Engagement", World Applied Sciences Journal } \\
\text { (Special Issue of Innovation and Pedagogy for } \\
\text { Diverse Learners), Vol. 14, pp. 58-63, } \\
\text { http://www.idosi.org/wasj/wasj14(IPDL)11/12.pdf. }\end{array}$ & 58 & $\begin{array}{l}\text { A form of professional organisation in which all members are } \\
\text { able to learn new skills and knowledge continuously so that } \\
\text { they are capable of dealing with change and realising the goals } \\
\text { of the country's education system. }\end{array}$ \\
\hline 22 & $\begin{array}{l}\text { Coppieters, P. (2005), “Turning schools into learning } \\
\text { organizations", European Journal of Teacher } \\
\text { Education, Vol. 28/2, pp. 129-139, } \\
\text { http://www.tandfonline.com/doi/pdf/10.1080/026197 } \\
\text { 60500093131. }\end{array}$ & 134 & $\begin{array}{l}\text { The essential characteristics of a school as learning } \\
\text { organisation are a shared insights or vision; learning based on } \\
\text { experience; willingness to change mental models; individual } \\
\text { and group motivation; team learning; learning nurtured by } \\
\text { new information; increasing the learning capacity to reach a } \\
\text { state of continuous change or transformation. }\end{array}$ \\
\hline 23 & $\begin{array}{l}\text { Moloi, K., B. Grobler and S. Gravett (2006) } \\
\text { "Educators' perceptions of the school as a learning } \\
\text { organization in the Vanderbijlpark-North District, } \\
\text { South Africa", South African Journal of Education, } \\
\text { Vol. } 22 / 2, \quad \text { pp. } \\
\text { http://www.ajol.info/index.php/saje/article/view/2487, } \\
\text { 9/20556. }\end{array}$ & $88-89$ & $\begin{array}{l}\text { Learning organisations are characterised by their ability to: } \\
\text { create continuous learning opportunities and systemic problem } \\
\text { solving; promote inquiry and dialogue, making it safe for } \\
\text { people to share openly and take risks; encourage collaboration } \\
\text { to learn from experiences and best practices of others; } \\
\text { embrace creative tension as a source of energy and renewal; } \\
\text { establish systems to capture and share knowledge quickly } \\
\text { throughout the organisation; and continuously be aware of and } \\
\text { connect with their external environment. The basis for } \\
\text { continuous learning is underpinned in Senge's five learning } \\
\text { disciplines: namely, personal mastery, mental models, shared } \\
\text { vision, team learning and systems thinking. }\end{array}$ \\
\hline 24 & $\begin{array}{l}\text { Brandt, J. (2003), "Is this school a learning } \\
\text { organization? 10 ways to tell", Journal of Staff } \\
\begin{array}{l}\text { Development, } \\
\text { hol. }\end{array} \\
\text { http://learningforward.org/docs/jsd-winter- } \\
\text { 2003/brandt241.pdf?sfvrsn=2. }\end{array}$ & & $\begin{array}{l}\text { Learning organisations have an incentive structure that } \\
\text { encourages adaptive behaviour; have challenging but } \\
\text { achievable shared goals; have members who can accurately } \\
\text { identify the organisation's stages of development; gather, } \\
\text { process and act upon information in ways best suited to their } \\
\text { purposes; have an institutional knowledge base and processes } \\
\text { for creating new ideas; exchange information frequently with } \\
\text { relevant external sources; get feedback on products and } \\
\text { services; continuously refine their basic processes; have a } \\
\text { supportive organisational culture; are 'open system' sensitive } \\
\text { to the external environment including social, political and } \\
\text { economic conditions. }\end{array}$ \\
\hline
\end{tabular}


EDU/WKP(2016)11

\begin{tabular}{|c|c|c|c|}
\hline & Author(s) \& book or article & Page(s) & Definition \\
\hline 25 & $\begin{array}{l}\text { Clarke, P. (2000), Schools as Learning organisations, } \\
\text { Learning Systems, Bloomsbury, London. }\end{array}$ & 5 & $\begin{array}{l}\text { Learning organizations means to move from the } \\
\text { individualized view of schooling, where learners experience } \\
\text { their education as a product driven along by efficiently } \\
\text { managed schools that see results in the form of outcome } \\
\text { performance, through to a new type of school, one that can } \\
\text { learn from its actions and develop ways of working that re- } \\
\text { norm the school to develop more ecologically compatible } \\
\text { systemic practice. }\end{array}$ \\
\hline 26 & $\begin{array}{l}\text { Schlechty, P.C. (2009), Leading for Learning: How } \\
\text { to Transform Schools into Learning Organizations, } \\
\text { Jossey-Bass, San Francisco. }\end{array}$ & $41 ; 114$ & $\begin{array}{l}\text { Learning organization as a concept provides a way to } \\
\text { describe a more flexible and creative mode of organization, } \\
\text { one where working on and working with knowledge and } \\
\text { putting knowledge to work are primary modes of operation. } \\
\text { Learning organizations are formal social organizations that } \\
\text { purposefully create, support, and use learning communities } \\
\text { and communities of learners as the primary means of } \\
\text { inducting new members; creating, developing, importing, and } \\
\text { exporting knowledge; assigning tasks and evaluating } \\
\text { performances; and establishing goals and maintaining } \\
\text { direction. Learning organizations create and maintain } \\
\text { networks of learning communities and use these networks as } \\
\text { the primary means by which the work of the organization is } \\
\text { accomplished. }\end{array}$ \\
\hline 27 & $\begin{array}{l}\text { Davidoff, S. and S. Lazarus (2002), The Learning } \\
\text { School: An Organisation Development Approach, } \\
\text { South Africa, Juta. }\end{array}$ & $49-50$ & $\begin{array}{l}\text { Learning organisation is an organisation which has learnt how } \\
\text { to learn about itself, and about the world within which it exists } \\
\text { and functions. In being able to learn, a learning organisation is } \\
\text { able to understand and make sense of its own patterns and } \\
\text { organisational reality, and also its broader context. }\end{array}$ \\
\hline 28 & $\begin{array}{l}\text { Middlewood, D. et. al. (2005), Creating a Learning } \\
\text { School, Sage Publications, London. }\end{array}$ & 64 & $\begin{array}{l}\text { The schools that have embraced the notion of learning } \\
\text { organization have found it a key to their success through: } \\
\text { - providing a focus on learning; } \\
\text { - regarding needs of the learner as central; } \\
\text { - establishing an ethos of enquiry; } \\
\text { - recognising that learning comes from many sources; } \\
\text { - acknowledging that learning is a lifelong process and that } \\
\text { the school is making a contribution to this; } \\
\text { - Schools accepting that they need to be in a constantly } \\
\text { transformational state. }\end{array}$ \\
\hline 29 & $\begin{array}{l}\text { Leithwood, K., L. Leonard and L. Sharratt (1998), } \\
\text { "Conditions for Organizational Learning in Schools", } \\
\text { Educational Administration Quarterly, Vol. 34/2, } \\
\text { pp. 243-276. }\end{array}$ & & No. \\
\hline 30 & $\begin{array}{l}\text { Louis, K.S. and S. Kruse (1998), "Creating } \\
\text { community in reform: images of organizational } \\
\text { learning in inner-city schools", in K. Leithwood and } \\
\text { K.S. Louis (Eds.), Organizational Learning in } \\
\text { Schools, Swets \& Zeitlinger, Lisse. }\end{array}$ & 18 & $\begin{array}{l}\text {... change and improvement occur [in a learning organization] } \\
\text { because the individuals and the groups inside the school are } \\
\text { able to acquire, analyze, understand and plan around } \\
\text { information that arises from the environment and from } \\
\text { internal monitoring. ... Organizational learning as a model for } \\
\text { school reform suggests that staff working within a school } \\
\text { setting share a common social understanding related to the } \\
\text { purposes of their work. The image of a learning organization } \\
\text { evokes assumptions about the members of the school } \\
\text { organization a participative, intrinsically motivated and } \\
\text { engaged in learning with greater personal effort than other } \\
\text { organizational models. }\end{array}$ \\
\hline 31 & $\begin{array}{l}\text { Mitchell, C. and L. Sackney (1998), "Learning about } \\
\text { organizational learning", in K. Leithwood and K.S. } \\
\text { Louis (Eds.), Organizational Learning in Schools, } \\
\text { Swets \& Zeitlinger, Lisse. }\end{array}$ & 177 & No. \\
\hline
\end{tabular}


EDU/WKP(2016)11

\begin{tabular}{|l|l|l|l|}
\hline & Author(s) \& book or article & Page(s) & Definition \\
\hline 32 & $\begin{array}{l}\text { Senge, P. et al. (2012), Schools that Learn, Crown } \\
\text { Business, New York. }\end{array}$ & $\begin{array}{l}\text { A school as learning organisation is re-created, made vital, } \\
\text { and sustainably renewed not by fiat or command, and not by } \\
\text { regulation, but by taking a learning orientation. This means } \\
\text { involving everyone in the system in expressing their } \\
\text { aspirations, building their awareness and developing their } \\
\text { capabilities together. In a school that learns, people who } \\
\text { traditionally may have been suspicious of one another - } \\
\text { parents and teachers, educators and local business people, } \\
\text { administrators and union members, people inside and outside } \\
\text { the school walls, students and adults - recognise their common } \\
\text { stake in the future of the school system and the things they can } \\
\text { learn from one another. }\end{array}$ \\
\hline
\end{tabular}

